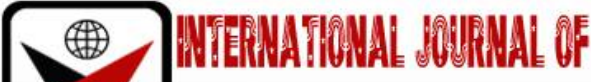

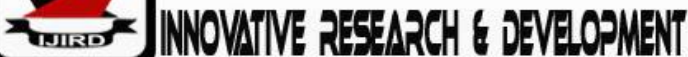

ISSN 2278 - 0211 (Online)

\section{Analysis of Creativity and Innovation with Frugal Innovative Capabilities on Small and Medium Enterprises (SMEs) in Ghana}

\author{
Dr. Boateng Elvis \\ Lecturer, Department of Marketing, Anglican University College of Technology, Ghana \\ Abraham Attoh \\ Assistant Registrar, Office of the College Registrar, College of Technology Education, Kumasi \\ University of Education, Ghana \\ Acheampong Kwadwo \\ Director of Finance and Administration, A-B Excellence Academic Consult, Kumasi Ghana \\ Goddana M. Darko \\ Senior Assistant Registrar, Faculty of Business Education \\ College of Technology Education, Kumasi University of Education, Ghana
}

\begin{abstract}
:
Innovation and Creativity are considered as the backbone of enterprise development, a reality that is beginning to be absorbed by the African business community. Th concept of Frugal Innovation (FI) is a disruptive type of innovation that seeks to provide goods and services to underserved BoP consumers who are unable to pay a premium for goods and services. As resources are becoming limited and leaving the gap of underserves some markets, there is the need to adopt Frugal (Jugaad) Innovative practices to enable consumers to acquire their demands at quality and affordable price. This study analyzed creativity and innovation with frugal innovative capabilities on Small and Medium Enterprises (SMEs) in Ghana. Both research questionnaires and interview guides were used to solicit data from the coverage area which is the Kumasi metropolis of Ghana. A total of 268 respondents were the selected size of the sample for the study. The SMEs in the Kumasi metropolis admitted to almost all the measuring items as being positively impacted or enhanced by creativity and innovation which invariably improve the performance of SMEs. The SMEs support creativity and innovative strategies with the motive of meeting customer demands, promoting growth, reducing operational cost and enhancing quality and productivity. An assessment of the effects of frugal innovative capabilities on SMEs has shown that adversity as a source of innovation is vital for organisational survival and growth. SMEs believed that well FI practices will lead to waste reduction in business operations therefore resulting in high productivity at low cost at customers expected quality. Firms capabilities are the most important elements when it comes to frugal practices. Some of the firm's capabilities required to achieve frugalism are firms' processes, finances, employees and collaborations. They FI capabilities aid SMEs to achieve their frugal practising objectives though a lot of challenges abound to detract SMEs from achieving their frugal practices.
\end{abstract}

Keywords: Innovation and Creativity, Frugal Innovation (FI), Frugal Innovative Capabilities, Jugaad, Small and Medium Enterprises (SMEs)

\section{Background of the Study}

This study became necessary as a result of the frequent closure of Small and Medium Enterprises SMEs, especially Timber Industry in Ghana and Sub-Sahara Africa due to lack of creativity and innovativeness among the entrepreneursC: \Users\NANA \AppData\Local\Temp\www.trid.trb.org. The fall out of these SMEs leads to loss of investor's capital, high unemployment levels and retards economic growth. Evaluating the role of Creativity and Innovation to the success of Small and Medium Enterprises (SMEs) in Ghana could, therefore, promote the Gross Domestic Products (GDP) of the nation and leads to economic growth.

Although many internal corporate innovations in many parts of the world have dedicated Research and Development (R\&D) units, very few African organizations do what is standard on the continent, however, our product development units, market research units, and sales and market development units.

Innovation has long considered as the critical factor for the survival, growth and development of small and medium-sized enterprises (SMEs). According to the www.pdfs.semanticscholar.org site, developing their SMEs capacity to innovate is a mission-critical task for all organizations.

Based on evidence from economical solutions in and outside Asia, it is clear that Frugal Innovation (FI) is a cutting-edge initiative that has challenged conventional ways of innovation management. It is destined to address the needs of both the lower and middle-income groups all over the world. 
The Smaller and Medium firms in Western countries have problems using Frugal Innovation for developing 'Frugal' products. The word 'frugal' is defined as 'simple, plain and costing little'(Oxford Dictionaries, 2014).Frugal Innovation (FI) refers to innovative products and services that seek to minimize the use of the material and financial resources in the complete value chain to reduce the cost of ownership while fulfilling or even exceeding specific predefined criteria of acceptable quality standards (Tiwari \&Herstatt, 2012). Smaller firms' innovative capability is a crucial driver of sustainable competitive advantage in today's rapidly changing markets, where the continuous development of new products and processes is the key to survival, growth, and profitability (Wolff \&Pett, 2006; Verhees\& Meulenberg, 2004).

The Economist defined 'frugal innovation or constraint-based innovation as which is not just a matter of exploiting cheap labour (though cheap labour helps). According to Woolridge (2010), it is a matter of redesigning products and processes to cut out unnecessary costs.

Tiwari and Herstatt (2012) defined frugal innovation as 'innovations that seek to minimize the use of the material and financial resources in the complete value chain to reduce the cost of ownership while fulfilling or even exceeding specific predefined criteria of acceptable quality standards. This definition is much broader and includes the complete value chain while taking about cost characteristics, other vital resources and quality standards, which feels like the entire innovation idea is appropriately defined in its definition.

Whereas in the similar vein Bhatti (2012) defined Frugal Innovation as the one that redefines business models, reconfigures value chains and redesigns products to use resources in different ways and create more inclusive markets by serving users with affordability constraints, often in a scalable \& sustainable manner'.

The ability to innovate is considered to be one of the most if not the most important strategic capability of manufacturing SMEs (Branzei\&Vertinsky, 2006).

\section{Introduction}

As the importance of innovations for business researchers have recognized a critical economic driver, many different schools of thought within organizational research have addressed the issue of innovation and creativity within organizations. The practical interest behind the study lies in questions such as why some firms manage to be more innovative and creative than others. Can organizational innovativeness and creativity be achieved and how Small and Medium Firms could improve their innovative performance?

Companies from emerging markets such as HTC and Haier are already giving Western consumer goods companies a run for their money by offering low-cost, high-value cellphones, fridges, and wine coolers to financially stretched Western consumers. Similarly, Western carmakers need to worry about the upcoming launch in the U.S. and European markets of Tata Motors' US\$2,000 Nano, as the car is poised to capture the hearts (and wallets) of cost-conscious Western consumers clamouring for affordable, fuel-efficient transportation.

According to Wang and Ahmed (2004), organizational innovativeness as an 'organization overall innovative capability of introducing new products to the market by combining strategic orientation with innovative behaviour and process'. Hult et al., (2004) stated that 'Innovativeness relates to the firm's capacity to engage in innovation; that is, the introduction of new processes, products, or ideas in the organization'.

Creating a successful SME has never been easy, but it is more difficult in developing countries such as Ghana. Developing countries often have high rates of start-up businesses, but the chances of the creation of sustainable business are different when compared to developed countries.

According to Aryeetey and Boateng (2007) Ghana's GDP grew at an annual rate of 5.4 per cent between 2001 and 2007 as per statistics provided by the United Nations Economic Commission for Africa 2010. Such an impressive performance was due to the robust growth of the SMEs sector in Ghana. Available data from the Registrar General in Ghana indicates that $90 \%$ of companies registered are micro, small and medium enterprises (Mensah, 2004). C: UUsers\NANA \AppData\Local\Temp\www.ukessays.com

Majority of companies in Western market's innovation has meant the development of new products services with more quality features at higher prices. However, in emerging markets, where company's products must appeal to the millions who do not have more money, companies will need to master the art of frugal innovation.

According to www.core.ac.uk, innovations often emerge under conditions of resource scarcity where the standard solutions are deemed too expensive unavailablehttps://www.sciencedirect.com/science/article/pii/S0268401216305400 - bib0010. In these constrained environments, people work with what they have, using affordable but useful tools, processes and techniques to solve their problems.

In the modern business environment, companies hoping to perform well to expand have shifted their focus to emerging markets. However, if they are to succeed in these markets, ' companies must understand that their FI capabilities have to impact the business significantly.

Majority of companies in Western market's innovation has meant the development of new products services with more quality features at higher prices. But in emerging markets, where company's products must appeal to the millions who do not have more money, companies will need to master the art of frugal innovation.

From the above premises, the question then is, how can SMEs, with their limited time and financial resources, innovate consistently and profitably. However, this study, therefore, explores how frugal innovations capabilities can aid Small and Medium Enterprises (SMEs) to become efficient in their business operations in Ghana. 
Analyzing creativity and innovation with frugal innovative capabilities in Small and Medium Enterprises (SMEs) in Ghana.

\subsubsection{Secondary Objectives}

The study seeks to determine the following:

- To find out the role of creativity and innovation towards the success of Small and Medium Enterprises in Ghana growth;

- To find out the motivations for innovation and creativity practices by Small and Medium Enterprises;

- To find out the effects of frugal innovations capacities on Small and Medium Enterprises

- To investigate some of the benefits of practising frugal innovations by Small and Medium Enterprises; and

- To identify some of the challenges that mitigate the adoption of frugal innovation practices by Small and Medium Enterprises.

\subsubsection{Hypothesis}

- $\mathrm{H}_{0}$ : Creativity and Innovations do not have a significant effect on SMEs performance

- $\mathrm{H}_{1}$ : Frugal Innovations Capabilities (FI) significantly affect SMEs growth

\subsubsection{Scope of the Study}

The study analyzed Creativity and Innovation with Frugal Innovative capabilities in Small and Medium Enterprises (SMEs) in Ghana. The geographical coverage of the survey was Ghana but further delimited to Kumasi Metropolis, which is the second capital of Ghana dominated by Small and Medium Enterprises. The study covered all sectors of the SMEs, which included Rubber and Foam, Wood and Timbers, Metals and Welding, Shoemaking, Water Producers and many more in the Kumasi metropolis. All of the selected firms are production-oriented, which adopts creativity and innovations in their day to day operations.

\section{Literature Review}

According to Pitt and Clarke (1999), empirical studies have demonstrated that to manage the innovation process successfully, and enterprises must develop particular practices. An organizational practice differentiates one organization from another and also determines the success or failure of that organization in the long run. They call creativity and innovation management as a process of searching for effective practices. Innovation and creativity management practices of SMEs are considered as the activities that SMEs undertake to provide in new solutions for their products, production, marketing and administration to cope with the dynamics of the markets.

Nevertheless, in these tough times, firms cannot rely on the old formula that has sustained innovation efforts for decades of expensive Research and Development (R\&D) projects and highly-structured innovation processes. Jugaad Innovation argued the West must look to places like India, Brazil, and China for a new approach to frugal and flexible innovation.

Frugal Innovation is defined under several names and characteristics in different studies. Frugal products and services must serve the needs of the consumers in the emerging world in an affordable, easy to use and functional way.

Similarly, Kumar and Puranam (2012: p.114) argued that frugal engineering is not mere jugaad. They agree that Jugaad are very creative and inventive in making fixes and finding workarounds to overcome constraints. However, according to them, frugal engineering can achieve more with fewer resources in a systematic approach and make those constraints irrelevant or less relevant. They argued that the Jugaad mindset is transferred to disciplined, frugal engineering.

Prahalad (2010) suggested that companies should radically rethink their entire business models to create innovations in emerging markets. According to Prahalad, the technology choices, distribution, pricing, scale, workflow and organizational structures must be built again. Additionally, some companies have become globally successful with new, altered business models (Prahalad \&Mashelkar, 2010).

Govindarajan et al., (2012) also agreed with this view as they claimed most frugal innovations should be businessmodel innovations. They suggested that frugal changes may require new processes, new partnerships or even reinvention of value chains. In their book, they presented the case of Bharti Airtel Limited. The company focused on its core capabilities which were branding and accurately diagnosing customer needs. It outsourced the other necessary activities such as network installation, maintenance and service to other companies.

As a result of Bharti's innovative business model, the company dramatically lowered its costs and became capable of offering the world's lowest telecom rates (Govindarajan et al., 2012).

Creating and acquiring new capabilities is also another approach to create frugal innovations. According to Prahalad and Mashelkar (2010), companies can build new skills through technology development or collaborative approaches. A third approach to creating frugal innovations is to modify organizational capabilities. The authors suggested that some companies have brought different technologies together, altering their abilities in design skills and the deployment of resources, which resulted in innovative products and services.

Frugal innovation can also include business model innovation. Eyring et al. (2011) viewed business model innovation as the key to success in emerging markets. They claim; "Targeting the middle market can be lucrative, but companies will not be able to deliver unless they start from scratch' (Eyring et al., 2011). According to them, companies cannot succeed in emerging markets by lowering prices, selling smaller sizes or using low-cost labour, materials or resources. All approaches would fail as long as their basic profit formulas, and operating models remain unchanged. 
Authors claim that companies can exploit emerging markets by identifying critical unsatisfied needs and devising their business models fundamentally so that they can meet these needs and requirements profitably and affordable.

\subsection{Definitions of Creativity}

According to www.scholarsarchive.byu.edu, as early as 1961, researchers had propounded about 50 and 60 definitions of creativity in the research literature. The profusion of definitions was enough to give one the impression that creativity is a province for pseudo-intellectuals'.

Definitions of creativity can generally divide into two opposing views. In the first view, creativity is defined by culture, meaning work must be of novelty or new to that culture to be creative according to www.scholarsarchive.byu.edu. Their view limits the application of creativity to products judged as novel and accepted by society. According to Steinberg et al., (2004), artists and inventors whose work were just not taken would not be considered novel and therefore, not creative.

The other view of creativity says 'it is probably only a layman's idea that the creative person is peculiarly gifted with a certain quality that ordinary people do not have'. This conception can be dismissed by psychologists, very likely by common consent. According to Guilford, (2005: p.444-454), creative activities can, therefore, be expected no matter how feeble or infrequent, of almost all individuals.

It is possible to define the concept 'creativity' through a wide range of probabilities; from the direct derivation of the term 'create' or 'creating' to definitions that point out how the inherent quality is increased, decreased or improved. DeBono (2010) defined creativity as the formulation or creation of something that was not previously available in its present state. Value is continually placed on or added to the new creation. It is compared to the work of an artist who is always creating something new, which consequently has a certain value. He also adds that this is not at all an 'apparent 'or 'easy' process.

It is therefore essential to note that something unique or unlikely forms part of it. The 'unexpected' and 'variation' are thus, two fundamental constructs within creativity. Kazanjian et al., (2008) defined creativity as follows: a process of being sensitive to problems, deficiencies, gaps in knowledge, missing elements, disharmonies, and so on; identifying the difficulty: searching for solutions, making guesses, or formulating hypotheses about the deficiencies: testing and retesting them; and finally communicating the results.

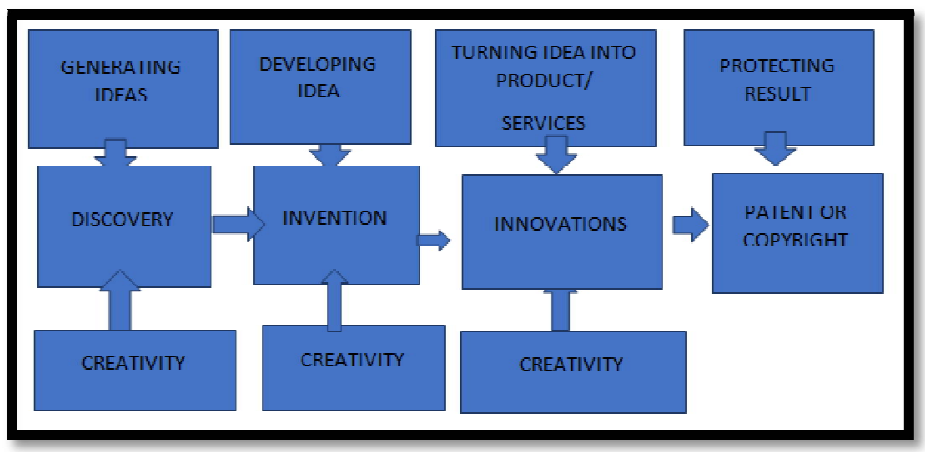

Figure 1: The Influence of Creativity in the Creation of New Products Source: Adapted from Couger (1995: P.18)

Figure1 illustrates that the 'product 'of creativity is more than just a new idea. Creativity forms a platform and integral input into the entire developmental process. The following 'products' or outcomes are thus the result of creativity, as derived from the graph:

\subsubsection{Idea Generation}

A multitude of options is generated to, for example, solve a problem, address a market need, or change the existing. Emphasis is placed on quantity and not quality. Badie (2002: p.68) suggested that effective idea generation is not merely the result or outcome of creativity, but needs to be perceived as part of integrated analogical thinking. An integrated analogical thinking framework accompanied with creativity serves as a focusing and targeted process that results in a far more successful outcomes-based methodology.

\subsubsection{Idea Development}

Some good ideas are chosen and filtered until the most viable option comes to light. The analogical thinking or reasoning method, as discussed in the previous paragraph, gives purpose to idea development, again an integrated approach to creative thinking.

\subsubsection{Discovery}

A discovery occurs typically without purpose or accidentally. About invention that needs systematic thinking and operating process, the detection still requires some testing, to determine the feasibility thereof. 


\subsubsection{Invention}

An invention is directed in line with a goal. The entrepreneur realizes, for instance, that a technological product will become obsolete in six months. The invention process is then based on various research and testing interventions, before the new or changed product is commercialized.

\subsubsection{Innovation}

The exploitation of the invention is seen as innovation. The new design is now developed into a unique product, service or process.

All the variables, as discussed, are the result of creative thinking. Couger (1995: p.286) argued that the product of creativity should be based on a two-fold measurement, firstly novelty or newness and secondly utility or value-added. The author lists some characteristics of the product of creativity as measured to determine its novelty or utility:

- Qualified intellectual activity or creative strength

- Usefulness

- Newness accompanied by overcoming specific difficulties in the creation process

- A proper experimentation phase before the novel 'instrumentality' took place

- Negative perception and scepticism before the success of the novelty

- An unsatisfied need, before the product existed

- Proof of increased income/sales after the introduction of the product (thus value-added)

- Evidence of precise novelty: 'novelty of a combination', 'novelty of a new application', spatial and kinematic novelty', the novelty of deletion of useless parts' and 'novelty of a substitution'.

The author cited Brogden and Sprecher, stating that only 14 studies up to 1995 showed evidence of how to measure the actual novelty of a product, therefore being the result of the creative thinking process. No progress on this was found in the search for more recent findings, thus opening an opportunity for further research.

\subsubsection{Enhancing Creativity in Organizations}

The significance of institutions to be competitive has sparked the interest of researchers and practitioners to study and better understand creativity among firms. Andriopolous (2001) identified five major organizational dimensions under which the characteristics and behaviours that enhance or inhibit creativity in a work environment. Those dimensions indicated are corporate climate, organizational culture, organizational structure and systems, leadership style and resources and skills. Morris, and Leung, (2010) in their study, reviewed the literature under each of those dimension headings and attempted to identify the characteristics and behaviour required in each to enhance organizational creativity. Morris and Leung, (2010) stated that although the dimensions such as corporate climate, organizational culture, regulatory structure and systems, leadership and resources and skills were explored individually, it is essential to acknowledge that the dimensions are somewhat overlapping and the boundaries between them are blurred. It is the sum of the whole rather than the individual parts that enhance creativity in organizations.

Damanpour and Wischnevsky (2006) stated that 'Most research on creativity fails to recognize the importance of distinguishing between different organizational contexts when studying determinants of creativity and innovation. For instance, members of organizations that employ complex, intensive or customized technologies that operate in intensely competitive environments must engage continually in the generation of new ideas and creative problem-solving. Consequently, such organizations require both a flexible structure and a climate conducive to innovation; self and peer controls replace hierarchical control.

Morris went further to state that organizational creativity is linked to a risky balance of complexity, compromise and choice; thus creative organization needs to be flexible while controlling risk, but at the same time provide the freedom to search for the new through learning and experimentation and that an environment that is conducive to creativity is critical and is linked both to the culture, the climate, and the physical aspects of the environment.

\subsection{Definitions of Innovations}

Creativity is the thought process that aids the development and generation of ideas. Innovation is the practical implementation of the idea concept to ensure that the set aims on a commercial, profitable basis are met, in line with a specific opportunity in the market environment. Innovation is, therefore, ideas that seem to be newer, faster, more costeffective and possibly more aesthetical. This implementation should be usable, practical and aimed at showing results. The similarities of the definitions are discussed below as follows.

\subsubsection{Technology Domain}

According to Smith (2006: p.149), it involves changing competencies and capabilities and producing qualitatively new performance outcomes. That new something that Smith mentioned can be qualified with an older definition. Innovation in the technology domain is focused on it is a product related to new technology. Afuah (2002) added to this definition of innovation by claiming it is invention plus commercialization. These definitions suggest that researchers in the technology domain believe that change is the process of creating a different outcome or process that is commercialized. It is assumed that commercializing an issue or process means the result or process is useful. 


\subsubsection{Engineering Domain}

A careful search of the literature in the engineering domain revealed that most engineering researchers do not clearly define innovation. It appears the word 'useful' is central to Carr and Johansson's (1995), the idea of innovation and implies that an innovative idea needs to be immediately 'useful' to keep up with the speed of change in society.

\subsubsection{Business Domain}

Lubart (2000) stated that researchers in the business domain used the term innovation at the organizational level instead of the individual level. Drucker (1985) searched for a way to define innovation in a way that would produce more refined distinctions of what innovation consists.

\subsubsection{Natured Social}

Changes that Drucker referred to may be considered changes in people interaction. Other researchers hold a similar view but add that innovation 'involves creative use as well as an original invention' (www.coursehero.com). Creative usage is to take an existing product and use it in a new way. Original invention means to create a new product that did not previously exist. More recently, in business, innovation is defined as 'the successful implementation of creative ideas within an organization' (Amabile et al., 2002). The definition from Amabile showed that the business domain is focused on the implementation of a product, system, or service, and its impact. Although that definition of innovation is broad, it has served as a baseline definition from which other researchers in the business domain have evolved it. These researchers suggest that change should be considered as the implementation of a new or significantly improved product (good or service), process, method, or organizational method (Baregheh et al., 2009) to advance, compete, and differentiating an organization in their marketplace (Baregheh et al., 2009; Bessant et al., 2005; Dyer et al., 2008).

Gilmartin (1999: p.34) located innovation between creativity and opportunity identification and regarded creativity as the foundation for innovative behaviour. Zimmerer and Scarborough (1998: p.80-95) broaden the viewpoint mentioned above by stating that, between the idea-generating process and the innovation process, a systematic filtering process should take place. This process acts as a development mechanism, intending to change 'raw ideas' into real, valuedriven innovations.

It would subsequently be essential to discussed innovation as a concept in broader terms because the innovation process is ultimately the commercializing of the entrepreneur's ideas.

Martin (1994), pointed out that innovative undertakings contribute more to economic growth and job creation than others.

Furthermore, newly industrialized and developing states' economic ability to grow to maintain international competitiveness, is primarily determined by the presence of technological innovation. Cumming (1998: p.6) divides the innovation process into three consecutive steps.

In the first place, the birth of the initial idea (creativity), secondly the successful development of that idea and thirdly the successful application of the concept. He developed a comprehensive and inclusive model that indicates the different factors which have a positive effect on the three steps.

Though more suitable for an existing business' need, Cumming's model is also applicable in an entrepreneurial context. It is also evident that all types of entrepreneurship are based on innovative acts. It serves as a prerequisite of change in the pattern of allocating resources, as well as new abilities to add value to new possibilities for the positioning of products or services in specific markets.

Drucker (1998) suggested that innovation is an entrepreneurial instrument, one which is used to develop a differentiated undertaking or service. It is possible to regard innovation as a discipline in itself, where it is possible to be taught as well as to practice. He adds that entrepreneurs should purposefully search for sources of innovation, as well as changes and their symptoms. It could point to specific opportunities for successful innovation. It is furthermore also essential to identify the principles of innovation and to successfully implement them.

In this regard, Drucker (1998) is quoted as follows 'Entrepreneurs are a minority among new businesses.

The origin of innovation is of the utmost importance. The causal relationship that leads to the invention of the successful instrument must be pointed out. Drucker identified seven resources of innovative opportunities:

\subsubsection{The Unexpected}

Unexpected success, or failure and the unanticipated external incident is highlighted. IBM is a very relevant example of unexpected success. IBM developed computer equipment to use in banks during the 1930s. Due to the depression of the American economy, nothing could, in reality, be sold to the banks. However, state libraries saw this computer equipment as very advantageous for their systems. All stacked stock was sold, which resulted in unheard of and unplanned success.

It is also relevant to mention Akio Morito's statement as quoted here by Martin (1994: p.4) 'I do not believe that any amount of market research could have told us that the Sony Walkman would be successful, not to say a sensational hit that would spawn many imitators. However, this small item has changed the music-listening habits of millions of people all around the world.

\subsubsection{Incongruence/Incompatibility}

An incompatibility exists between realities as it appears in practice and as it is supposed to be. During the 1950s, it seemed that the aeronautical industry would surpass the shipping industry. 
The costs of the shipping industry as a result increased and the speed at which stock reached their final destination went down dramatically. The result of this tendency was that more and more stock was heaping up in the harbours, leading to a higher incidence of theft. The industry tried to resolve the problem by manufacturing faster ships. This solution, however, was very capital intensive, and as a result, the economies of scale did not improve.

A solution was, however, developed with the invention of the process during which the products were loaded into specific cargo containers on land and then merely loaded onto ships as packed entities.

\subsubsection{Innovation Relies on the Need for Process}

The task-related nature, rather than the situation-orientated source of innovation is emphasized. The change occurs within the operations of the venture, industry or service. The importance of the completion of a specific task is crucial. It also points to the improvement of an already existing task or process, or the replacement of a missing or weak link in the process of the development of a new method, based on newly generated knowledge. This need arises where everyone in the venture or industry realizes that there is a problem in the process, but virtually nothing is done. Should a solution to the problem be found, it is usually accepted as apparent and later on as the standard.

\subsubsection{Changes in Marketing and Industry Structures}

These phenomena usually occur unexpectedly. The difference in the market structure of any industry (for instance, the information technology industry), often creates opportunities for innovation.

\subsubsection{Demographic Changes}

Change in the make-up of the population includes those relating to the size of the people, age structure, and composition, the rate of employment, educational levels and income, which then creates innovative opportunities. The Internet per se formed a platform for new venture creation by creative young entrepreneurs.

\subsubsection{Changes in Perception, State of Mind And Reason}

It could be most dangerous when the temporality of difference with regards to opinion is not addressed correctly. It is, therefore, essential to distinguish between real perception shifts and mere fads. Genuine innovations that influenced dramatic changes seemed to be sustainable products or services, and not short-term occurrences.

\subsubsection{New Knowledge}

Both scientific and non-scientific knowledge is emphasized. Knowledge-based innovation features high on the list of successful innovations. These innovations are not necessarily of a technical and scientific nature, but can also function on a social level. There is a relatively extended waiting period between the origination of new knowledge and the actual implementation of it as new technology.

Furthermore, there is a waiting period for new technology to appear as a new product or service. The outcome of the inventor of chemotherapy, Paul Erich, took 25 years to come into use. RudolpDiesel had to wait 35 years before the diesel engine was commercialized. The first four changes usually take place within the entrepreneurial enterprise. These are changes that are mostly visible within the specific service or industry sector. Drucker (1995: p.25) points out that these four are mainly symptoms, but that they are reliable indicators of changes that have taken place or things that can be changed with relatively little input. The last three changes or resources of innovative opportunities are visible outside the entrepreneurial enterprise or industry. It is also essential to analyze these resources separately as each fund has its unique qualities.

According to Hyvarinen (1993: p.11), the environment as such plays a vital role in the stimulation of innovative behaviour. This environment includes economic support structures, support groups, training, infrastructure, political influences, competition, location, tax 'know-how', economic growth and the diffusion rate of innovation. Hisrichet al., (2005) attached a reason to this by demanding that entrepreneurship and change are not only about the ability to create and conceptualize, but rather about the ability to consider all the forces in the environment.

Miller and Friesen (1983) strongly emphasized the environmental factor by pointing out that the more dynamic and competitive the external environment, the larger the chance of innovation presenting itself. When competitors' products 'change' faster, or when consumers' needs fluctuate, the occurrence of innovation will flourish. Pinchot and Pinchot (1996: p.24) suggested that a particular climate has to evolve wherein new ideas can be generated and made operational. The entrepreneur often acts as a climate controller during the innovation process. This climate supports the general belief in the success of the new as well as an environment where daredevilry, inquisitiveness and perseverance are stimulated.

On a practical level, Pearson (1993: p.7) identified essential qualities of innovative ideas and activity. It has a peculiar impact on the allocation of resources and the cash flow position of the entrepreneur.

\subsubsection{Intellectual Ability}

It is the ability to see problems in a new way, and the ability to cross the borders of conventional thought; the ability to distinguish between ideas that are worthwhile to investigate, influence and persuade other individuals. It includes evident and explicit knowledge of the area of interest, problems, products and services. There is a preference for new thoughts regarding their own choices to be made. 


\subsubsection{Personality Traits}

A willingness to overcome obstacles; to take calculated and worthwhile risks; to accept and handle ambiguities and chaos and self-efficiency are regarded as positive personality traits.

All the above qualities are mostly motivated and strengthened by intrinsic task motivation, which is part of a successful entrepreneur. The fact remains that these variables can be taught as was pointed out by various authors and the omission of this aspect definitely will not set up actual entrepreneurial achievement.

\subsubsection{Training and Creativity, Innovation and Opportunity Finding in an Entrepreneurial Context}

One can conclude from the above that it is evident that creativity or creative thoughts aim to achieve a so-called 'newness'. De Bono (2010). continually stressed that successful creativity calls for specific skills that change initial concepts and perceptions. He highlights the fact that creativity is a logical process and should the individual accept and understand the process as valid; it will motivate him/her to take further creative action. This statement presents particular training possibilities for the entrepreneurial training environment.

Couger (1995: p.12-13) supports De Bono in, the educability of individuals in creativity. He supports the statement regarding an analysis of 142 studies where the creativity of individuals increased markedly after a training intervention.

Carrier (1999: p.3) stated in her pioneering work that a necessity for new pedagogical paradigms exist in the field of teaching entrepreneurs the role of creativity, innovation and opportunity finding. This vital statement fueled the development of a new model regarding the creativity, innovation and opportunity finding intervention in the field of entrepreneurship training. This paradigm and method are primarily based on the needs of entrepreneurship training in South Africa, with a significantly different training milieu and needs a framework, compared to the typical Western or Eurocentric methods and views.

The need for training entrepreneurship in South Africa is a given fact without any further elaboration being needed. Although unique in a fundamental sense, it is still evident that the pedagogical paradigms regarding creativity, innovation and opportunity finding training also lack new approaches and successful outcomes.

- The lack of models addressing the creativity, innovation and opportunity are finding issues should form part of entrepreneurship training.

- Proper differentiation should be made between a business idea and an opportunity in a training context

- Less emphasis must be placed on the pre-entrepreneurial phase of actively seeking business opportunities, but rather an accentuation of feasibility and realistic market-related opportunities.

- The total lack of tools, textbooks and approaches to cultivating creativity, innovation and opportunity finding must be addressed.

- Creativity, innovation opportunity finding and the different stifling pedagogical paradigms in the teaching of business and entrepreneurship should be considered.

- Lecturing as a teaching method is an approach that often reveals more about the teacher than about the subject taught.

Solomon and Fernald (1991: p.47) noted that 'much of the criticism focuses on lack of creativity and individual thinking required at both undergraduate and graduate levels'. Plaschka and Welsch (1990: p.73) criticized the fact that many business schools follow a 'product' approach rather than a 'customer' approach to entrepreneurship education.

\subsubsection{Differences in innovation between SMEs and Large Enterprises}

Even SMEs have many advantages in technology innovation, most articles of open innovation focused on the hightech multinational enterprises, only a few researchers discussed the innovation models in SMEs. In the research of Christensen et al., (2005), the choice of open innovation paradigm mainly considered the level of the technology, and also the status of innovation systems as well as the selection of value. At the beginning of the technology, the necessary assets include innovation assets and related operating assets. For SMEs, the challenges of this stage are how to build the deep foundation of technology and how to attract complementary members (manufacturer, retailer) with efficient communication. In the research of Van de Vrande et al., (2009), they studied 605 innovative SMEs in the Netherlands from the database and concluded that open innovation was widely used in SMEs.

What is more, the open innovation in SMEs became more powerful. They thought that the motivation of the open innovation in SMEs was market-driven. The challenges of SMEs in open innovation are the differences between the achievement of external resources and organizational culture.

During the survey of SMEs in Germany, Australia and Switzerland, Lichtenthaler (2011) found that 32.5\% of the enterprises implemented open innovation. Lee et al., (2010) used the intermediated network model to research the apparent change in SMEs, and they found that open innovation worked well in SMEs. It is efficient access for SMEs to promote open innovation by the related network. The market is considered as an essential factor of successful, and successful innovation means successful commercialization. So, SMEs can benefit from the commercial phase.

Vahter et al., (2014) pointed out that SMEs can benefit more with innovative openness. When compared the effects of innovation performance with the influence of transparency, SMEs plays better than large enterprises. However, because of the massive gap in the level of openness between SMEs and large enterprises, the open innovation in SMEs is ignored by large companies. The utilization of external technology can avoid the high cost of internal development. It can also get the advantages of fast improvement and be close to the frontier technology. However, reality is not optimistic in China. Even China has implemented several large-scale importations of technology since the policy of reform and openness; the local enterprises have not achieved a high level of technical capability. Instead, many SMEs are trapped in 
the vicious circle of 'importation-fall behind-importation-fall behind'. It means, the enterprises import the advanced technologies, but cannot transform the technologies to their own, they waste money and fall behind. And they want to improve their performances and know importation can do help. So, they waste money to import technologies twice and fell behind again. The strategy of 'exchanging technology with the market' has not worked well (Chen \& Chen, 2006).

Some enterprises are a severe lack of innovation capability in core and critical technology. It results in the severe asymmetry in the manufacturing capability and technology capability of China. So, the exploration of the innovation strategy has been implemented. Meanwhile, since the policy of reform and openness of China, SMEs in China have increased. They have become essential parts of the socialist market economy.

According to the survey by National Development and Reform Commission of China (Status of SMEs in China, 2008), up to the end of 2008, the number of registered SMEs in China is more than 420 million, which contains more than $99.4 \%$ of the total enterprises in China. The industrial output and tax of SMEs make up 60\% and 40\%. SMEs comprise $90 \%$ of retail outlets in circulation areas. And they provide about $75 \%$ motives for employment. They also contribute $60 \%$ of the total exports of China. SMEs have some unique advantages in technology innovation. Generally, the managers of SMEs have consciousness of change. They are always good in some fields, and some SMEs are set based on their technical expertise. When meeting the changing environment, the managers of SMEs can be innovative. Additionally, SMEs have less bureaucratism. Since the innovation process needs to coordinate communication among different departments, less bureaucratism makes it easy for SMEs to make a decision.

Meanwhile, the market is changing rapidly because of the strong adaptability, SMEs can adjust their countermeasures quickly. However, when compared with large enterprises or multinational enterprises, the level of technology innovation in SMEs of China is low. There are considerable gaps in innovation investment, research capability and achievements transformation. These have become the bottleneck of the innovation development of SMEs. According to the research (Status of SMEs in China, 2008), the low capability of innovation in SMEs of China is influenced by some aspects as below:

- The ability of research and development process is weak in SMEs. SMEs are lack of technology innovators. According to the statistic, enterprises have $60 \%$ of researchers of the total; however, most of them are in large enterprises. The average academic level of employees in SMEs cannot even reach the national level. The lack of researchers and low education level limit the capability of technology innovation.

- Lack of innovation investment in SMEs. The rate of research investment can be a measurement of innovation ability. The investment in developed countries makes up about $2.5 \%-3 \%$ of GDP. However, China has only $1.34 \%$. Lack of innovation investment makes it difficult for SMEs to implement innovation.

- Absence of information on new technology and new production. Data can be one of the most important sources of change, but ways for SMEs to achieve knowledge are not productive, which influence the technology innovation in SMEs directly. To help SMEs acquire information, developed countries build information infrastructure as well as specific information departments. But in China, it is difficult for SMEs to get information. One reason is that the intermediaries to provide information are still in the beginning stage, and SMEs cannot build access to obtain information independently. The other is backward of information infrastructure in China. There are few information departments to provide service to SMEs.

- SMEs cannot utilize external resources efficiently. Due to the conditions of low research ability and lack of information, many SMEs use the technology of importation. It is one of the regular performances in open innovation. However, most SMEs only know import, but do not realize the digestive absorption and imitative innovation after importation. On the other hand, the lack of experienced management and marketing relationship makes it difficult for SMEs to have a collaborative relationship with external enterprises. SMEs in China is not doing well in research ability, information achievement and external resources utilization. If SMEs want to have further development, technology innovation and core competence should be improved. Meanwhile, when implementing open innovation, if SMEs want to keep growing, they may meet many motives and challenges.

From above, SMEs plays an integral part in the improvement of the economy. Limited by the lack of internal resources and technologies, SMEs are more likely to search the external innovation sources. While more and more enterprises change their innovation paradigm from closed innovation to open innovation, SMEs have more motives to improve their innovation capabilities. However, they will also meet many challenges because of their inherent shortcomings.

\subsection{Various Types of Innovations}

Some authors add institutional innovations to this typology, which is defined as the new rules regulating organizations' activities (www.scielo.br).The first assumption is that innovation is part of an innovation cluster and more broadly of an institutional context in evolution. The general idea developed here is that innovation is not a unique and isolated change within an organization, but is linked to a more general phenomenon of change within the socio-economic environment (www.scielo.br).

Schumpeter explained that an innovation primarily emerges from marginal and inspired creators and is quickly recuperated by imitators appealed by its potential (particularly regarding profits), who spread it by adapting it to other contexts (www.scielo.br).

Moreover, and more broadly, innovation, when spreading, transforms its institutional context (www.scielo.br). Therefore, it is produced by an individual with deviant behaviour, who transgresses established norms and rules. This transgression is generalized when imitators recover the innovation, which ends up questioning the whole way environment is organized (relations between actors, social representations, and regulation mechanisms). Innovation sets up a new dominant paradigm, new normality, which will be later overthrown by another change (Alter, 2002). 
Second assumption: innovation is unpredictable. The second point to outline is the uncertainty which surrounds the emergence of novelty.

It is not possible to predict neither what the final result of this project will be, nor its consequences (www.scielo.br). Also, the adaptation of innovation from imitators to other sectors implies a distortion of the original creation. This appropriation by actors on the ground-those Alter names 'everyday innovators' or 'facilitators' is necessarily unpredictable.

As a result, innovation cannot be known a priority (www.scielo.br).The third assumption is that innovation is 'at odds with the idea of an organization', and it is a bottom-up process. Whereas innovation is unpredictable, the organization, as its names presuppose, implies organizing action, planning and anticipating, and to reduced uncertainty. Organizations are always torn between the need to control and the need to leave space of freedom necessary to innovations' emergence. These spaces often take the form of research and development departments in enterprises, but they face some limits.

The organization's strategy orientates research in specific directions (www.scielo.br). On the other hand, if researchers can produce the 'original creation' at the source of innovation, it remains that it must be recovered by 'everyday innovators'. If actors on the ground do not appropriate it, instead it looks like change management (Alter, 2002). In the OECD Oslo Manual (2005), four different innovation types were introduced. These are product innovation, process innovation, marketing innovation and organizational innovation (www.research.sabanciuniv.edu). According to www.research.sabanciuniv.edu, product and process innovations are closely related to the concept of technological developments.

\subsubsection{Product Innovation}

Product innovation is the introduction of goods and services that are new or significantly improved regarding its characteristics or intended uses (www.research.sabanciuniv.edu). It includes significant improvements in technological specifications, components and materials, incorporated software, user-friendliness or other functional features.

Product innovation is used to strategically differentiate an organization's product offerings in the marketplace, thereby satisfying market demands, building customer loyalty, and improving firm performance.

Product innovations can utilize new knowledge or technologies or can be based on new uses or combinations of existing knowledge or technologies (www.research.sabanciuniv.edu). Product innovation is a complicated process driven by advancing technologies, changing customer needs, shortening product life cycles, and increasing global competition. For success, it must involve strong interaction within the firm and further between the company and its customers and suppliers (Akova et al., 1998).

\subsubsection{Process Innovation}

The process innovation is the implementation of a new or significantly improved production or delivery methods of production (www.research.sabanciuniv.edu). It includes significant changes in techniques, equipment and software (www.research.sabanciuniv.edu). Process innovations can be intended to decrease unit costs of production or delivery, to increase quality, or to produce or deliver new or significantly improved products (OECD Oslo Manual, 2005).

Process innovation is a type of process development, which is the development of a firm's manufacturing processes (Frishammar et al., 2013), and has been defined as the creation and implementation of new concepts and methods in manufacturing companies (Parida et al., 2016). It involves some different activities, such as the introduction of equipment, new management practices, and changes in the production process (Reichstein \& Salter, 2006). Performing a process innovation of a more significant scale often causes the involvement of both organizational and technological changes (Reichstein \& Salter, 2006).

When introducing process innovation, the company starts merely with making a process definition. It is typically followed by simple implementation projects where the description is implemented into the existing processes. This implementation sometimes also triggers supportive construction projects (Frishammar et al., 2013).

The firm's ability to achieve process innovation depends on a set of parameters. For example, on what overall method or strategy the company priorities, their cost focus, and to what extent the management is involved in the process innovation process (Reichstein \& Salter, 2006). A growing manufacturing strategy is the sustainability-related, which has been proven to be linked more to plant visibility compared with traditionally competitive strategy priorities such as cost, quality, and flexibility. Plant visibility encompasses greater foreign ownership or labour intensity and being more responsive to stakeholder perceptions and pressure.

\subsubsection{Marketing Innovation}

Marketing innovations are the implementation of new marketing methods involving significant changes in product design or packaging, product placement, product promotion or pricing. Marketing innovations address the needs of the customer better, creating new markets and positioning a firm's product in the minds of customers to increase the firm's sales. Marketing innovations are strongly related to pricing strategies, product package design properties, product placement and promotion activities along the lines of four Ps of marketing (Kotler, 2000).

Marketing is viewed as an organized, rational innovation, a function concerned with identifying opportunities for change, inducing the action required and monitoring the change once induced (Simmonds, 1986). This point of view establishes innovation as the eighth paradigm of marketing, the only paradigm that focuses on the marketing function, what precisely the marketer does to change. The seven models summarized by Simmonds (1986) are market, system, customer satisfaction, choice, exchange, conflict and influence. Without a paradigm of innovation, marketing will appear as 
a function separated from innovation (Drucker, 1985). The central role of innovation in marketing has been recognized since 1965 by Wroe Alderson. He considered that innovation in marketing is the direct expression of competition on the market: to turn out improved products and improve the methods to market them (Hislop, 1997).

\subsubsection{Organizational Innovations}

Finally, organizational innovation is the implementation of a new organizational plan in the firm's business practices, workplace organization or external relations. Organizational changes tend to increase firm performance by reducing administrative and transaction costs, improving workplace satisfaction (and thus labour productivity), gaining access to non-tradable assets (such as non-codified external knowledge) or reducing costs of supplies (OECD Oslo Manual, 2005).

The internal and external factors can have a direct impact on organizational innovation by the number of innovations adopted (www.researchgate.net). Internal factors - market orientation, learning and technology policy are designed to enhance a firm's innovative behaviour (www.researchgate.net). External factors (industry concentration and barriers to entry) directly affect the organization's attitude towards innovation or by inhibiting or stimulating related work (Lawson \& Samson, 2001).

Organizational innovation is a one-dimensional phenomenon. It highlights the trend of companies to initiate and implement various types of innovation: technological, administrative, product and process. This concept can be viewed from different perspectives within the organizational framework - technical perspective, behavioural perspective and in the light of the product (Lawson \& Samson, 2001).

\subsection{Managing Creativity and Innovations}

Several challenges are affecting the change process these occur from the idea generation stage to the commercialization of the notion.

One of the significant barriers to innovation is creativity. Large corporations lack the motivational capacity of small companies to nurture or motivate innovative people who have new, creative and have break-through ideas (www.ukessays.com). According to them, a few years after start-up, some firms begin to feel comfortable with where they are and forget about creativity. However, some companies rely on historical experience to help them solve their problems and come with solutions.

Without fail risk, aversion is the most common barrier to innovation. Most companies inform employees that they will not tolerate failure (www.ukessays.com). The challenge of balancing the need for success with the obligation to accept risk can be daunting. Knight (1971) suggested that innovation is risky because innovative actions aimed at the future always confront uncertainty.

According to Marnix (2006), managers cannot predict precisely the outcome and reactions of the market, resulting in uncertainty. Change makes it hard to obtain long-term internal support and resources. A framework was developed by Pearson used for analyzing and understanding the difference in the innovation process (www.ukessays.com). The structure was developed due to research in case studies in technological innovation with companies like 3M, Pilkington's float glass process and Sony's Walkman, Pearson divided uncertainty into two: Uncertainty about ends and uncertainty about means.

Furthermore, Salavou et al., (2004) surveyed the impact of strategy and competition on organizational innovation in SME's. The study employed structured questionnaires and semi-structured interviews, also, regression analysis to enhance the validity of the report. The foundation of the survey was hinged on internal strategy and external competition which influence the innovative actions of Greek firms. Internal drivers include market orientation, technology policy and learning (processes of knowledge creation), while external forces were industry concentration and barriers to entry. According to the study, organization driven strategies affect the firm's innovative behaviour, and direct impact pressures the company's product innovation ability either by inhibiting or impelling related creative activities. The empirical analysis represents the independent variable (organizational innovation) with the number of product innovation adopted by each firm for three years running, dependent variables described by the inbound strategy and external factors (www.lawteacher.net). The results depicted positive coefficients for market orientation variable, which implies that market-oriented SME's tend to be more innovative. Nwokah (2008) suggested that a firm's market orientation is related positively to business performance, irrespective of cultural context and the level of economic development. Nwokah's position was based mostly on the main conclusions of Sin et al., (2003), which suggested that the framework proposed also applies to Hong Kong and Mainland China.

\subsubsection{Innovation Activities of Small and Medium Enterprises}

Innovation activities are proceedings of scientific, technological, organizational, financial and commercial innovations involving all the materialization and implementation. Innovational activities include Research and Development (R\&D) even if are not directly related to the development of specific innovations, but pursuing the accumulation of new knowledge in mechanics, kinematics, electromagnetism and thermodynamics, which will be necessary for modern, innovative design of technical systems (www.seap.usv.ro). Innovation process includes a series of activities non-R\&D, as subsequent phases of production and distribution of new products, staff training on new procedures, implementation of innovation activities, e.g., new marketing methods or new organizational methods. Systematic innovation begins with an analysis of sources of new opportunities for innovation. Drucker (1985) argued that there are many sources of innovation, internal and external change. For domestic sources of firm or industry can be considered: 
- Unexpected events,

- Discrepancies between expectations and outcomes or between assumptions and reality can create opportunities for innovation,

- Process needs: Improvements in processes can create new opportunities. Example, the invention of linotype allowed to print large quantities of newspapers, with high efficiency in the media, and

- Changes in industry and market: increasing market demand and industry growth opened new opportunities to launch innovative processes.

- The Company's external sources (the social environment and intellectual) are:

- Demographic changes in population, e.g., age distribution, in education, occupations, etc. concerns are opportunities for innovative entrepreneurs.

- Changes in customer perception. Understanding customer perceptions of products are the key to exploiting opportunities.

- New knowledge of categories of inventions, patents, know-how, etc. or bring new goods and market opportunities. Managers must consider all these sources of new opportunities available.

Achieving innovation success is mostly based on decisions made by people. The concept 'complex man' created by Schein (1992) rests on the following assumptions:

- People are very adaptable, and the hierarchy needs change according to situation and time.

- People can learn and is done through workplace experiences.

- It is no single management concept to achieve the same results for all categories of employees. Depending on the motives, abilities and activities of people, everyone responds differently to management concepts and their instruments.

To generate creative ideas needed, people who could be defined as a combination of known elements and new elements, combined operations made by individuals' thinking. Creativity is not a defining characteristic of an elite, but how different is the fulfillment of creative potential.

Creativity is not taught, but can be developed and that the task managers in the company are to provide a work environment conducive to growing them. Creativity belongs to the sphere of 'can' be willing to innovate the field of 'want' depends on people. Be ready to innovate, in other words, means not against change. It can be improved through better information, cooperation and training.

\subsubsection{The Innovation Process in Enterprises}

According to most of the researchers, innovation must be followed by the reality in the market (wwwijbarr.com).

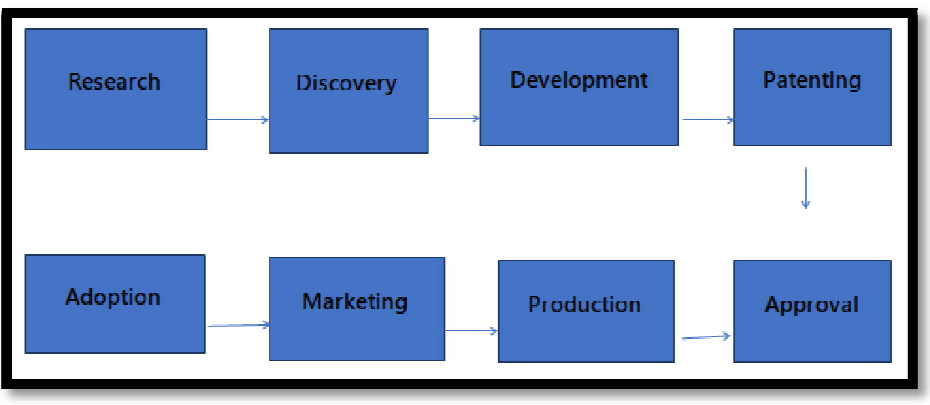

Figure 2: The Innovation Process in Enterprise Source: Iyer Et Al., (2006)

Hence, the innovation process relates to the creating of something different, with value, by devoting necessary time and effort, by assuming the accompanying financial, psychological, and social risks, and receiving the resulting rewards of monetary and personal satisfaction (www.ijbarr.com).

Entrepreneurship merely is the combining of ideas, hard work, and adjustment to the changing business market. It also entails meeting market demands, management (www.ijbarr.com). Hence, the Entrepreneur can lead innovation in the firm by the following main activities:

- Improvements in the design of the existing product.

- Inventions of new products.

- Outsourcing of R\&D and innovation

- Innovation based on process need

- Changes in industry and market structure

Bhattacharya (2006) specifically focused on the essence of entrepreneurial management, its policies and practices about innovation in entrepreneurship (www.ijbarr.com). It must be organized in a manner that it is willing to take up the challenge and do the hard work of the entrepreneur to become successful. However, he also suggested that the entrepreneur should avoid innovative efforts that take the existing business out of its field as they are rarely successful. 


\subsubsection{Factors Influencing Firms Innovativeness}

Excessive regulation, rigid hierarchy, lack of liberty, and excess control always discourage entrepreneurship to get into innovation confidently (www.ijbarr.com). The entrepreneurial function transforms society with new products, technologies, markets, processes and organizational forms; it represents a significantly different commercial activity from the traditional sector (www.ijbarr.com). Some main factors influencing innovation in the enterprise have been elaborated as follows:

\subsubsection{Leadership in Entrepreneurship}

Entrepreneurial leadership is about designing, cultivating and refining the networks of relationships between firms and individuals who come to see their visions and economic aspirations achieved through union with a team of likeminded people and organizations. When viewed through the entrepreneurship lens, the entrepreneurial leader's creativity includes the producing and managing of a new supply chain that generates innovation (www.ijbarr.com).

\subsubsection{Globalization}

In this globalization era, an industrializing economy moves towards an innovation-based economy which requires capability, infrastructure and resources. It leads to the overall growth of operations and businessman as a whole. The restriction on the firm in the form of licensing etc. is no more now, which ultimately encourage the enterprise to try the new ways of producing products even by transfer of technology etc. (www.ijbarr.com).

\subsubsection{Competitiveness}

An entrepreneur is the agent of change who identifies an innovation to match a market opportunity and mobilizes the human and financial resources to deliver the product at a competitive cost. Hence where, the competitiveness, on the one hand, leads to improvement in the quality of the product, on the contrary, the success of other enterprises that drives the innovation in the market also encourage other entrepreneurs to adopt the innovation accordingly (Parthasarthy \& Yoku, 2006).

\subsubsection{Image Building}

Successful entrepreneurs, whatever their motivation, be it money, power, curiosity or a great desire for fame and recognition try to create value and make a tangible contribution. It is true that successful entrepreneurs aim high; they are not contented merely to improve on what already exists or to modify it. Entrepreneurs try to create new and different value propositions to convert a 'raw material' into a 'resource,' or to combine the existing resources in a new or more productive configuration (www.ijbarr.com).

\subsubsection{Entrepreneurial Trait}

Entrepreneurs need to understand how institutions work, and individuals react to introduce activities and products that serve peoples' need and that are sustainable economically and politically (www.ijbarr.com). Entrepreneurs also need dedication and commitments and the capacity to overcome failure.

\subsubsection{Government Initiative for Entrepreneurs}

The Government has a role in identifying, promoting, and developing competitive advantages in strategic industrial sectors. About innovation in enterprises, the government should try to encourage them to drive innovation in the market (www.ijbarr.com).

\subsubsection{Financial Support}

To promote the innovation, in most industrializing countries, there exist a variety of financing sources for businesses, but these are often poorly managed without an understanding of the mentality and unique needs of the innovator (www.ijbarr.com). In the case of India, various such schemes have been launched, but further information on how to access this money is not available.

\subsubsection{Education System}

In India, the education system is such that the youth are not prepared to face the outer world with own creativeness. Moreover, youths in Ghana here come into the category of professionally unemployed persons. Also, the myth that entrepreneurs are born with some innate traits is fortunately no longer held. Many research studies have brought out that entrepreneurship can be taught and learned. Entrepreneurship is a discipline, and like all disciplines, it has models, processes and case studies, which can help an individual to explore this subject. The necessary competencies required of a successful entrepreneur can be acquired through training and development (Sethi, 2004).

\subsubsection{Principles of Creativity and Innovation}

Organizational culture is an essential determinant of corporate creativity and innovation. Several authors have proposed laws that enterprises should follow to build and sustain a culture that promotes the generation and implementation of new ideas and different outcomes.

The building of an innovative culture requires creating an environment of faith and trust, in which good ideas have a chance to become great products. Indeed, innovative companies maintain creativity and innovation as a key 
corporate priority. Rather than focusing on safe ready-made solutions, visionary managers see and continuously support the world of discovery and the fact that innovation helps to increase profitability (Lesakova, 2009a).

Be genuinely experimental in all parts of the business process is a critical part of the creative process. Particularly in the early stages of original discovery, encouraging employees in creative endeavors and taking the sensible risk, is essential. Creative employees need to be always challenged, and highly experimental work can help in this respect.

\subsubsection{Building Close Relationships between Marketing and Technical People}

Promoting close and meaningful connections between the technological innovators and the marketing people is another essential principle for promoting a culture of creativity and change. Although such arrangements may create some conflict, open communication and constructive criticism between marketing and technical people are critical. Some authors encourage enterprises to bring together these two functions formally and informally (Andriopoulos\& Dawson, 2010). Such a relationship does not solve the traditional tensions between cost control and experimentation but also helps to provide a balance between the ideas of creative discovery and the concept of feasibility.

\subsubsection{Building Customer Intimacy}

The commercial reality requires from enterprises to anticipate and to meet market-driven requirements. Innovative businesses achieve the client's intimacy by observing potential users, videotaping their actions, interviewing key stakeholders and studying customer's lifestyles and product decisions. They also increasingly employ sociologists, anthropologists, who are becoming part of the creative process; larger enterprises frequently use them as full-time staff, while smaller firms often subcontract their services. Being creative in enterprises should not be a privilege of selected few employees. Visionary leaders try to engage the whole business in generating and implementing new solutions. Creating a sense of community, where everyone works to achieve a common goal and beliefs in the value of discovery and innovation, is critical. It is organized both formally and informally. Formally, through planned communication activities such as regular meetings motivating staff and providing opportunities for feedback, through e-mail celebrating achievements, through the internet that bring the employees together.Informally, by 'leading by example', initiating social 'get together', engaging staff in discussions and others (Berchicci, 2009).

Acknowledging the individuals, providing opportunities for personal expression and encouraging employees to work on challenging projects, that all is important in mobilizing culture of creativity and innovation. Innovative companies create a fun working environment and support employees in achieving their ambitions. A fundamental principle for fostering a creative culture in enterprises is a collaborative approach to management whereby employees are always aware of the company's actions and can present their views and opinions in numerous formal and informal occasions. Creating a no fear climate and culture that supports experimentation is essential in mobilizing innovation-enhancing behavior. The fair of failure can be detrimental to organizational creativity. Creating a system that assists individuals in their creative endeavors helps to foster a 'no fear' climate in the workplace.

The action should be taken to unleash innovation is encouraging to entrepreneurship. Despite the increasing variety of actors in the innovation process firms remain the pre-eminent means of translating good ideas into jobs and wealth.

\subsubsection{The Need for Creativity and Innovation in Small and Medium Enterprises}

As more and more family businesses are established, the marketplace is becoming saturated with different products that confuse the end users, and competition is stiff between firms. In other, for these enterprises to achieve new gains for its owners and meet their needs and requirements, there is the need for these businesses to continuously search for the development of its product and services through innovation and creativity (www.studymode.com). Creativity and innovation play a significant role in helping family businesses achieved a competitive advantage over their competitors through product and process improvement etc.

According to Kotler and Keller (2006), competitive advantage is an organization's ability to perform in one or more ways than its competitors. And this can be achieved through creativity and innovation. Innovation is considered to be the key to creating competitive advantage. Change is associated with a competitive edge in both growing and mature markets.

\subsubsection{Implementation of Innovative Ideas}

Though creativity is critical, commercial reality requires an application; ideas need to be turned into innovations that will positively influence the corporate profit. To encourage action, several norms are relevant. The first standards are an emphasis on teamwork and effective group functioning, a focus on speed and urgency, a need for flexibility and adaptability and a sense of autonomy (www.researchgate.net). The necessity of teamwork and effective group functioning is frequent in the creative environment. Staff may join various groups to promote a new perspective and encourage employees to utilize their work capabilities and interpersonal skills. Employees need to be invited to work and communicate effectively. Implementation is successful when teams work harmoniously, communicate well and have shared goals (Lesakova et al., 2009b).

Promoting behaviors that support speed and urgency is essential for quick translating ideas into innovations (www.researchgate.net). After the initial experimentation stage which is a key to generating creative outputs, decisions need to be made quickly. Norms like speed, a sense of urgency and commitment to achieving deadlines (even if teams need to work long hours to meet their goals) are also important. It seems that creativeness and the wiliness to discover and to deliver something new and novel drive people to excel and redefines acceptable 'working hours. 
Promoting flexibility and adaptability in the workplace is a critical factor in supporting implementation. The constructive confrontation in the creative process requires from staff to be open-minded and flexible in thinking (www.researchgate.net). Changing the status quo and the way in which things can be done differently is necessary for generating new solutions. Employees need to be perpetually challenged; this requires from employee's strong characters that can consistently deal with change and cope with the inevitable conflict.

Sustaining a sense of autonomy in the workplace is also essential in promoting implementation in the work setting (www.researchgate.net). Individuals need to be autonomous and take action without being asked to do so. It does support not only the generation of new ideas but also the quick implementation of valuable concepts. Developing a culture of creativity and innovation requires from managers to support the production and application of views in the workplace perpetually (Monch, 2006). Despite the fact, that change involves autonomy and personal initiative, and overemphasizing individual accountability can be detrimental to the creative process.

Though staff has to be given different targets and has to be evaluated against their achieved outcomes, overemphasizing personal responsibility can create a climate of fear and may discourage employees from taking risks. It also goes against the requirement for open communication, constructive feedback and the necessity of a free learning culture (Lesáková, 2009).

Moreover, though individual performance appraisals serve as essential human resource management tools, they need to be carefully implemented and not promote a risk-averse culture (www.researchgate.net). Though enterprises need to consider also financial constraints, overemphasizing quantitative goals and financial budgets rarely promote a culture of continuous discovery and innovation. Objectives and financial difficulties indeed set the frame, in which the creative process will be initiated, but employees also need to be encouraged to act outside the firm and, if necessary, negotiate with the client or their company for other resources (Lesáková ,2009).

The way how enterprises handle the inevitable mistakes can increase or constrain creative processes at work. Punishing mistakes is a typical fall in business environments; it creates a culture of fear and hinders organizational creativity (Lesáková, 2009). Managers need to acknowledge mistakes as part of the learning experience. Creative thinking involves (often long) trial-and-error processes and punishing errors can be detrimental to the generation of new ideas. Enterprises that are innovation-driven tend to promote a forgiveness culture.

Such a managerial attitude mobilizes an action across the company, where people focus on doing things rather than on hesitating because of fear of failure (Lesáková, 2009). Promoting internal competition is often used as a mean for mobilizing initiative within work settings. However, innovation usually entails collaboration across intra- or extraorganizational boundaries.

Consequently, promoting internal competition may hinder active team working and stimulate organizational politicking that may be detrimental to the creative process. Though managers increasingly acknowledge the value of creativity and innovation as a means of developing and sustaining competitive advantage, paradoxically, many enterprises strive to be the same as their competitors. They use similar processes, generate identical products and avoid the implementation of dangerous novel ideas and practices. Innovation requires managers to be different because the profit from successful innovations is far higher than that achieved through imitation.

\subsection{Overview of Frugal Innovation}

The term 'Frugal Innovation' refers to an extensive range of innovative solutions from social innovations by nonprofit organizations to for-profit products aimed at the poor, and from grassroots entrepreneurs in the informal sectors of rural areas. Popularly in the developing countries to highly formalized product development by multinational corporations (MNCs) targeted at price-sensitive customers. The word 'frugal' is an adjective that denotes characteristics of being 'economical in use or expenditure; prudently saving or sparing; not wasteful; entailing little expense; requiring few resources' (Tiwari et al., 2016). Hence, the term frugal implies the careful and cautious use of organizational resources to minimize waste and to ensure optimum utilization of scarce resources.

Business models suggest that Frugal innovation opens opportunities for new business by devising low-cost highvalue products and services. It is likely to disrupt existing capital-intensive and top-down forms of innovation, contributing to more inclusive forms of development (Knorringai et al., 2016). According to Zeschky et al., (2011), 'frugal innovation is an innovation manifestation that aims to bring products, services, and systems within reach of billions of poor and emerging middle-class consumers at the middle and base of the pyramid'. A relatively new approach to development and growth, frugal innovation is a constraint-based response to the unmet needs of BoP consumers (Kahle et al., 2013). The focus of frugal innovation is to bring the cost down while safeguarding user value (Tiwari \&Herstatt, 2012; Rao, 2013; Radjou \& Prabhu, 2015).

\subsubsection{Distinguishing Reverse Innovation from Other Types of Innovations}

The term 'reverse innovation' is undoubtedly recent. However, any attempt to go deeper into this topic will prove that the theoretical concept has https://hbr.org/2004/04/the-ambidextrous-organization/ar/1some similarities as well as differences with other types of innovations. Reverse innovation is related to disruptive and frugal innovation and the concept of 'Jugaad'. Researchers often used some of the terms mentioned above and concepts interchangeably. considering them to be synonyms or different names for the same phenomenon. Sharma and Iyer (2012) talk about resourceconstrained product development (RCPD) taking place in emerging markets that lack better infrastructure. The authors mentioned frugal innovation as an alternative term for RCPD. The following sections aim to determine where does reverse innovation stand about other types of innovation, and whether it is justified to treat them innovation practices as identical. 


\subsubsection{Frugal Innovation}

According to Sehgal et al., 2010, the CEO of Renault Carlos Ghosn coined the term 'frugal innovation' in 2006 to describe the competency of Indian engineers in developing products based on frugal engineering. The adjective 'frugal' means 'reflecting an economy in the use of resources'. They are of the view that in the business world, frugal is use to denote simpler and cheaper products developed in the underdeveloped countries. Frugal innovation can therefore be explained as a concept of innovating, which avoids unnecessary wasting of resources.

Sehgal et al., (2010) sees frugal engineering as an 'overarching philosophy' (p.1) which does not mean to simply cut costs but instead offers a clean-sheet approach to product development. According to Radjou and Prabhou, (2013) Frugal innovation is not even a new strategy but a whole new mindset. Frugal innovations can be further defined as 'goodenough, affordable products that meet the needs of resource-constrained consumers' (Zeschky et al., 2011 cited in Agarwal and Brem, 2012) and place the focus on functionality (Tirawi and Herstatt, 2012). Frugal goods and services are mainly low-end and mid-end according to their performance characteristics; they are simple, robust and maintenance-friendly, produced in high-volumes and sold at a low price point (Roland Berger Strategy Consultants, 2012).

Developing frugal products is necessary because merely removing features from existing matured market (Sehgal et al., (2010), products to sell them cheaper will be a losing game as it cannot address the unique needs of customers in emerging markets. Tiwari and Herstatt (2012) added that the costs of ownership (purchase price, low cost of usage, maintenance and repair across the product lifespan) have to be reduced while acceptable quality standards are met or even exceeded. A prerequisite to achieving this is to lower the use of the material and financial resources throughout the whole value chain (Tiwari \&Herstatt, 2012). According to Radjou et al., (2012), the opposite approach which is overengineering products is no longer sustainable for economic and environmental reasons. They claimed that the 'good enough' offerings will deliver significant value for money to cost-conscious consumers.

Similarly, Agarwal and Brem (2012) maintained that the strategy behind frugal and reverse innovation is to develop low-cost products that can meet the needs, preferences and buying the power of low-end consumers in emerging markets. The rationale behind approach is that additional consumers from the MNCs' domestic markets could be switched by the benefits or usages of the frugal products.

Bound and Thornton (2012: p.14), however, emphasized that frugal innovation must not be equated with cheap, low-tech products. The authors argued that frugal innovation has four particular attributes as it entails making better things.

According to Ramamurti (2012) the less complicated regulatory environment in different fields of emerging markets aids SMEs to come up with innovations easier, quicker and cheaper.

According to Radjou \& Prabhou, 2013), frugal innovation does not only result in more business and cost-cutting opportunities but can also create economic social value to consumers. Similarly, Sharma and Iyer (2012) argued that producing a product at the lowest possible cost, besides the intended benefits like a lower price, also has unintended benefits such as the frugal use of resources and thereby conservation of constrained resources. In conclusion, frugal innovation can be interpreted as the first step of the process and a necessary precondition for delivering a reverse innovation (Agarwal \&Brem, 2012).

\subsubsection{The Disruptive innovation}

Bower and Christensen (1995) explained that the main feature of disruptive technology is the rejection of mainstream customers because the products performs far worse along dimensions which are essential to them. According to Hang et al., (2010) described frugal products as 'low-end, dumb, shoddy, and in almost every way inferior'. They may not offer a wide range of features and may be smaller or made of less expensive materials (Hang et al., 2010) or they are more convenient than products established on the dominant technology (Tellis, 2006).

Christensen et al defined disruptive technologies., (2002: p.961) as 'simpler, more convenient products that initially do not satisfy the mainstream markets'. Danneels (2004) argued that these widely accepted characteristics of disruptive innovation are typical but not necessary for disruptive technologies and doubts about whether mainstream customers do not initially value disruptive technologies. Danneels (2004) again, questioned whether disruptive technology always matures in the low-end segments and whether a disruptive technology still has initially lower performance.

According to www.diva-portal.org, to be successful in pursuing this disruptive strategy, companies should pay attention to the full user context and develop local capabilities to ensure an acceptable price/performance ratio (Hang et al., 2010).

The above literature discussion above depicts that disruptive innovation is indeed a relevant concept for the developing and emerging economies. As they can easily be the hosts of products/services based on disruptive technologies. About the connection between disruptive and reverse innovation, Ruan et al., (2012: p.26) called reverse innovation an 'extended disruption model' which means that it could be treated as a type of disruptive innovation. Di Minin and Bianchi (2011: p.17) also considered reverse innovation as 'a form of disruptive innovation that did not originates from the same geographical market that incumbent companies dominate. It is rather from the markets of emerging economies, where a technology/product is commercialized to fit the characteristics of those markets. Govindarajan et al., (2012) admitted that there is an inevitable overlap between reverse innovation and disruptive innovation. However, they further explained that not every case of reverse innovation is accepted as case of disruptive innovation. Reverse innovation does not spread in lower customer market segments because the products are not good enough for the more sophisticated market segments. In an attempt to differentiate the mutual relationship of these theories and concepts, it is said that reverse innovation is a broader activity or event that entails a potential for disruption. 


\subsubsection{Jugaad Innovation}

Understanding Jugaad is made somewhat tricky because one can encounter various sharply differing opinions among authors. According to Singh et al., (2012: p.89), Jugaad refers to 'innovations in products and processes practiced by people to solve their immediate or long-term problems under a resource-constrained environment and often under hostile surroundings'. However, instead, it pointed to people's ability to improvise and fix everyday problems. Jugaad is therefore seen as a business practice and a synonym for frugal innovation.

According to Prahalad and Mashelkar, (2010) Jugaad is said to entail a compromise on quality as it means coping with what is available.

According to Radjou et al., (2012: p.5), even though it is a Hindi word and relates to India in particular, 'the entrepreneurial spirit of Jugaad is not limited to India.' Radjou et al., 2012 indicated that it is common and often practised in other emerging countries with same characteristics such as Brazil, China and Kenya and referred to as the concept of Jugaad.

\subsubsection{Dimensions of Frugal Innovation}

Anderson and Markides (2007) suggested that 'Frugal innovation need to meet numerous socioeconomic, institutional and environmental requirements of developing countries and the specific criteria of affordability, acceptability, availability, and awareness'. Kumar and Puranam (2012) have identified six dimensions of frugal innovation: robustness, portability, defeaturing, mega-scale production, leapfrog technology, and serving the ecosystem. Radjou and Prabhu (2015) present six principles of frugal innovation viz. do more with less, seek opportunity in adversity, keep it simple, think and act flexibly, follow your heart, and include the margin. Brem and Wolfram (2014) have classified frugal innovation using three dimensions-sophistication, sustainability, and emerging market orientation. Angot and Ple (2015) have included the dimensions of affordability, excellent performance, sustainability, and usability as critical characteristics of frugal innovation. Based on different attributes of frugal innovation specified in the literature, this study proposes affordability, acceptability, core functionality and sustainability as the critical dimensions of frugal innovation.

\subsubsection{Affordability}

Frugal products often offer extreme cost advantages compared to existing solutions. According to Prahalad (2010), 'affordability is a key consideration while developing products and services for BoP markets'. The focus of frugal innovation is to cut the cost down for the entire innovation process; from the generation of ideas to the development of products and services, and their commercialization. Frugal innovations often go for 'ingenious use of existing resources and technologies rather than pushing the technology frontier per se' (Prabhu \& Gupta, 2014). It is a science of breaking complex processes and products into essential components. It results in simple design, reducing production cost and generating cheaper products.

Frugal innovation provides solutions specifically for the low-income market (Agarwal \&Brem, 2012). Tiwari and Herstatt (2014) suggested, that 'the value proposition of frugal products and services is reduced total ownership cost (not only initial investment but also low maintenance and repair), robustness, user-friendliness and economies of scale'. According to literature, frugal innovation's core focus is low cost (Brem\& Wolfram, 2014). The consumers in BoP markets always support products that have a low cost of ownership, i.e. low cost over the life cycle of a product. The producers in BoP markets have to keep in mind that BoP consumers support the culture of use and repair. In low-income markets, many service providers can provide cheap services. Organizations need to design products that can allow these service providers to repair the products to reduce the overall cost of ownership. Here, companies have to develop a product/service that fits the buying power of the market.

\subsubsection{Acceptability}

A deep understanding of the needs of BoP customers is a prerequisite for the success of frugal innovation. The needs and requirements of BoP consumers differ significantly from the consumers on the top of the pyramid. The needs of consumers on top of the pyramid is influenced by relative affluence and technological advancements. In contrast, the needs of the BoP consumers are primarily driven by 'life experiences of chronic resource, literacy, psychological, and social barriers' (Viswanathan \& Sridharan, 2012). MNCs that want to cater to the low-income economies cannot replicate global products, developments or production processes in low-income markets (Radjou et al., 2012). In BoP markets, MNCs need to redesign their products and processes from a 'clean-sheet' perspective to develop frugal innovations is based on the same technologies but with different guiding principles. Brem and Wolfram (2014) suggested that 'Frugal innovation integrates the specific needs of BoP markets as a starting point and works backwards to develop solutions, which often end up very different from existing solutions in developed markets'. Brown (2008) also suggested that the productiondriven module and customer-driven module are two ways of building frugality. Frugal innovations are fulfilling or even exceed specific pre-defined criteria of acceptable quality standards (Tiwari \&Herstatt, 2012). Frugal innovation aims at performance and quality levels which are needed.

\subsubsection{Core Functionality}

Frugal products are often associated with core benefits, essential functions, and reduced complexity. According to Cunha et al., (2014), 'Frugal innovation aims to respond with extreme efficiency to some essential need'. Wooldridge (2010) suggested that firms should strip their products down to bare essentials. By focusing on essentials, frugal 
innovations minimize the use of material and financial resources and bring products, services, and systems within reach of billions of poor and emerging middle-class consumers. The following Andel, 2013; Wooldridge, 2010; Barclay, 2014) authors criterion 'concentration on core functionalities' is not just a means to reduce costs; instead, it also makes a product user-friendly. As a result, in ease of use (Tiwari and Herstatt, 2012; Rao, 2013), has less environmental intervention (Sharma \&Iyer, 2012), and just meet a specific sense of life or consumer. According to Radjou and Prabhu (2015), 'Frugal innovation is the ability to 'do more with less' that is, to create significantly more business and social value while minimizing the use of diminishing resources such as energy, capital and time'. Frugal products often offer extreme cost advantages compared to existing solutions and are much simpler and cheaper with limited features (Agarwal \&Brem, 2012). These products and services provide a cheap replica of existing products, meet the needs of BoP markets, concentrate on core functionality, and provide a unique value proposition. It is not sufficient to focus only on core functionalities. There has to be a close examination of the level of performance and quality needed. Literature characterizes frugal innovation by 'high-end, low-cost technology products' (Radjou \& Prabhu, 2012; Brem\& Wolfram, 2014). Frugal products and services do involve not only new technologies but also innovative ways of altering traditional value creation and capturing mechanisms of maximizing product value through re-engineering and simplification (Agarwal and Brem, 2012; Knorringa et al., 2016).

\subsubsection{Sustainability}

Frugal innovations are eco-friendly, leave low carbon footprints and meet the green marketing objectives. The demand for sustainable and affordable solutions is increasing across the globe. Frugal innovation plays a significant role in this regard (Kahle et al., 2013). Frugal innovations are not only affordable but also sustainable (Bhatti, 2012). According to Tiwari et al., (2016), the success of frugal products and services often depends on their simplicity and sustainability. Sustainability is a necessary condition for frugality. By focusing on core functionalities and minimizing the use of environmental resources and factors of production, frugal innovations attain an inbuilt sustainability component across the entire value-chain (George et al., 2012). According to Tiwari et al., (2016), frugal innovation is an integrated framework for (i) designing and developing new product and services, (ii) assessing the acceptability of product by consumers and relevant societal stakeholders, and (iii) evaluating the scalability of the product and (iv) examining its effect on environment. All these characteristics of frugal innovation process make frugal innovation a sustainable solution for the society.

\subsubsection{Frugal Innovation and Industrial Environment}

Contingency theory suggests that congruence or fit among critical variables such as industry conditions and organizational processes is critical for obtaining optimal performance and the relationship between two variables is dependent upon the interference of a third variable (Vij\&Bedi, 2012).

In strategic management literature, a central theme is a fit or alignment between a firm's internal structure, strategy, processes and its environment (Venkatraman, 1989). Kreiser et al., (2010) said, 'the impact a predictor variable has on a criterion variable is often dependent upon the level of a third variable called as moderator/ mediator'. Covin et al., (1994) demonstrated that the fit between organizational factors, environmental variables, and entrepreneurial posture is an essential measure for increasing firm performance. They claim that performance can be improved when key variables are correctly aligned, and the role of moderating and mediating variables is rightly defined. The survival of an organization does not depend on strategic choices or environmental forces alone. Rather the degree of fit between entrepreneurial efforts and environmental effects decides the future of an organization (Aldrich, 1999). Therefore, the relationship between frugal innovation and business performance is contingent upon various attributes of the firm's environment. Environmental factors such as legal environment and regulations, sociodemographic factors such as income and education level, social beliefs etc. would significantly impact the strength of frugal innovation business performance relationship.

The culture of an organization significantly impacts the extent of frugality. All the characteristics of organic culture equip organizational members with strategic autonomy and create an ideal environment for frugal innovations. Freedom of selection of means and goals does not only enhance the morale of employees, but it also brings positive energy in work environment and strengthens the current capabilities of an organization for developing economical solutions for BoP consumers. McGrath (1999) pointed out that innovativeness flourishes in a culture, where human resource policy and reward systems embrace success while not personalizing failure.

According to Poskiene (2006), organization culture generally reflects on the complex set of traditions, ideologies, commitments, and value system of an organization directly bearing on the degree of innovativeness demonstrated by an organization. It is not the only vital individuals, who impact the degree of organizational innovativeness; instead, it is the culture and value system of an organization which affects the behaviour of organizational members while introducing newness, novelty, and frugality (Jassawalla\&Sashittal, 2002). Innovations take place when the top management of a firm encourages experimentations and novelty even in the situations where the benefits from these actions are unclear. Organizations looking to be genuinely innovative have to focus on mutual trust, individual achievement, exchange of information, and so forth. Such initiatives, at times, involve management restructuring and technological transformation (Van de Ven, 1986; Damanpour, 1995).

Frugal Innovation is required to be seen as a process rather than a characteristic per se. Organizations with flat structures and high levels of communication between departments and functions are likely to be more innovative than traditional hierarchical organizations. An organic form of organization allows a firm to exhibit a rapid response to environmental change. Vij and Bedi (2016) suggested that organizational demography characteristics determine the strategic posture of a firm. Small firms may exhibit a higher degree of frugality due to resource constraints. Manufacturing firms might have a higher inclination for frugality, to achieve full capacity utilization, to bring continuous differentiation in 
products and processes, and to better serve the customer's needs with high quality and unique products. The inclination towards frugality may fade with age of the organization.

\subsubsection{Frugal Innovation Is More than Just Jugaad}

Frugal innovation leads to sustainable development that saves valuable resources and energy (www.thehindubusinessline.com). Many business executives have come to think of the country in terms of 'Jugaad', or quick-fix solutions that address acute customer needs. For examples, Jugaad abound a plastic water bottle used as a gas tank for a modified motorized bicycle, using a motorcycle to drive a pump in the fields, changing a tractor to turn into a road roller, etc. while Jugaad is the reflection of innovative capability. India's breakthrough innovations have brought about by frugal innovation, a structured process that focuses on delivering customer value at pre-determined price points. The principle of 'doing more with less' is the new challenge for all companies. Emerging market customers offer an opportunity that can only be profitably leveraged when value proposition and cost structure matches price expectations. In developed markets, for instance, value-for-money is the new mantra, especially in population segments that have suffered from the global financial turmoil. The act of doing more with less is more ecologically viable and sustainable than over-engineered products.

In emerging markets, frugal products are expected to play a vital role until 2030. In less endowed markets like Africa, share in population growth at 33 per cent is over twice as much as a share in GDP growth (15 per cent) (www.thehindubusinessline.com).These expected results are homogeneous across industries and indicate the growing importance of value-oriented customers in emerging and developed markets.

According to www.thehindubusinessline.com site, developed market companies that do not take frugal competitors do so at their own risk. Haier's entry into the USA market is an example of its approach to target market segments precisely. It has been realized that low-priced compact refrigerators (mostly used by students) and electric wine cellars were underserved market segments. Through a successful entry in these segments, Haier built a reputation with Walmart, Best Buy and others that resulted in market penetration.

Ideally, co-creation with customers' needs to be pushed to ensure that relevant features find their way into products.

\subsubsection{Functions of Frugal Innovators}

Frugal innovation is more than a strategy and it denotes a new frame of mindset. One sees resource constraints not as a liability but as an opportunity and one that favours agility over efficiency. Frugal organizations do not seek to wow customers with technically sophisticated products, but instead, strive to create good-quality solutions that deliver the highest value to customers at the lowest cost.

\subsubsection{The Right Capabilities at the Right Time}

It takes a long time to acquire capabilities even longer in China and other developing countries(www.ibr.or), where companies face a lack of competent suppliers, distribution networks, and qualified candidates to fill managerial positions. The four best approaches to develop firms' capabilities are as follows:

\subsubsection{Seize the Moment}

Business opportunities such as industry privatization or the emergence of a new customer segment with money to spend are fleeting, so companies must move quickly and be tenacious. In this early stage, they typically do not have the time or inclination to invest in anything more than necessary capabilities in payroll, finance, factory operations, and employee management.

\subsubsection{Strength Building}

Once the company is up and running, its strategic focus should shift to getting the business model right and becoming profitable. It is at this stage that many companies neglect to develop the necessary capabilities they will need when the industry grows, such as innovative product design and engineering and quality management not (www.ibr.org) just in manufacturing but in other activities. Companies needs specific competencies that are aligned with its strategy.

An excellent way to attain them is to learn through licensing or contract to manufacture, for example, companies that already have advanced capabilities. Galanz, a Chinese company that started as a duck feather dealer, became a respected maker of microwave ovens and other appliances after working as a contract manufacturer for Toshiba and other global players.

\subsubsection{Scale and Consolidate}

Next companies must focus on scaling up to become leading players in the domestic market and on consolidating their positions, often by acquiring competitors. However, they must not overstretch management resources or become an ill-functioning collection of poorly integrated business units: They should keep product lines and markets relatively narrow and fill capability gaps through more significant investment in R\&D, acquisitions, and partnerships.

The Chinese automotive supplier Wanxiang took this approach, building capabilities step-by-step. The company initially focused exclusively on improving quality performance and lowering its costs for just one product line: universal joints. It was able to win lucrative contracts with world-class multinationals such as Bosch and Delphi, and gradually it developed from a domestic tier-three supplier into a global tier-one supplier by expanding into other parts. In the process, Wanxiang acquired, merged with, or established 30 companies around the world. 


\subsubsection{Move Up and Out}

At this stage, companies are typically expanding into higher-value customer segments and international markets. This kind of breakout growth requires that they have a portfolio of strong brands to compete across multiple price points, innovation capabilities and advanced technology to develop premium products.

Back in the 1990s, China International Marine Containers (CIMC), recognizing that China would soon play an important role in world trade, expanded its presence in the country's coastal regions (www.ibr.or,). During the scale-andconsolidate stage, it focused exclusively on low-tech dry-goods containers. It then used an IPO to grow and acquire its local competitors, becoming the largest dry-goods container manufacturer in China. Ultimately, it expanded into refrigerated containers through acquisitions and a licensing agreement with a German competitor, Graaff, and invested heavily in its technology. According to www.ibr.or, site, only after its global market share exceeded 50\% did CIMC start to move into new areas of growth and always to make use of its capabilities in low-cost manufacturing.

Great Wall, too, followed the right pattern in acquiring capabilities according to www.hbr.org. From the very beginning, it has focused on becoming proficient at automaking rather than trying to achieve rapid top-line growth according to www.ibr.or. During its start-up stage, it found an opportunity as a niche player, making pickup trucks and low-end SUVs, and began building its know-how in product development, safety technology, sheet-metal stamping, and total quality management. During its growth stage, it improved its R\&D, honed product quality, and adopted international standards for safety as well as emissions. During its scaling-up phase, it prioritized its original products but moved judiciously into making sedans.

Great Wall's cautious expansion of its product line did not limit its growth: Sales rose sharply from just over 100,000 vehicles in 2008 to well over 500,000 in 2012. During the first six months of 2013, Great Wall's sales grew by $43 \%$. The company has recently pulled ahead of BYD and Chery in both sales and profits (www.ibr.or). In 2012 its gross margin stood at a healthy $27 \%$, in comparison with about $12 \%$ for BYD.

\subsubsection{The Concept of Dynamic Capabilities of Firms}

According to www.journals.sagepub.com, research on dynamic capabilities has evolved, so too has the definition of dynamic capabilities. While building on earlier interpretations, the following definitions have made incremental improvements. A\&B focused their critique on the recent Helfat et al., (2007) definition in particular.

According to www.journals.sagepub.com, the 'resource base' includes the 'tangible, intangible, and human assets resources as well as capabilities which the organization owns, controls, or has access to on a preferential basis' (Helfat et al., 2007: p.4). The application of dynamic capabilities to a firm's resource base is entirely consistent with prior definitions not a radical departure from previous work, as A\&B assert. Teece et al., (1997: p.515) stated that dynamic capabilities operate on 'organizational skills, resources, and functional competencies. Also, Eisenhardt and Martin (2000) stated that dynamic capabilities alter a firm's resource base, which includes its physical, human and organizational assets. According to Zollo and Winter (2002), dynamic capabilities act on ordinary capabilities. According to Di Stefano et al., (2009), these three definitions have been the most influential to the new definition is a synthesis of these evolving but highly related views.

According to www.journals.sagepub.com, since there are many different types of dynamic capabilities, the meaning has always been intentionally general in form. Because different types perform various tasks, ranging from new product development to post-acquisition integration, Helfat et al., (2007) recommended that researchers should be specific in characterizing the particular dynamic capabilities that they are investigating.

The word 'capacity' in the definition derives from Teece et al., (1997) indicated only some minimal ability to perform a task, regardless of whether it is done well or poorly (Helfat et al., 2007). A\&B argued that this somehow implies that a lack of observed change demonstrates a lack of dynamic capabilities.

Empirical research on alliances suggested that firms with more significant prior experience in undertaking alliances have better outcomes (Helfat et al., 2007).

The Helfat et al., (2007) definition also added the word 'purposeful' to prior definitions, to make explicit what previously was implicit (www.journals.sagepub.com). According to Helfat et al., (2007), the word purposeful indicates a minimal degree of intentionality, to distinguish a capability both dynamic or otherwise from pure luck. Helfat et al., (2007) were of the view that this minimal standard does not require, as A\&B claimed, that observed changes must precisely match the managerial intention. The www.journals.sagepub.com site considered the example of an Italian candy company that decided to develop new chocolate for a perceived untapped market segment, without knowing what attributes the new candy might have or whether the effort would succeed (www.journals.sagepub.com). Nevertheless, this product development effort was 'purposeful' which involved an intent to develop a new candy for a particular purpose. According to Helfat et al., (2007), the word purposeful also distinguished a capability such as product development from routines that are utilized in a somewhat automated fashion. As the comments of A\&B indicates, scholars differ slightly in how they conceptualize routines. Our definition relies on the evolutionary economics definition of methods as consisting of patterned and predictable behaviour (Nelson \& Winter, 1982). According to www.journals.sagepub.com, regardless of how one defines routines, it is hard to claim, as do A\&B, that new product development capability consists entirely of methods. More generally, although dynamic capabilities utilized routines and other organizational processes, they also have an element of the plan (Eisenhardt \& Martin, 2000). According to Eisenhardt and Martin, 2000, Dynamic capabilities such as new product development have utility in both moderately dynamic and more fast-paced environments. In contrast to the assertion of $A \& B$, frequent use of dynamic capabilities is often justified even in moderately dynamic environments (www.journals.sagepub.com). A\&B also questioned the relevance of dynamic capabilities in fast-paced environments, noting that repeated, frequent strategic reorientations may be so disruptive that firms cannot function effectively. Major 
strategic redirections, however, do not occur overnight. Often what looks like a sizeable diplomatic shift ex-post consists of a series of incremental and less disruptive changes.

According to www.journals.sagepub.com, not all fast-paced environments are marked by the regular disruptive change in which some are better characterized in terms of frequent incremental change. For coping with situations such as these, dynamic capabilities may be critically important (www.journals.sagepub.com). Moreover, O'Reilly and Tushman, 2007 was of the view that dynamic capabilities hold the potential to promote ongoing adaptation, so that disruptive change becomes less necessary.

\subsubsection{Dynamic Capabilities and Competitive Advantage of Frugal innovations}

The Helfat et al., (2007) definition of dynamic capabilities purposefully does not include a reference to firm performance or competitive advantage (www.journals.sagepub.com). According to Peteraf and Barney (2003), understanding the link between dynamic capabilities, firm performance and competitive advantage requires a more general understanding of the distinction between firm performance and competitive advantage.

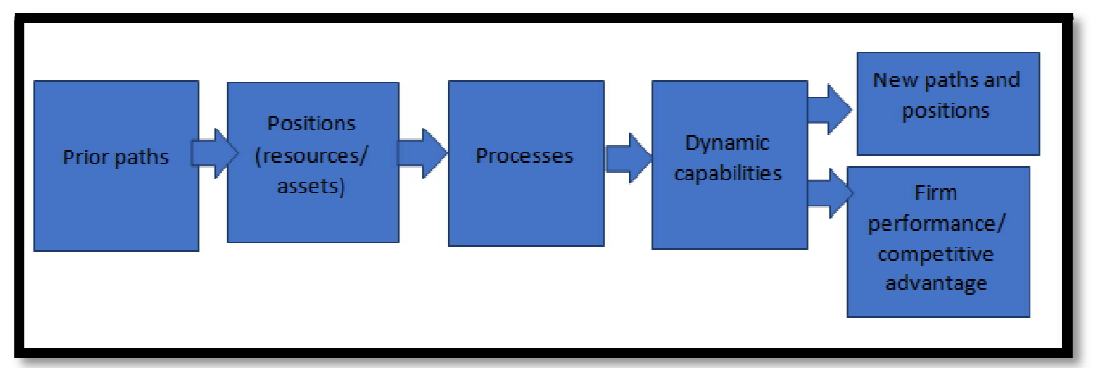

Figure 3: Dynamic Capabilities and Competitive Advantage Source: Teece Et Al., 1997

Eisenhardt and Martin (2000) described dynamic capabilities as processes that firms can use to obtain, integrate, reconfigure and release resources, leading to new resources and resource configurations. Dynamic capabilities have a direct effect on firm performance and competitive advantage, as well as an indirect effect through resource reconfiguration. Although Eisenhardt and Martin (2000) view competitive edge as more challenging to achieve through dynamic capabilities than does Teece, their primary chain of logic is very similar to that of Teece and Helfat et al., (2007). In all of these treatments, organizational processes play a central role. It is therefore inaccurate for A\&B to suggest that dynamic capabilities 'jumps directly to', modelling the change performance relationship' without considering underlying organizational factors.

Teece et al., (1997) have prior paths leading to current firm positions consistent with evolutionary economics. According to www.journals.sagepub.com, dynamic capabilities rest on firm processes that can alter current positions, leading to an effect on firm performance and competitive advantage, as well as to new positions and paths. Teece (2007) focused on particular types of dynamic capabilities, using a chain of logic that expands upon that in Teece et al., (1997). After the investment, dynamic capabilities for recombination and reconfiguration can alter the accumulated asset base of the organization further, leading to an additional effect on firm performance and competitive advantage, and new positions and paths.

\subsubsection{Difference between Standard Innovation and Frugal Innovation}

Innovation is defined by the Oslo Manual of the Organization for Economic Cooperation and Development (OECD) as 'the implementation of a new or significantly improved product (good or service) or process, a new marketing method, or a new organizational method in business practices, workplace organization or external relations'. In economics, further to Schumpeter's lesson, it is now part of mainstream thinking to consider innovation as the primary engine of economic dynamic. This notion is particularly relevant in today's globalized world and knowledge-based economies, which rely ever more on intangible resources. Not surprisingly, innovation is widely recognized as one of the essential drivers of successful business and a key contributor to the productivity and economic and social development of nations.

Finding ways of fostering innovation is a central concern for both forward-thinking companies and governments. In many countries, there is a strong focus on public funding of research and development and intellectual property rights (IPR) as instruments of innovation policy and business strategy.

According to Godin (2008), change is often brought about by innovation which is considered as a scientific and social phenomenon. Not only is it a driver of improvement in people's lives and society as a whole, but it also facilitates the work and everyday activities of companies. For example, the way people communicate with each other has been facilitated by several innovations, starting from the first telegraph invented in 1794 and later entirely replaced by the telephone in 1877 (Bellis, n.d.b). Modern transportation was made possible by the emergence of the first automobile in 1769 (Bellis, n.d.a), while the emergence of the Internet whose beginnings date back as far as the 1960s and 1970s (Zakon, 2011), truly revolutionized every aspect of our lives.

According to www.mafiadoc.com, frugal innovations are characterized by affordability, robustness, userfriendliness, scalability, and finally by an attractive value proposition. Again, research has shown that frugal innovations can lower the price point by 50 per cent to well above 90 per cent. Companies target consumers who might hitherto have 
never had the occasion to use a similar product they should be able to cope with 'unsophisticated' users and withstand hazards like dust, heat or power failure (www.mafiadoc.com). Such frugal products aimed at serving volume-driven markets with comparatively thin margins can lead to success in price-sensitive markets (www.mafiadoc.com).

According to www.global-innovation.net, frugal innovations signifies a transition from heavy technology and Research and Technology-driven 'inventions' to more market-driven 'innovations'. Frugal innovations show that the primary purpose of a product development activity is to tap an unfulfilled demand and enable consumption (www.globalinnovation.net). Frugal innovations again show that sophistication of a solution is not rooted in 'the newest and most advanced technology' but in a 'comfortable, robust, and affordable solution capable to uplift the standard of living to the next better level' (www.global-innovation.net).

\subsubsection{Drivers of Frugal Innovation}

Opportunities for future growth now mainly lie in the unsaturated markets of the emerging economies, according to www.global-innovation.net. With the great current reduction in the absolute number of people living below the poverty line, a new class of consumers has emerged in the developing world, creating a large market ready for consumption. Since the purchasing power of the most of these consumers does not allow them, yet, to consume at the same level as the most of their counterparts in the industrialized West, they need products which can match their aspirations while catering to their specific environmental and cultural requirements. In the era of the Internet and television, the traditional concepts building upon the international product life-cycle theory have been rendered redundant.

It is no more feasible for companies to send their commoditized 'outdated' products to the countries of the 'Third World'. Second, the relative importance of developing nations is set to increase even further. They have become not only major recipients but also significant sources of foreign direct investment (FDI). Between 1992-2012, the stock of inward FDI in developing nations rose from 611 8,592 billion US-Dollar, demonstrating the growing economic activity there. Increased (outward) FDI by emerging market firms also means that they are bringing in their frugal products also to the Western markets. To pre-empt this threat, many Western multinational (e.g. GE and Siemens) are also taking recourse to frugal products. This strategy has been called 'reverse innovation'.

\subsubsection{Why Smes Should Be Passionate about Frugal Innovation}

Carlos Ghosn, CEO of Renault-Nissan, stated that frugalism is not changing Business Models, but the mental model of employees and organization in order to embed the frugality in them according to www.peoplematters.in. He further reiterated that the Western world is under severe resource crunch; and is feeling the pressure of 'do more with less,' which means deliver more value to customers at less cost.

FI also presents an opportunity in developed economies for many reasons. Firms adopt FI in order to sell products and services at a low price. Consequently, people living in poverty can become consumers. Moreover, in the recessionary context of low growth, firms develop frugality in order to cut their R\&D expenditure and manufacturing costs (Laurens \& Bas, 2016. In addition to FI (but related to this), other types of low technology products providing solutions for low and medium markets have been identified as cost innovation, or good enough innovation (Zeschky et al.,2014). They can revitalize mature industries (for example the car industry, with low-cost new cars). With this goal, developing new types of standards could enhance the diffusion of FI in developed nations.

Last but not least is the insight that indicates that firms from developed countries can learn about innovation from less developed economies. MNEs can learn from new technologies (very often frugal), which meet poor people's needs and which are developed in emerging countries, in order to transfer ideas and knowledge to their technology centre in developed countries. They contribute to designing improved products intended for the markets of developed nations. These cases of reverse innovations have very recently been identified by the literature (Le Bas in this issue). While any type of innovation can be at the origin of such reverse transfer, many FIs are often implicated (Laurens \& Le Bas, 2016).

\subsubsection{Conceptual Model of Frugal Innovation for the study}

The proposed conceptual model of frugal innovation was presented as dimensions of frugal innovations as follows: Affordability, acceptability, core functionality, and sustainability are the antecedents of frugal innovation. The study offers frugal innovation as a firm-level construct and suggests a significant positive impact of frugal innovation on business performance. Therefore, improved business performance is the consequence of frugal innovation. The organizational and industrial environments moderate the proposed relationship of frugal innovation business performance. 


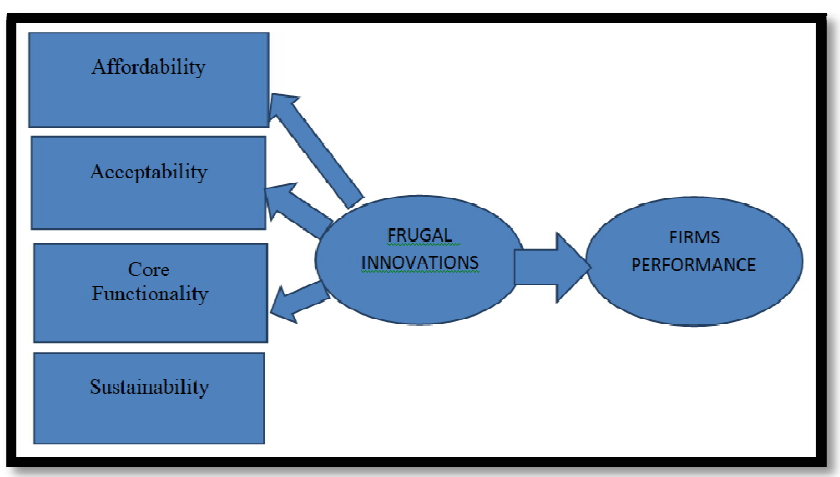

Figure 4: Dimensions of Frugal Innovations

Sources: Researchers Construct, 2019

\subsubsection{Innovative Capabilities of Small and Medium Enterprises}

The two dependent constructs, growth and productivity, constitute the two main dimensions of the SME's competitive performance in a globalized economy (Wolff \&Pett, 2006). For individual researchers, growth, that is the increased penetration of existing markets or the penetration of new markets, be they local, national or international, is intrinsically linked to entrepreneurship (Moreno and Casillas, 2007) and even constitute sits essence (Wiklund\&Sheperd, 2003). For other researchers, a large number of SMEs if not, the majority are not 'entrepreneurial', and their ownermanagers do not show a growth orientation or intent (Nummela et al., 2005). In the manufacturing sector, the latter instead seek to maintain or increase their firm's competitiveness and financial health through productivity gains, that is, by limiting or reducing unit production costs, especially labour costs.

Growth-oriented firms increase their competitiveness by seeking new markets and putting the emphasis on technological leadership and product innovation (Özsomer et al., 1997). Other manufacturing SMEs, more defensive in their outlook, focus on productivity in terms of reduced costs and improved delivery capabilities, by increasing the flexibility of their productive apparatus and emphasizing process innovation (DeSarbo et al., 2005; Wang et al., 2008).

An essential characteristic of innovation in empirical research lies in the distinction between product innovation and process innovation (www.pdfs.semanticscholar.org). Also, process innovation is the adoption of technologically new or significantly improved production methods. Hence, developing a product innovation capability would enable manufacturing SMEs to maintain their position in the market or their relation with essential customers. On the other hand, developing a process innovation capability aims at improving firms' competitive advantage by a reduction in production costs and increasing the flexibility of their productive apparatus (www.pdfs.semanticscholar.org).

The process innovative management activities are to best support exploitative innovations when there is already some existing knowledge (Benner and Tushman, 2002), and to be advantageous for organizations that evolve in a stable environment. Other ways to conceptualize the effect of process and product innovation on performance, including Tidd's (2001) conceptual framework that includes environmental contingencies (uncertainty and complexity) and the degree of innovation (incremental or radical), as additional factors influencing organizational performance. Also, best product development practices such as concurrent engineering found on the coordination and integration of both product innovation and process innovation (www.pdfs.semanticscholar.org).

The research model developed and tested in this study is based upon the conceptual distinction between product and process innovation capabilities, presuming that SMEs who emphasize either one type of activity. The two main dimensions of a firm's competitive performance are their growth and productivity (www.pdfs.semanticscholar.org).

In empirical studies of innovation in SMEs, researchers have sought to explain why individual firms can innovate more successfully than others by identifying specific strategic capabilities as vectors of change (Bhattacharya and Bloch, 2004), including technology integration capabilities in particular.

Concerning process innovation capability, several SMEs have adopted and assimilated advanced manufacturing technologies (AMT) such as computer-aided design (CAD) and manufacturing (CAM) and flexible manufacturing systems (FMS) that enable firms to achieve a competitive advantage with more flexibility.

\subsubsection{The Innovative Capability of Firms}

The organizational capability view of innovation holds that firms do not merely compete with new products or services, but rather with their unique capabilities underlying their product-market activities (Liao et al., 2010). Compared to resources, routines and skills are embedded in the dynamic interaction of multiple knowledge sources and are firmermore specific and less transferable, thus leading to competitiveness (Peng et al., 2007).

As innovation grew in popularity as a topic of strategic management research, the shift to a resource-based view of organizations led scholars to look inside of an organization rather than the competitive environment for sources of innovative activity. Within the firm, organizational capabilities have proposed as a source of competitive advantage due to specialist knowledge held by the firm (Grant, 1996).

Winter (2000) also defined organizational capabilities as 'a high-level routine (or collection of routines) that, together with its implementing input flows, confers upon an organization's management a set of decision options for producing significant outputs of a particular type'. 
Importantly, capabilities require the recognition and deployment by management for the firm to fully capture their value. Skills can evolve through the creation or acquisition of products, processes, and knowledge. Skills influence not only what a firm is currently capable of doing, but also serve as a platform and a threat for entry into other areas (Zander \&Kogut, 1995).

Even when a firm aspires to imitate an innovation, mimicking the new ideas is dependent upon the imitator's organizational capabilities. The speed by which a design is a transfer throughout the industry is dependent upon the number of competitors engaged in a similar trade, the ease by which an innovation is understood and the degree of improvement (Zander \&Kogut, 1995; Teece, 1977). While two firms may be rivals, a lack of capabilities in a given area decreases the likelihood of imitation. Even with the motivation to mimic a peer organization and a similar product profile, a firm may be unable to imitate due to the combinative process of innovation (Zander \&Kogut, 1995). An analysis and comparison of capabilities provide insight into the likelihood of adoption and can serve as a predictor of post-adoption success.

As new capabilities are developed, competitors familiar with the landscape may attempt to mimic the innovative capabilities. Although the innovation literature primarily assumes eventual adoption by all competitors within the industry, firms may intentionally decide not to adopt these strategic innovations based on the capabilities that they have developed.

Recognizing the type of capability each firm has developed can impact managerial decision-making around which innovations to try and mimic. Analogous to prior research suggesting those firms follow their industry's market leader Absoulnasr et al., (2008) capability classification provides managers with a more direct comparison to competitors. Imitating unique capabilities may not be logical even when a competitor holds a similar market position given the current bundling and deployment of resources.

A capability can be defined as 'the proficiency of a bundle of interrelated routines within firms for performing specific tasks' (Ngo and O'Cass, 2013: p. 1135). Capabilities do not reside in individual routines but emerge from the integration of multiple interrelated routines and processes. It implies that capabilities are built through managerial choices in identifying, developing, and integrating routines and processes to undertake specific functionally oriented behaviours (Ngo \&O'Cass, 2012). Capabilities require that multiple characteristics be already embedded in a firm (Grant, 1996).

Lawson and Samson (2001: p. 384) defined innovation capability as the ability to continuously transform knowledge and ideas into new products, processes and systems for the benefit of the firm and its stakeholders. According to Bullinger (2008), innovation capability is a holistic, corporate-wide potential of a firm to generate new and unique values. Innovation capability relates to a variety of areas and is influenced by different factors inside and outside the organization. Similarly, Ngo and O'Cass (2012) concluded that innovation capability is embedded within the application of knowledge and skills embedded within the routines and processes of the firm to perform innovation about technical innovations.

Thus, innovation capability may relate to creating a new product or service, a new production process technology, a new structure or administrative system, or a new plan or program. This study adopts the view of Ngo and 0'Cass (2012) that suggested that innovation capability is manifested in innovation-related business processes (technical and nontechnical), is something beyond resources and is a valuable input for firms to develop and maintain competitiveness. Based on earlier definitions of Bullinger (2008) and Ngo and O'Cass (2012), innovation capability is defined in this study as organizational routines and processes affecting an organization's ability to perform innovation. It consists of determinants that influence an organization's ability to perform innovation, and innovation capability is thus a predictor of innovation, both process and outcome.

A firm's capabilities are essential in providing and sustaining its competitive advantage, and in the implementation of the entire strategy (www.pjitm.com). Authors such as Lawrence and Lorsch (1967), Prahalad and Hamel (1990), considered innovative capability as a key for competition.

Again, a high level of innovative capability indicates that, in response to the changing market conditions, the firm can develop new ideas and transform them into new products, processes or systems.

The innovative capability of a firm is highly contingent upon the level and the types of resources and other competencies of the firm (Neely et al., 2001), as well as on the extent to which the firms management successfully integrate and manage such resources (Lawson \& Samson, 2001). Innovation capability consists of a firm's ability to generate knowledge in the form of intellectual property such as a patent. Firms innovation capability is the application of relevant knowledge towards the achievement of market value and adopting creative ideas by the firms (Zhao et al., 2005). Innovative capability is defined as an essential factor that facilitates an innovative organizational culture, characteristics of internal promoting activities and capabilities of understanding and responding appropriately to the external environment. In order to make the small high-tech firms such as software firms to survive in today's fast-changing environment, the innovative capability is likely to be crucial to gaining dynamic competitive advantage (Romjin \&Albaladejo, 2002). Also, firms need skills to choose, install, operate, maintain, adapt, improve and develop technologies and products. Therefore, the innovative capability is an absolute requirement for small high-tech firms specifically in developing countries.

One can observe that the firm's capabilities are grouped into two main drivers: technological and business drivers (www.scielo.br).

Development Capability (DC) is the firm's ability to sense technological options and decipher novel market solutions (www.scielo.br). Every firm has a certain operations level that arises from the selection of competing priorities to exploit low costs, quality, delivery times, responsiveness, and flexibility. Moreover, Lall (1992) mentioned such activities as quality control, preventative maintenance, and workflow and inventory controls, among others (www.scielo.br). 
Every firm needs a business driver to transport technical solutions to the market following the lead of the technological driver, in which only DC and OC are collectively responsible for offering technical solutions to potential markets. This driver decides what the firm will efficiently conduct in-house, and what it will outsource to the market, from both its supplier and clients. If technology gives the firm a path, the business gives it a reason.

The firm must guarantee that the right things will 'get done,' and therefore, should have the specific ability to coordinate assets and activities; Management Capability (MC) is responsible for this task. Trott (2008) argued that the task of all managers is to improve their operations otherwise, they are supervisors and do not justify their job title. If capabilities can be explained by a set of routines embedded in applied technology, MC then requires a more extensive repertoire to act through choice and decision where technology fails to have a perfect routine. Management's Capabilities requires a wide range of skills, which should be flexibly applied in problem-solving to cope with various and often unpredictable circumstances (www.scielo.br).

Finally, the firm must bring to the market whatever it develops, operates, and manages in order to generate economic value (www.scielo.br). As every firm uses, manages, and operates a given technology with the explicit goal of obtaining positive economic returns, it should have specific capabilities to trade its products. According to www.scielo.br site, all these activities are collectively referred to as the Transaction Capability.

In contrast to firms with complementary capabilities, firms with substitutive capabilities utilize different resources to achieve the same goal (Hess \& Rothaermel, 2011). Firms with substitutive capabilities differ from those with complementary capabilities in that they lack the specific resources needed to adopt the innovation. While the firm is currently oriented towards the same strategic objective, resources must be bought on the open market, leading to a higher degree of risk in adoption.

Reverting to the previous deployment is not a simple proposition as the substitutive resources would have been exchanged for the adoption-specific needs. For example, in healthcare, two treatment plans may be substituted for each other, depending on the patient's needs. For the patient's treatment plans, this may involve different levels of inpatient versus outpatient care. Equivalent nurses and doctors would be involved in caring for the patient, but using different routines and procedures for diagnosis and treatment. For this hospital to adopt an innovation, additional training of medical staff would be required. First, the organization would have to bring knowledge of the innovation to the hospital, either through re-engineering or hiring. The resources may have to be redeployed, including personnel and medical equipment. None of this would ensure success as the hospital may experience a disruption in services. Although the organization may not need a total makeover, the firm is accepting a higher level of risk than those with complementary resources.

Due to the path-dependent nature of resource acquisition, firms that have neutralizing capabilities may be less likely to take note of an opposing innovation (Dierickx \& Cool, 1989). Neutralizing capabilities can be seen as those which neutralize the competitive threat posed by the innovation by reducing the market value of the idea (Barney, 1991; Porter, 1980). As capabilities are developed based on the available resources, firms with a resource acquisition strategy that differs from the innovator may be deterred from pursuing the innovation. If a firm with neutralizing capabilities were to try to adopt, they must overcome not only the inertia of their current strategic deployment but also must convince internal and external personnel that the new direction is superior. If the firm is currently successful, this strategic shift is highly risky with no guarantee that the appropriate resources can be acquired, and without previous knowledge about how to bundle and deploy these resources. Although knowledge can be acquired on the market, sourcing of this manner is expensive and would require a reconfiguration of the entire organization. It eliminates any previously held advantages derived from knowledge stocks, current routines, actors, and activities.

The high levels of agency and improvisation inherent to capabilities lead to a high degree of individual and group tacit knowledge within an organization's routines and capabilities (Berman et al., 2002; Winter \&Szulanski, 2001). Since management and actors within a routine seek to maximize efficiency, changing the structure eliminates the previous gains and resets the clock on building a competitive advantage. Moreover, these firms are behind the first mover and potentially others in the industry as they develop a capability to accomplish similar goals. When compared to other capabilities, firms operating neutralizing capabilities and considering adoption would find duplication to be highly tricky and may elect not to adjust their routines to the innovation.

The classification of capabilities does not suggest that all firms possess particular capabilities about the innovation. The new idea may be in an area of secondary interest to a competitor or a market in which an organization does not compete. Additionally, a firm may compete in an area without having any distinct capabilities at all. While these firms are unlikely to be successful, managers may use current innovations as a model by which to imitate. By viewing the innovators as market leaders, managers in this firm may elect to adopt, thus increasing competition for resources. Little research exists on firms with weak or nonexistent capabilities as these organizations are apt to perish due to their competitive struggles.

\subsubsection{Development of Firms Capabilities}

While capabilities lead to increased efficiency and repetition, excessive stability of capabilities has been linked to inertia and competency traps (March 1991). To prevent these problems from arising, firms routinely evaluate and change critical processes and actors. As a function that encourages organizational learning (Levitt and March, 1988), this new knowledge that is integrated into firms may eventually lead an organization to develop additional capabilities and expertise. Further, employees often change jobs and earn promotions, thus necessitating increased investment in capability development. Thus, the evolutionary aspect of replacing employees creates an opportunity to integrate new knowledge. 
Firms that is consistently able to develop capabilities that create new products and processes to account for changing market conditions may have dynamic capabilities (Teece et al., 1997). Dynamic capabilities are the 'adapting, integrating, and reconfiguring of internal and external organizational skills, resources, and functional competencies towards the changing environment' (Teece et al., 1997). Dynamic capabilities can enhance a firm's ability to adopt an innovation through the higher-order skill of facilitating change within the organization (Winter, 2003). Organizations that possess dynamic capabilities respond favourably to radical innovations and can quickly adapt to the new competitive environment.

Dynamic capabilities also help firms avoid becoming myopic in response to environmental changes (Teece et al., 1997; Levinthal \& March, 1993). Firms capable of acting quickly to market forces can avoid becoming path dependent upon their resources. By assimilating new information into the firm, management can deploy resources in numerous configurations that enhance the value of each asset. The successful development of dynamic capabilities must occur at the managerial level due to the impact that an environmental change may have on the entire firm's routines and capabilities (Teece et al., 1997).

\subsubsection{Innovation Capabilities' Measures of Firms}

According to Schumpeter (1934), innovation must necessarily lead to extraordinary profits for the innovator. This view poses some difficulties in gathering the necessary data to convey precisely whether any extraordinary profit is a result of specific changes by the firm due to firms' complexities and dynamics. Dynamic capabilities similarly seek to generate Schumpeterian returns. Teece (2010: p. 692) argued that dynamics capabilities aim to generate abnormal returns. All of a firm's actions (new product developments, processes, managerial arrangements, or commercial relationships) are intended to improve economic performance, such as sales increases or cost reductions; in other words, increases in profits. Therefore, a firm's innovative performance is a function of its development, operations, management, and transaction capabilities.

Innovation is the result of any of its capabilities, or a combination thereof, depending on firms' internal resources and market conditions. From this perspective, one should expect new products, processes, organizations, or transaction actions as novelties that could outperform the market's existing technical and economic value solutions and generate extraordinary profits. This Schumpeterian way of understanding a firm's dynamics and success draws on the shape of its innovative performance.

This model captures dynamic capabilities' effects on innovation by combining such capability measurements as processes and routines with an innovation performance (IP) outcome, measured as economic gains in terms of increase in profits, sales and market share.

The following equation relates IP with minimum industrial standards $(\beta 0)$, namely, the minimum technical, legal, and economic requirements to compete in a given industry; and the impacts of different innovation capabilities.

$\mathrm{IP}=\beta 0+\beta 1 \mathrm{DC}+\beta 2 \mathrm{OC}+\beta 3 \mathrm{MC}+\beta 4 \mathrm{TC}+\mathrm{e}(1)$

Each capability (CD, CO, CG, or CT) has a standardized coefficient (respectively, $\beta 1, \beta 2, \beta 3$, and $\beta 4$ ). This combination of coefficients will precisely determine the arrangement of capabilities and, to determine the role of these dynamic capabilities, the relative importance of each.

\subsubsection{Conceptualization of Frugal Innovation}

The term 'frugal innovation' has been used to refer to an extensive range of innovative solutions, from social innovations by non-profit organizations to for-profit products aimed at the poor. It ranges from grassroots entrepreneurs in the informal sectors of rural areas in the developing countries to highly formalized product development by multinational corporations (MNCs) targeted at price-sensitive customers. The word 'frugal' is an adjective that denotes characteristics of being 'economical in use or expenditure; prudently saving or sparing; not wasteful; entailing little expense; requiring few resources' (Tiwari et al., 2014). Hence, the term frugal implies the careful and cautious use of organizational resources to minimize waste and to ensure optimum utilization of scarce resources.

Frugal innovation opens opportunities for new business models by devising low-cost high-value products and services. It is likely to disrupt existing capital-intensive and top-down forms of change, contributing to more inclusive forms of development (Knorringai et al., 2016). According to Zeschky et al., (2011), 'frugal innovation is an innovation manifestation that aims to bring products, services, and systems within reach of billions of poor and emerging middleclass consumers at the middle and base of the pyramid'. A relatively new approach to development and growth, frugal innovation is a constraint-based response to the unmet needs of BoP consumers (Kahle et al., 2013). The focus of frugal innovation is to bring the cost down while safeguarding user value (George et al., 2012; Tiwari and Herstatt, 2012; Rao, 2013; Radjou and Prabhu, 2015). 


\begin{tabular}{|c|c|}
\hline Definition & Source \\
\hline $\begin{array}{c}\text { Frugal innovations are 'good-enough, affordable products that meet the needs of } \\
\text { resource-constrained consumers'. }\end{array}$ & Zeschky et al., (2011) \\
\hline $\begin{array}{l}\text { Frugal innovation is 'an art of overcoming harsh constraints by improvising an } \\
\text { effective solution using limited resources'. }\end{array}$ & Radjou et al., (2012) \\
\hline $\begin{array}{l}\text { Frugal innovation is 'an innovation redefines business models, reconfigures value } \\
\text { chains and redesigns productions by optimizing resources in different ways by } \\
\text { creating extensive markets by serving consumers with affordability constraints }\end{array}$ & Bhatti (2012). \\
\hline $\begin{array}{l}\text { Frugal innovation 'involves (re) designing products, services or systems to } \\
\text { significantly cut costs, without sacrificing user value, to reach a mass customer } \\
\text { base, especially in low-income settings'. }\end{array}$ & Rao (2013) \\
\hline $\begin{array}{l}\text { Frugal innovation 'reflects products, services, technologies or processes that do } \\
\text { not compromise on necessary quality, reliability or safety standards but can enable } \\
\text { significant cost reductions by, for example, making use of state-of-the-art } \\
\text { technologies, inventive analogies and accessing open global innovation networks'. }\end{array}$ & $\begin{array}{l}\text { Tiwari and Herstatt, } \\
\text { (2012) }\end{array}$ \\
\hline $\begin{array}{l}\text { Frugal innovations are 'cheap, robust in harsh environments, easy to use and } \\
\text { repair, and made of used and local materials'. }\end{array}$ & Douglas, (2013) \\
\hline $\begin{array}{l}\text { Frugal innovation refers to 'the systematic innovation processes that had been } \\
\text { adopted to develop high-end, low-cost technology products for underdeveloped } \\
\text { and developing economies, which are demanding regarding features of the } \\
\text { products and services, offered but are also demanding regarding the price'. }\end{array}$ & Ojha, (2014) \\
\hline $\begin{array}{c}\text { Frugal innovation is 'a product, service or a solution that emerges despite financial, } \\
\text { human, technological and other resource constraints, and where the outcome is } \\
\text { less pricey than competitive offerings (if available) and which meets the needs of } \\
\text { those customers who otherwise remain un-served'. }\end{array}$ & Simula et al., (2015) \\
\hline $\begin{array}{l}\text { Frugal innovations are new or significantly improved products, processes, and } \\
\text { organizational methods that seek to minimize the use of resources in the complete } \\
\text { value chain to reduce the total cost of ownership and usage significantly. }\end{array}$ & Knorringai et al., (2016) \\
\hline $\begin{array}{l}\text { Frugal innovations seek a substantial reduction in the cost of usage and ownership } \\
\text { while fulfilling or even exceeding prescribed quality standards. }\end{array}$ & Tiwari et al., (2016) \\
\hline
\end{tabular}

Table 1: Definitions of Frugal Innovations

Sources: Researcher's Construct 2019

Frugal innovation entails the focus of organizations on:

- $\quad$ Combining of existing materials, processes, and resources through bricolage (prabhu and gupta, 2014);

- Ensuring the prudent and cautious use of the-scarce organizational resources (holger et al., 2015);

- Employing and demonstrating flexible thinking and pragmatic action (jain, 2012); (iv) creating self-service options for users, and

- Focusing on including excluded groups, not just as users but also as members of an ecosystem producing and distributing these services, thereby augmenting their income and contributing to their development (kahle et al., 2013).

\subsubsection{The Potential Broader Benefits of Frugal Innovation (FI)}

Interest in Frugal Innovation (FI) amongst policymakers also stems from the theoretical possibility that it may help to address other public policy challenges, including the 'Societal Challenges' highlighted in the context of Horizon 2020 (H2020). Research and examples to date suggest that frugal innovation can contribute in two main ways.

First, the themes covered by the H2020 Societal Challenges (SCs) are areas in which there is demonstrable potential for successful frugal innovation. For example, many existing cases of frugal innovations fall into the category of 'new models and tools for health and care delivery' (Health, demographic change and wellbeing). Moreover, some of these are also examples of 'reverse innovations', having been designed for emerging economies and then successfully introduced in the west. Secure, clean and efficient energy has also been a strong focus for frugal innovation in emerging and developing economies. However, the context in which these innovations have been designed lack of access to an electricity grid means that they may not have so much direct potential for an introduction to industrialized economies.

Second, the characteristics of frugal innovation are complementary to several of the Horizon 2020 Societal Challenges. For example, by increasing access to goods and services, frugal innovation could help to foster socio-economic inclusion (Inclusive, innovative and reflective societies). There is considerable evidence of this in emerging economies, where well-documented examples in sectors like energy, mobile banking (M-Pesa in Kenya) and healthcare (Aravind Eyecare in India) have broadened access to essential services and helped to generate improved social and economic outcomes for customers. There are equal opportunities in at least some of these sectors within Europe - for example, Master Card estimates that some 93 million Western Europeans are 'underbanked' but at present few examples of frugal solutions developed for these markets. Similarly, there is considerable potential in how frugal innovation can contribute to 
achieving the objectives of given the focus of some frugal innovations on more efficient use of natural resources and the promotion of 'circular economy' principles.

Nevertheless, as pointed out below, the contribution of frugal innovation to environmental sustainability is not always straightforward. It can be in tension to improve access to goods and services. It can happen if frugal innovation results in the more widespread use of a solution, thus increasing its ecological footprint.

It also suggested that frugal innovation can help achieve a range of other socially and economically desirable outcomes. Literature in this study uncovered frugal innovation aspirations, including:

- Preservation of cultural heritage, possibly through a combination of traditional manufacturing techniques with prudent distribution methods, to reach broader markets.

- Job creation, as a result of new economic opportunities.

- We are promoting global development through research and innovation partnerships, rather than traditional development assistance.

However, while each of these remains a theoretical possibility, none are inevitable outcomes of frugal innovation. Reid et al., (2015) found that while collaboration between UK SMEs and large Chinese firms generated new jobs in the UK, the employment gains tended to be much higher in China. The question for policymakers will therefore not merely be whether to promote frugal innovation, but how to improve it in a way that generates the most positive social, economic and environmental outcomes and minimizes adverse impacts.

Mass customization refers to efforts aimed at substantial increases in variety without a corresponding increase in costs (Tseng \& Jiao, 2001). Through company-customer interaction at the conception, fabrication and assembly stages, it constitutes a strategy to better meet individual customer's needs at prices close to that of standardized products (Kaplan \&Haenlein, 2006). Thus, it, by definition, creates a substantial opportunity to increase the scope and impact of frugal innovation on developed markets. In the foreseeable future its broad-based, technology-driven implementation may thus become a technology as equally 'game-changing' as the broad availability of steam engines, artificial fertilizer or industrialscale electricity 'fourth industrial revolution'.

Nonetheless, 'hard' or 'collaborative' customization (Chen et al., 2009), customer-producer interaction at the development stage, is still most likely to provide genuinely transformative potential in the long run. Arguably, such earlystage collaborative efforts are particularly productive as they help to more effectively match the individual specific needs of customers with the growing customization capabilities of manufacturers.

\subsubsection{Challenges and Barriers of Frugal Innovation}

While stressing the growing importance and opportunities of emerging markets, many authors (Govindarajan et al., 2012: p.19), (Kumar \& Puranam 2012: p.15) underline that these particular markets have their challenges to business and innovations. Although many international companies may recognize the importance of emerging markets and frugal innovations, many fail due to emerging market barriers to innovation. Prahalad (2006) and Krishnan (2010: p.138) have mentioned different types of obstacles for local and multinational companies to innovate in emerging countries.

Frugal innovations do not begin with inventing, but instead with forgetting. It is claimed that traditional methods used in developed countries face a tremendous challenge in emerging markets and therefore, they should be left behind (Govindarajan et al., 2012: p.14). Globalization is the previous strategies of multinationals in emerging markets, and it has been successful until now. However, globalization strategies are not sufficient enough to serve as the base of the pyramid consumers. Moreover, the structures and capabilities that served well for globalization strategies might challenge the frugal innovation process. According to Govindarajan \&Ramamurti, 2011, there are three kinds of traps that multinationals face while striving to seize opportunities of frugal innovation in emerging markets.

\subsubsection{Familiarity Trap}

The trend is given that organizations favour what is familiar to them, and it is a challenge for MNCs to disrupt their existing structures and to understand the needs of emerging markets. Govindarajan and Ramamurti (2011) underlined that emerging market managers do not get the power and voice to develop strategies for emerging markets. Therefore, it becomes harder for them to understand the unique features of these markets. They claim that it is consequently robust for international units to identify opportunities for innovations in profoundly different markets.

\subsubsection{Competency Trap}

Existing competencies in companies may become barriers to building new ones. Companies tend to exploit their existing capabilities instead of making new ones. For emerging markets which require brand new approaches and competencies, previous competencies are as traps. Needs of emerging markets include low-cost, good enough quality, functional and value products. This definition conflicts with last premium product offerings and capabilities of some multinational companies. The authors also stressed the issue that value products developed for emerging markets could also cannibalize the sale of premium products and brand image in their home countries (Govindarajan \&Ramamurti, 2011).

\subsubsection{Complacency Trap}

Value products for emerging markets and premium products in developed markets require inconsistent business models. One focuses on low margin, high volume and the other focuses on high margin low volume. Given that the value products have uncertain future potential and revenues, Govindarajan and Ramamurti (2011) suggested that multinational 
companies may choose to invest on their scarce resources on premium products which formerly have proved to bring success.

Chandra and Neenkavil (2008) believed that multinational companies devote less attention to emerging markets due to low marginal potentials. They claim that developing new products from scratch is costly and opportunities for profit are uncertain. Given that the product development process is complicated, time-consuming, expensive and risky; creating new and innovative products for these markets might raise challenging issues. Authors suggest four significant areas that create barriers for multinational companies in developing new products and services for emerging markets. These four areas are; price income levels, technology development issues, capital constraints and creativity.

\subsubsection{Price-Income Levels}

Despite the growing middle-class consumers, the majority of consumers in emerging markets have low-income levels, and most developed country product prices are too high for them. At the same time, this situation makes it difficult for multinational companies to generate profits by serving customers with low incomes. It claimed that multinational companies have fewer incentives to create innovative products in emerging markets due to low price-income levels (Chandra \&Neenkavil, 2008). Govindarajan et al., (2012: p.40) also discussed the same issue., where they claim that this concern of MNCs does not match with experience. Moreover, they suggest that despite the low gross margin percentages, fixed costs in emerging countries are much smaller than developed nations and potential volumes are much more significant. However, this issue remains a concern in the minds of the MNC managers, creating barriers to frugal innovation in emerging markets.

If the technology is the root of innovation, lack of sound technology and trained scientists in emerging markets will create a barrier to innovation in these countries. Multinational companies hesitate to invest in human and financial capital to develop new technologies for new products and services in these countries. Chandra and Neenkavil (2008) also discussed capital constraints in emerging markets. Financial money in these countries is scarce for the development of products and services. MNCs usually set limited budgets for R\&D due to the high costs of product development and lack of capital.

Kumar and Puranam (2012: p.127) focused on three major problems in the innovation system of India. They claim that the Intellectual Property regime (IP), talent pipeline and the venture capital sector to be the most critical barriers to innovation in India, among many other problems.

Talent Pipeline: India Inside presents that India supplies one-third of the world's low-cost labour. Although India has an abundant amount of work, only a tiny section consists of the skilled talent necessary for innovation. The authors claim that even the best educational institutions in India are understaffed, and they operate at the one-third level of their strength. According to them, the Indian university system fails to train, and they lack the capability of creating new knowledge and innovation (Kumar \& Puranam 2012: p.127).

Lack of skilled talent affects the capability of multinational companies creating innovations in India. Authors of India Inside present an example of Astra Zeneca as head of the Indian R\&D lab of Astra Zeneca, Tanjore Balganesh complains that in a brainstorming session for drug discovery, no single chemist exists among seventy-five contributors in the meeting. Even though it is the chemists who make a drug, biologists are trying to make a drug on their own since there are not enough medicinal chemists in India (Kumar \& Puranam, 2012: p.128).

The final issue in the talent pipeline, according to the authors, is the lack of quality in the labour pool. R\&D managers of many MNC subsidiaries in India have reported that only a small proportion of the graduates in their disciplines are employable. Therefore, the quality of skilled labour is an additional problem to the quantity shortfall, and they both affect the innovation capability of India and the multinational companies in India (Kumar \& Puranam, 2012: p.132).

Krishnan (2010) also mentioned problems with the talent pool as a barrier to innovation. He presents that Indians are sensitive to criticism and thus not very efficient in teamwork and problem-solving. Moreover, he claims that contemporary innovation and knowledge requires knowledge-based authority, not the position in the hierarchy; however Indian society and organizations yet remained hierarchical. This structure of the Indian society also forced multinational companies operating in India to introduce more levels into their organizations on the contrary to their global flatorganizations. Therefore, he claims that society and culture affect the talent pool by poor teamwork, hierarchical progression, low tolerance to failure and hence lack of confidence in innovation capabilities (Krishnan 2010: p.140).

\subsubsection{Intellectual Property and Pirates}

Intellectual property regime has denied the composition of patents in many industries. This approach was taken at when the foreign companies held most of the patents. It was fear that foreign patents would prevent domestic competition with imported items, and Indian consumers would not be able to access goods at lower prices. This restrictive legislation has resulted in a lack of importance of Intellectual Property (IP) and its protection. The poor IP infrastructure creates challenges for MNCs to protect their information which results in fewer incentives to innovate in India (Kumar \& Puranam, 2012: p.139).

Kumar and Puranam (2012: p.139) quoted the CEO of Novartis in their book; 'In principle, you can discover in India, you can do research. There has been some progress on the protection of intellectual property, but it is not up to the standard that would expect to invest in discovery-led research.' The authors argue that multinational companies operating in India cannot wait for improved legislation or let their secret information stolen. Therefore, many multinationals in India had to develop internal IP regimes to protect their data or segment their innovative projects in a way to minimize the risk of any potential leakage. 
The Economist (2011) also mentioned this challenge as piracy, where multinational companies face competition from rivals. They also claimed that branding is also challenging factor due to cheaper pirate products. Therefore, multinationals in India still have legitimate concerns to protect their IP rights. According to Kumar and Puranam (2012), developing their internal IP regimes leads to additional costs and may deter some multinational companies from leveraging innovation capabilities (Kumar \& Puranam, 2012: p.16).

\subsubsection{Venture Capital}

New entrepreneurial venture support in India is immature. Despite the emergence of new networks of investors and venture funds in recent years, the global financial community still argues that there is a big gap between the available venture capital and existing opportunities in India. Some individuals and companies try to overcome this challenge in creative ways, but it still creates an essential barrier to innovation (Kumar \& Puranam 2012: p.142).

It is also claimed the scarcity of capital in emerging countries as a barrier to innovation. Chandra and Neelankavil (2008) argued that multinational companies could not justify investing in research and innovation in countries with difficult access to capital. Due to the high costs and scarcity of money, MNCs in developing countries keep their budgets very limited for R\&D in these countries. This situation creates a barrier to firms and entrepreneurs who aim to design new products and innovate in India.

\subsubsection{Western Fears}

In their book Reverse Innovation, Govindarajan et al., (2012) mention several fears that west MNCs have while considering creating reverse innovations. First of them is having too low margins to make profits. According to the authors, this concerned is invalidated by experience as the fixed costs in these countries are relatively, and volumes are much higher. Moreover, they claim that reverse innovation requires a redesign of the product, and it is cost structure which makes it comparable or better to invest in innovation in developing countries. Eyring et al., (2011) supported the argument that these fears are unjust; they claim that MNCs can adapt and overcome these challenges by changing the cost structure and profit formulas and by renewing their business models. However, this fear remains as an essential barrier to frugal innovation in developing countries and makes MNCs hesitate to get going (Govindarajan et al., 2012: p.40).

Another fear mentioned by the authors is putting existing brands at risk and cannibalize the sales of premium offerings. While admitting these risks are real, it is suggested that having multiple price points is necessary to be competitive internationally. The authors argue that the chance of being passive against other companies could cause more damage than the risk of cannibalization. In this case, another company can do the cannibalizing instead. The authors have a point; fear of cannibalization still stands as a barrier to frugal innovation in emerging markets (Govindarajan et al., 2012: p.41).

The final fear of multinationals presented is the incompatibility of technology leadership and ultra-low-cost. Some technology-driven companies fear that they cannot develop ultra-cheap products for the needs of developing countries while keeping their technology-leader positions. Therefore, they refrain themselves to create frugal innovations (Govindarajan et al., 2012: p.41).

\subsubsection{Differences from the Western World}

Every characteristic in emerging markets shows great variety and deviations from the West. Demands are varied and volatile. Infrastructure, geography, language, religion and government have their distinct conditions. Culture is complicated, and tastes are very fluid. Kumar and Puranam (2012) mentioned Indian consumers as the world's most value-conscious consumers. Creating the most value for the best price, especially in a country with high variation is a challenge for MNCs. The Economist (2011) presents another difference between the western world and calls the distribution system in India 'dreadful'. Finding reliable suppliers is difficult. Recruiting and retaining talented labour is a big challenge. All these differences and complex characteristics of developing countries create barriers for multinational companies to establish frugal innovations.

On the other hand, these differences might lead to new ways and approaches to doing business. To cope with these differences and adapting to varied needs, MNCs should start with abandoning their traditional practices. Govindarajan et al., (2012: p.14) claim that frugal innovation begins not with inventing, but with forgetting. Complete new approaches require open minds, and this might be the biggest challenge for MNCs creating innovations in developing countries.

\subsection{Defining Firm's Smallness}

SME is a holistic term that implies an ambiguity about a company's categorization and positioning, as the firm size is expressed in many different ways. The term 'SME' clouds the fact that firm size is also related to the industrial sector it belongs to just as firm age should be considered about the age of the area. The word 'size' expresses either the number of employees or the amount of turnover. It is a misleading term, however, due to the realities of the current, dispersed economy.

The earliest form of business entity in the world is the small business enterprise. Ahmed (2006) explains that (SMEs) to now seem the sub-sectors of the industrial sector which plays crucial roles in industrial development. It suggests that Small and Medium Scale Enterprises are very vital in shaping the growth agenda of countries (www.irssh.com). Primarily, they have added to increasing production, giving out value-added activities in the industrialized sector, providing jobs avenues particularly in the services sector, and helping to broaden Ghana's export base (Ghana Investment Promotion Centre, 2010). 
However, the SMEs within this sector is saddled with a series of challenges and difficulties. Most of the productive poor and unemployed Ghanaians are engaged in self-employment to better their living and that of their families (www.irssh.com). This action subsequently has made Entrepreneurship a fast and better option in Ghana, thereby reducing the rate of unemployment. Currently, employment seeking corporate entities by the Ghanaian youth is declining (www.irssh.com).

According to Acolatse (2012), SMEs represent greater than ninety per cent of most operations in Ghana. SMEs engage a vital fraction of the Ghanaian financial system. However, the growth of these businesses seems a mirage as most of them collapse soon after coming into existence. Most of these businesses also suffer from the actions and inactions of the more prominent companies who do not typically employ the local people and generally too are foreign companies (www.irssh.com). The government of Ghana has instituted some policies to appraise the operations of SMEs to develop SMEs to a better status. Since the enactment of PNDC Law 328 in 1991 to permit different groupings of commercial organization which includes savings and loans companies, SMEs a lot has been done to promote the SMEs to greater heights.

It is important to discuss 'smallness' in the context of the new economy since this economy is influenced by the Information Technology (IT) revolution. When assessing the current system, the numerical, clear-cut, artificial borders used in the past should be downplayed; they are confusing and probably not reflective of the economic realities of today. Today's firms can mature rapidly and become global actors within a short time (www.manualzz.com). Thus, it is more appropriate to use other ways to categorizes SMEs. An alternative nomenclature for SMEs can be, for example, young firms or potential growth firms who have attained a business platform.

\subsubsection{Small and Medium Enterprises}

In developing countries, entrepreneur, particularly in the context of Small and Medium Enterprises (SMEs) is essential for economic growth. Small and Medium workforce contributes as a solution to the country's economic growth, in term of generating employment Birchall et al., (2011), offering innovative products or services and competitiveness Porter, (2001) and enhance international trade of an economy through diversification. The entrepreneur may be a solution for workforce empowerment by creating jobs for themselves and others.

Small-Medium Enterprises (SMEs) businesses are defined as employing not more than 5-10 workers, including the owners and family Chawla, et al., (2007). The United Nation Industrial Development Bank (UNID0) classified smallscale enterprises as those with less than 150 employees. The definition is only applicable to industrial and newly industrializing countries. Based on a Secretary-General of the United Nations Conference on Trade and Development, SMEs are a source of employment, competition, economic dynamism, and innovation (www.unescap.org). SMEs stimulate the entrepreneurial spirit and the diffusion of skills because SMEs enjoy a more extensive geographical presence than large enterprises. Therefore, SMEs also contribute to better income distribution.

Unfortunately, there is no single agreed definition of a 'small' firm. A company considered to be small in one sector of business such as manufacturing may be considerably different in size from one in, say, the road haulage business (www.memoireonline.com). In 1971, the Bolton Committee, set up to investigate the small firm sector, attempted to resolve this problem by establishing both an economic and statistical definition of a small company.

SMEs are defined as non-subsidiary, independent enterprises that employ less than a given number of employees. This number varies across national statistical systems.

\subsubsection{Growth of Small and Medium Business}

It is often assumed that all businesses wish to grow. However, is it true? Do small companies want to become big companies? It may well be that all entrepreneurs of the small firm have no aspirations to expand the operations of their enterprise (www.memoireonline.com). Small businesses are frequently perceived to grow in stages. The number of stages of business growth may vary depending on the nature of the firm and on how each step is defined, but typically we can identify five (www.memoireonline.com).

According to Sloman, and Sutcliffe (2001) at the initial stage, inception, the entrepreneur plays a critical role in managing the enterprise with the title if any formalized management structure. In the next, two steps we see the firm establish itself (survival stage) and then begin to grow (www.memoireonline.com). The entrepreneur devolves management responsibility to non-owner managers. Such non-owner managers can add specific skills to the business, which might enhance their chances of growth and success. According to www.memoireonline.com, the fourth and the fifth stages, expansion and maturity, see the firm become more bureaucratic and rationalized; power within the organization becomes more dispersed.

To explain why a small firm grows, there is the need to examine some factors under the following headings: the entrepreneur, business and strategy (www. memoireonline.com).

Entrepreneur: factors in the section relate attributes and experience of the individual entrepreneur predominantly. They include:

Entrepreneurial motivations and desires to succeed, i.e. motivation, drive and determination are essential qualities for a successful entrepreneur (www.memoireonline.com).

Prior management experience and business knowledge include background experience accumulated by the entrepreneur in the same, or related industry is likely to offer a small firm a far higher chance of survival and growth (www.memoireonline.com).

Firm: the following are the essential characteristics of the small business that determine its rate of growth. 
It adds to the company's stock of human capital and thereby increases the quantity and possibly also the volume of the output per head; the use of external finance: taking on additional partners, or, more significantly, taking on shareholders, will increase the funding available to firms and therefore allow a more rapid expansion (www.memoireonline.com).

Export markets: even though small firms tend to export relatively little, export markets can frequently offer additional opportunities for growth (www.memoireonline.com).

What the above factors suggest is that, if a small business is to be successful and subsequently grow, then it must consider its strategy of activities, the organization of the firm and the utilization of the individuals 'abilities and experience (www.memoireonline.com).

Applying the findings of Greiner to the small entrepreneurial business situation, Churchill and Lewis (1983) have developed a model. As defined by them, an enterprise can have five stages of growth.

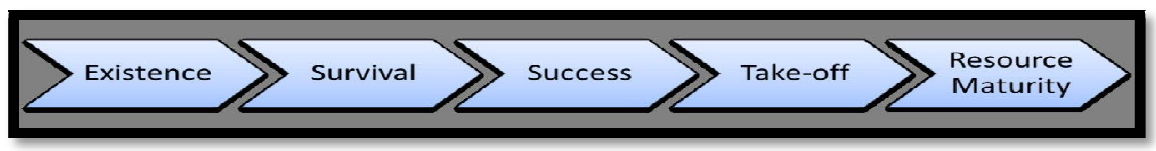

Figure 5: The Five Stages of Small Business Growth Adapted from (Churchill and Lewis1983)

In this stage, the enterprise struggles to establish its processes and works without a formal structure in place (www.link.springer.com). The founders of the enterprise take close supervision of every business activity at the early stages of establishment.

According to www.link.springer.com, the second stage is the survival where the entrepreneurs grow the business and feel the need to have additional money to expand the business. Since the business activity is increasing, he/she prefers to add family members or known people as partners to grow the business (www.link.springer.com). The main aim of the enterprise is to reach the breakeven point so that adequate cash flow can be maintained to meet the expected entrepreneurs' requirements.

At the third stage of success, the enterprise begins to earn profits (www.link.springer.com). Entrepreneurs have enough capital to either invest in the further business opportunity or continue at the same pace of growth. At this stage, the enterprise may take up team building and people development as some of their focus areas; however, these initiatives are driven by personal values and vision of the entrepreneur.

At the early stage, the focus is on further growth, expansion, and seeking new opportunities (www.link.springer.com). The organization becomes more formal, and work is defined correctly and delegated. Finally, at the resource maturity stage, the enterprise is no more called a small enterprise. The company gives more emphasis on quality control, financial control, and creating a niche in the market.

Bridge et al., (2003) suggested that an enterprise does not need to develop in discrete phases with clear boundaries between them. They further highlighted that 'separating the development process into stages is rather like dividing the spectrum of visible light into colours. The authors argue that, while large stages of development of an enterprise can be indicted, it is challenging to say when the business moves from one scene to another. According to www.innovation-entrepreneurship.springeropen.com, firms can grow, stagnate, and decline in any order. Authors suggest that the growth of an organization is a result of many discrete efforts. It depends on the strength of the growth aspirations and growth-enabling factors of an enterprise (www.innovation-entrepreneurship.springeropen.com). Therefore, it is not possible to consider growth as a norm or a smooth progression of an enterprise.

The stages model and life-cycle theories of entrepreneurial growth do not provide ample evidence of enterprise growth and development (www.link.springer.com). The site further pointed out that previous researches lack proper evidence on what is the path of progress from one step to another and the reasons behind the shift. Dynamic states offer that an enterprise can survive and maintain itself by being flexible and by adopting continuous changes in the background. Leitch et al., (2010) also suggest that there is a need to understand the growing phenomenon and its importance to conceptualize the event adequately. The heterogeneity of the enterprise and entrepreneur's context add further challenges to the study and understanding of growth. The www.link.springer.com site, further suggested that there is still much scope of exploration on growth as 'internal process of development'.

\subsubsection{Barriers to Small and Medium Enterprises Growth}

According to Ward (2005), two main obstacles retard the growth of Small and Medium Enterprises, namely the Internal and external constraints.

\subsubsection{Internal Factors}

Entrepreneurs have their self-identified traits about their specific behaviours, abilities and skills. However, these opinions from themselves are more or less distinct from those described by social scientists who study entrepreneurs (Hentschke, 2005). Entrepreneurial skills which summarized the primary characteristics of entrepreneurs outlined by both entrepreneurial leaders and social scientists from five dimensions: financial management, communication, tolerance for risk, ambition and perseverance.

Arguably, financial management is the most significant skill from the perspective of entrepreneurs, and in fact, encompasses several interrelated but different abilities: developing and marketing business plans, improving the financial capital, appropriate use of funds and so on (Hentschke, 2005). Eggers and Leahy (1995) declared that entrepreneurs need 
to develop a consistent and convincing business plan, then convince others to attract their venture capital, and maintain healthy relationships with investors to ensure long-term access to the funding.

All successful entrepreneurs have to be an excellent communicator; communication skills for all entrepreneurs are crucial. Those skills such as listening, vast and small group, one-on-one (Eggers \& Leahy, 1995) assist entrepreneurs in motivating employees, conveying a vision, and encouraging themselves (Hentschke, 2005). According to a study carried out by Eggers and Leahy (1995), entrepreneurs emphasized communication not only regarding skills but also regarding content. Entrepreneurs convey the enterprise's vision, mission and business model strategy to inspire both understanding and supporting from employees, customers and suppliers (Hentschke, 2005).

According to Hentschke (2005), social scientists view the first attitude of entrepreneurs as tolerance for risk. Entrepreneurs are more willing to put professional welfare as well as individual family property at risk to achieve their goals than many other peers. The most common phenomenon of risk tolerance is that entrepreneurs mortgage their assets to guarantee bank loans. However, entrepreneurs tend to rationalize their risk-taking behaviour due to various reasons, including the confidence to themselves, the value of fixed assets, a standby retreat, and even the support from their friends (Hentschke, 2005).

Ambition is defined by Hentschke (2005: p.155) as a 'relentless pursuit of success'. An entrepreneur with ambition is a person who participates in the entrepreneurial process and creates as much value as possible for the new venture. An ambitious entrepreneur aims at a certain degree of achievement and is willing to strive for this. Aspiring entrepreneurs wish to discover their paths and work towards their visions, rather than function leisurely under the constraints of modern society.

People only fail in their business as they give up when running into a stone wall (Burley, 2012). However, as it happens, no enterprise will always fail if people persevered (Ressi, 2014). Individuals with perseverance manage business though setback (Hentschke, 2005). Nearly each success story has familiar elements of persistence and determination (Burley, 2012). As Ressi (2014: p.11) stated: 'In business, persistence means leaning forward, walking one foot after the other into the chill entrepreneurial wind until you have reached your milestones and eventually achieved your goal.

\subsubsection{Financial Management}

The crises arising from financial ramifications are the common problems faced by many entrepreneurs; mainly include cash flow problems, poor credit control, bad debts and lack of proper budget controls (McCarthy, 2003: p.6). He pointed out that at the beginning of the start-up, the management methods of enterprise financial planning are loose, unstable and imperfect. The founders of many businesses believe that maintaining financial control is the most important thing. As we mentioned before, entrepreneurs need to develop a consistent and convincing business plan, attract their venture capital, and maintain long-term access to the money in the daily business activities (Eggers \& Leahy, 1995). After the crises, the entrepreneurs are forced to carefully consider the allocation problem of resources in short supply and spend more time to study and plan for potential customers.

\subsubsection{Communication} 1998).

Effective communication is the critical ring to put enterprise resource planning into practice (Falkowski et al.,

Wee (2000), insisted that people from each level of the entire company need to master the communication skills. Entrepreneurs glean information through some communication channels, for instance, talking to customers directly, subscribing to business magazines, attending industry information exchange meetings, or visiting the trade exhibition (McCarthy, 2003). As McCarthy (2003: p.5) explained, this enabled them to keep up to date with customer needs, with technological developments and to develop ideas for new products. Middle managers use communication to get to know the relevant latest information with enterprise (Wee, 2000). The staff should be tipped off in advance about the 'scope, objectives, activities and updates,' and 'admit the change will occur' (Sumner, 1999: p.298).

\subsubsection{Tolerance for Risk}

McCarthy (2003) deemed that the strategy formation process of the business model is controlled by the entrepreneur's individuality and his/her experience of crisis. Once the founders of enterprises confirm for their faith, abandon the real stable job, invest all their money, to choose a way of establishing and developing their own business to proceed without hesitation, they have put themselves and their entire families into the risk.

An enterprise's risk tolerance is crucial (Harrington \& Reed, 2000). The ability to adapt the business model is becoming more and more critical for those who need to manage organizational uncertainty in the current economic environment or organizations which are subjected to the risk (Giesen et al., 2010).

To enhance the risk tolerance of an enterprise, Harrington and Reed (2000) emphasized one effective method: iterative learning, which contributes to establishing the necessary skills and the thinking mode quickly. Because of the long-term strategic plan, even if with sophisticated management processes, it is impossible to overcome flexible new entrants without any burden.

\subsubsection{Ambition}

Entrepreneurs are the primary source of value creation. They determine the success of the enterprise in conjunction with other resources (Holcomb et al., 2009). Wiklund et al., (2003) stressed the importance of 'Attitude towards growth' to the development trend of an enterprise. Also, researchers showed that the entrepreneurial attitude (Majumdar, 2007) has a strong effect on economic growth-related and development related to strategic decisions, 
especially for small enterprises. Moreover, sometimes, entrepreneurs of small firms do not want to take advantage of growth opportunities (Wiklund et al., 2003) as 'they do not have an automatic bias towards growth' (Lesger, 1997: p.1591). Their ambition for growth and development are relevant (LeBrasseur et al., 2003). If they decide to grow, those entrepreneurs often choose the sooner, the better, so that they can take advantage of market opportunities (Lesger, 1997).

\subsubsection{Perseverance}

The majority entrepreneurs will say that the early stages of establishing a new business are an exciting and exciting period; however, just starting a new company does not mean doing business successfully (Cornwall, 2013). A Chinese saying goes that 'to initiate a business is difficult, but to keep it going is more difficult'. Virtually, the hardest part of the entrepreneurial process is to maintain and grow a sustainable enterprise, which demands 'creating systems, building the structure, hiring staff, raising money, managing cash flow, increasing revenues 'and so on (Cornwall, 2013: p.9). All of these steps take the patience and perseverance of entrepreneurs.

\subsection{External Factors}

Sure, external situations are assumed to directly or indirectly affect the capability of firms within the defined industry to produce value (Ward, 2005). PEST analysis offers a 'satellite view' of the industry to evaluate the external environment (Ward, 2005).

PEST is the collection of acronyms of political, economic, social, and technological characteristics of the external environment (Morden, 2012).

PEST analysis is as an analytic framework for macro-environmental factors (Buchanan \& Gibb, 1998). As Ward (2005) mentioned, these characteristics cannot be manipulated or altered by the enterprises. The only thing that an enterprise can do is to assess potential changes and make a better response to the changes than competitors.

These four characteristics are expressed in terms of the following factors: Political component includes government policies and regulations like 'environmental protection, consumer protection; tax policies; trade restrictions; tariff regulations; as well as, political stability and safety regulations' ('PEST ANALYSIS', 2012; Ward, 2005: p.11). Economic characteristics usually are related to 'economic growth; interest rates; exchange rates; inflation rates; monetary policies; government spending; unemployment policy', etc. Social characteristics are often concerned with 'the cultural aspects including health consciousness, population growth rate, age distribution; while the changes in lifestyles, tastes, buying patterns, philosophies and social conditions'(Ward, 2005). According to PEST ANALYSIS, 2012; Ward, 2005: p.11), technological characteristics usually consist of 'governments research spending; industry focus on technological effort; new inventions and development of R \& D activities, automation and technology incentives; the rate of technology transfer; life cycle and speed of technological obsolescence'.

PEST is used in two different ways (Peng \& Nunes, 2007): first, to analyze the status of a particular organization (Vrontis\&Vignali, 2001) or industry (McManus et al., 2007: p. 19-36) in a specialized business environment; second, to analyze the feasibility of integrated management solutions in an intricate business climate (ESCWA, 2005). In this study, the second method is used to evaluate the impact of four variables (PEST) on the business model.

\subsubsection{Political Dimension}

McKelvey et al., (2008) described four factors which affect the development of sound business models. One of those factors is public policy institution and regulation (www.studylib.net). Meanwhile, www.studylib.net believed that the majority of the business models has political importance, especially in the contexts of countries that are experiencing the development of an enterprise (Zhilong et al., 2003). Also, Ye et al., (2011) interpreted the close relationship between political factors and business model in two scenarios. First, enterprise business models need always to be changed to adapt to the particular political resources; second, when a company is not satisfied with the political funds provided by the local government, they can ask the government to provide better political resources. Coincidentally, Provance et al., (2011) pointed out that national agencies use regulations and policies to affect technical and managerial selections, the distribution or acquisition of resources and the cooperation between companies and public institutions.

\subsubsection{Economic Dimension}

According to Giesen et al., (2010) in an increasingly sophisticated and rapidly changing business environment, enterprises must rethink and review their business models more frequently than ever before to continuously adjust and improve their standards. Business model innovation offers significant opportunities both in a period of rapid economic development and in the turbulent period.

In the periods of rapid economic growth, enterprises usually cooperate to increase revenues and save cost (Håkansson\&Johanson, 1992).

It also leads to lower market entry barriers and indirectly decreases the investing risk factor for new entrants in the new business model, which cause a more intense competition (Chung et al., 2004). Another example is economic globalization. It provides access to the right skills with the appropriate cost at the right time and supports the successful delivery of business model innovation.

Conversely, once entering the time of extensive industry change or economic downturn, enterprises actively search for new ways to gain advantages in cost and flexibility, for example, the employment of a new partnership model or a new service model. During the recession, enterprises can more effectively reduce the business while creating new opportunities for more rapid expansion. Also, revenue model innovation, including new customer preference and consumption patterns, will significantly promote the changes to the pricing model and value proposition. 


\subsubsection{Social Dimension}

Hastings and Saren (2003) indicated the negotiability of commercial marketing thinking to social problems. Social factors stimulate enterprises through value propositions so that firms are willing to make every effort to change their behaviour (Dann, 2008) to generate ideal social changes. However, if the interests of society required by the value proposition are much higher than the benefit of the enterprise itself, the company may be less willing to sacrifice its interests and refuse to change.

\subsubsection{Technological Dimension of Innovation}

The initial stages of technological innovation, technical factors are critical to the success of business activities. Particularly in the information age, many businesses derived from the appearance of technological change. Therefore, in this era, looking for a business model which can successfully commercialize operation technique is of necessity. Meanwhile, technological innovation network will also provide a practical resource for business model innovation.

However, Giesen et al. (2010: p.22) pinpointed that 'while technology innovation often enables or even creates new business models, flexibility in the underlying infrastructure is critical to allowing an organization to shift and adapt its business model through a delivered platform for rapid growth and scaling'.

\section{Research Methodology}

This study used a survey approach in the form of questionnaire administration. The survey approach was used to sample Small and Medium Enterprises, the Kumasi metropolis. Also, both structured questionnaire and interview schedules were used as tools to collect data from the SME Operators and staffs.

The questionnaire included the role of Creativity and Innovation, motivations for innovation and creativity, effects of frugal innovation capacities, benefits of practising frugal innovations and some challenges mitigating adaptation of Frugal Innovation by SMEs in Ghana. By providing in-depth analysis or description of the selected Small and Medium Enterprises, a qualitative technique was applied. Hanson and Grimmer (2007) stressed that most qualitative research is carried out to gain and describe complexity. Qualitative method again provided a concentration on understanding and interpretation of the subject selected (Carson et al., 2001). However, a quantitative technique was further developed to measure the extent to which the creativity and innovation with frugal innovative capabilities implementation affect SMEs performance.

All the categories of Small and Medium Enterprises were involved in the research and included the Food processing industry, Bakery industry, Timber/Wood/Furniture works industry, Metalworks industry, Machinery works industry, Financial Services Rubber and plastic and others.

This study adopted cluster sampling (also known as one-stage cluster sampling) is a technique in which clusters of participants that represent the population are identified and included in the sample. Cluster sampling involves identification of a bunch of participants representing the population and their inclusion in the sample group. All the categories of SMEs which include Garment, Leather and Textiles, Wood Processing, Metals and Building and Construction, Food and Beverages, Toiletries and Cosmetics and Rubber and Plastic were clustered separately.

This study sampled 250 respondents to represent the target population of all the Small and Medium Enterprises in the Kumasi metropolis. Data from primary sources included questionnaires and interviews on the analysis of creativity and innovation with frugal innovative capabilities in Small and Medium Enterprises (SMEs) in Ghana.

A total of 248 selected SMEs respondents were surveyed through a questionnaire to analyze the role of creativity and innovation with frugal innovative capabilities in small and medium enterprises (SMEs). Also, 20 Small and Medium Enterprise Operators and some senior staffs were interviewed to supplement the 248 respondents on the role of creativity and innovation with frugal innovative capabilities in small and medium enterprises (SMEs). In all 268-sample size was used in this study to analyze the role of creativity and innovation with frugal innovative capabilities in small and medium enterprises (SMEs) in the Kumasi metropolis of Ghana.

\section{Data and Information Description}

The survey sought to collect information on creativity and innovation with frugal innovative capabilities on small and medium enterprises (SMEs) in Ghana.

The study data was collected from Small and Medium Enterprises within the Kumasi Metropolis in the Ashanti Region of Ghana. The study covered all the Small and Medium Enterprise operators, management and their staffs. All the categories of enterprises were given equal opportunity to represent their industry through 268 questionnaires and interview administration.

Data for the study were collected from SMEs in a wide range of industries including the brewery, marketing, manufacturing, wood and furniture and food and beverages. Also included were metal and welding, clothing and textiles book as well as some service industries.

Apart from the interview guide for the management of SMEs responded, data for the study was gathered with a Likertscale questionnaire and was then subjected to a reliability test to assess their internal consistency. 


\subsection{Data Analysis of Questionnaire}

\begin{tabular}{|c|c|c|c|}
\hline Variables & $\begin{array}{c}\text { Number of } \\
\text { Variables }\end{array}$ & $\begin{array}{c}\text { Valid } \\
\text { Cases }\end{array}$ & $\begin{array}{c}\text { Cronbach's } \\
\text { Alpha }\end{array}$ \\
\hline Role of Creativity and Innovation & 248 & 7 & .890 \\
\hline The motivation for Creativity and Innovation & 248 & 6 & .951 \\
\hline Six principles of Frugal Innovation & 248 & 6 & .970 \\
\hline Frugal innovative and capability concept & 248 & 7 & .906 \\
\hline Dimensions of Frugal & 248 & 4 & .962 \\
\hline Benefits of practising frugal Innovation & 248 & 5 & .951 \\
\hline Challenges in adopting frugal Innovation & 248 & 7 & .944 \\
\hline
\end{tabular}

Table 2: Reliability Statistics

Source: Field Data, 2019

Cronbach's Alpha coefficient of between 0.6 and 1.0 is good enough to suggest the reliability of research instruments, but the higher the value, the better. Therefore, the Cronbach's Alpha correlation coefficient 0.890, 0.951, $0.970, .906, .962$ and 0.944 were appropriate for this study. With the high level of reliability of the research questionnaire used in this research work, the results herein obtained could be generalized from the sample to the population.

- $\quad$ Objective 1: The Role of Creativity and Innovation towards the performance of SMEs

Drawing from the knowledge and experiences of respondents in SME Businesses, the study sought to find out the role of creativity and innovation towards SMEs performance. Descriptive statistics in mean values were generated from participants' respondents on a 4-point Likert scale ranging from highly positive to highly negative and presented in Table 3

\begin{tabular}{|c|c|c|c|c|}
\hline & N & Minimum & Maximum & Mean \\
\hline Roles of Creativity and Innovation & Statistic & Statistic & Statistic & Statistic \\
\hline High productivity level & 248 & 2 & 4 & 3.12 \\
\hline Greater profit & 248 & 1 & 4 & 1.73 \\
\hline Competitive edge & 248 & 1 & 4 & 3.32 \\
\hline Business growth & 248 & 1 & 4 & 3.33 \\
\hline Building credible perception & 248 & 1 & 4 & 2.25 \\
\hline Customer satisfaction loyalty & 248 & 1 & 4 & 3.30 \\
\hline Increase market share & 248 & 1 & 4 & 3.36 \\
\hline Valid N (listwise) & 248 & & & 2.92 \\
\hline
\end{tabular}

Table 3: Descriptive Statistics on the Role of Creativity and Innovations towards SMEs Performance Source: Survey Data, 2019

Respondents admitted almost all the measuring items as being positively impacted on or enhanced by creativity and innovation, which invariably improve the performance of Small and Medium Enterprises (SMEs). In this wise, respondents in the current study concord with Romano's (1999) position that practical, innovative strategies are capable of enhancing organizational competitiveness and business growth. Similarly, the affirmative response supports the role of creativity and innovation in creating a competitive edge (3.32) and customer satisfaction (3.30).

However, respondents in the current study have divergent views for creativity and innovation, bringing higher profitability and building credible perception as they pertain in their organizations. Given respective mean values of 1.73 and 2.25, some respondents in the current study decline the assertion that creativity and innovation bring higher profits, neither does it build credible perceptions about the organizations.

It is also noted among the study factors that are increasing market share has also pointed out as the factor creativity and innovation mostly impact on, given the highest mean value of 3.36, signifying nearly four-fifths (80\%) affirmative response. Notwithstanding, a rather low mean value for creativity and innovation on SMEs profitability, the average response of 2.92 indicates that creativity and innovation more often than not play a positive role on the performance of SMEs in the areas of productivity, competitiveness, growth, customer satisfaction and as well increasing market share.

- $\quad$ Objective 2: Motivations for Creativity and Innovations

Touching on what motivates SMEs into embarking on creativity and innovative strategies, respondents were interrogated on meeting customer demands, increasing revenue, promoting business growth, cost reduction, enhancing the quality of offerings and improving marketing/selling of business offerings. Mean responses from the study participants on a 5-point scale ranging from strongly agree (5) to strongly disagree (1) have been presented in Table 4. 


\begin{tabular}{|c|c|c|c|c|}
\hline & N & Minimum & Maximum & Mean \\
\hline Motivations for Creativity and Innovations & Statistic & Statistic & Statistic & Statistic \\
\hline Meeting customer demand on time & 248 & 1 & 5 & 4.10 \\
\hline Increasing revenue & 248 & 1 & 5 & 2.11 \\
\hline Promoting business growth & 248 & 3 & 5 & 4.42 \\
\hline Reducing operational cost & 248 & 2 & 5 & 4.09 \\
\hline Enhanced quality and productivity & 248 & 1 & 5 & 3.94 \\
\hline Aid marketing and selling goods and services & 248 & 1 & 5 & 1.98 \\
\hline Valid N (listwise) & 248 & & & \\
AVERAGE & 248 & & & 3.44 \\
\hline
\end{tabular}

Table 4: Statistics on Motivations for Creativity and Innovation by SMEs

Source: Survey Data, 2019

Results in Table 4 suggest that SMEs in this study support creativity and innovative strategies with the rationale of meeting customer demands, promoting growth, reducing operational cost and enhancing quality and productivity. These were supported by high mean values of 4.10, 4.42, 4.09 and 3.94, respectively. The Small and Medium Enterprise (SMEs) here are mostly involved in creativity and innovation with the motive of promoting business growth, as this motivation has the highest support from a majority of the study respondents, given the highest mean value of 4.42.

It is again clear from Table 3 that these SMEs under study do not think primarily for increasing revenues or necessarily to aid the marketing of their offerings through creativity and innovation. These two study items have minimal mean values of 2.11 and 1.98, respectively. However, most of these SMEs adopt creativity and innovations with the motive of increasing revenue. Perhaps, SMEs in the current study support assertion that, once a firm improves innovativeness and creativity to meet customer demands and improves the quality of offerings revenue will increase through customer patronage resulting in high sales levels.

\begin{tabular}{|c|c|c|c|c|}
\hline Frugal Innovative and Capability Concept & $\mathbf{N}$ & Minimum & Maximum & Mean \\
\hline Frugal is the same as innovations & 248 & 1.00 & 4.00 & 3.1008 \\
\hline $\begin{array}{c}\text { Frugal is careful and cautious use of organizational resources } \\
\text { to minimize waste and ensure optimization }\end{array}$ & 248 & 1.00 & 3.00 & 2.2702 \\
\hline $\begin{array}{l}\text { Frugal innovation is a constraint-based response to the } \\
\text { unmet needs of Bottom of Pyramid consumers }\end{array}$ & 248 & 1.00 & 4.00 & 2.0685 \\
\hline Frugal is about cheap goods and services & 248 & 1.00 & 4.00 & 2.3831 \\
\hline $\begin{array}{l}\text { Frugal innovative capabilities lead to a firm's ability to } \\
\text { perform and compete well }\end{array}$ & 248 & 1.00 & 4.00 & 1.8548 \\
\hline $\begin{array}{c}\text { Firms without frugal innovative capabilities risk an } \\
\text { opportunity to adopt frugalism concept }\end{array}$ & 248 & 1.00 & 4.00 & 1.8508 \\
\hline $\begin{array}{l}\text { Frugal innovative capabilities involve firm's finance, } \\
\text { processes and employee management }\end{array}$ & 248 & 1.00 & 4.00 & 1.9637 \\
\hline Valid N (listwise) & 248 & & & \\
\hline
\end{tabular}

Table 5: Descriptive Statistics of Frugal Capability Concept of SMEs

Source: Survey Data, 2019

In a quest to find out the respondents understanding of frugal innovation and capability concept, as demonstrated in Table 5. Respondents disagree with the assertion that frugal is the same as innovation. The SMEs in Kumasi respondents indicated with a high mean value of 3.10 , implying that frugal is different from innovation with various definitions and explanations from the respondents.

About $70 \%$ greater proportion of SMEs respondents agreed that Frugal is careful and cautious use of organizational resources to minimize waste and ensure optimization of firms. It, therefore, implies that frugal innovation is the ability of firms to use scarce resources to provide goods and service without compromising the quality expected from the consumers and was represented by about 2.3 mean value. It cannot be achieved without a proper strategy and well-structured production process.

Similarly, little over $72 \%$ of SMEs respondents believed that frugal innovation is a constraint-based response to the unmet needs of the Bottom of Pyramid consumers. Firms are, therefore, expected to segment consumers that are not served by the more significant or Multi-National Companies with 2.10 mean value.

Little about $50 \%$ of SMEs respondents are of the view that Frugal concept is all about cheap goods and services with 2.4 mean value. Though the SMEs accept the fact that frugal is about competitive products and services, the margin between those who believe frugal is cheap is not strong enough to link frugal with cheap goods and services. It means that the SMEs respondents in Kumasi metropolis have divergent views of the purpose of Frugal innovation concept.

Again, 81\% of SMEs respondents agree to the assertion that Frugal innovative capabilities lead to a firm's ability to perform and compete well in the market. It was represented by 1.9 mean value indicating the need for SMEs to identify and develop its capabilities to posses' competitive advantage over competitors. It was further realized that finance, production processes are employee management among the capabilities that firms can manage to compete well towards SMEs performance and was represented by 1.9 mean value. It implies that SMEs funding is essential for frugal innovations. 
Also, the SMEs production structure, including the manufacturing layout and the processes should be as efficient as possible to reduce waste in the system and maximize productivity. Finally, employees play a vital role in frugal innovation concept and therefore, should employ and train staff to meet all the challenges facing the implementation of the firm's frugal policies. The application of all the frugal capabilities depends on the management of SMEs, and it serves as a strategic tool to compete against competitors.

\begin{tabular}{|c|c|c|c|c|}
\hline Dimensions of Frugal & N & Minimum & Maximum & Mean \\
\hline Affordability & 248 & 1.00 & 4.00 & 2.2782 \\
\hline Acceptability & 248 & 1.00 & 4.00 & 1.8589 \\
\hline Core functionality & 248 & 1.00 & 4.00 & 1.7944 \\
\hline Sustainability & 248 & 1.00 & 4.00 & 1.8508 \\
\hline Valid N (listwise) & 248 & & & \\
\hline
\end{tabular}

Table 6: Descriptive Statistics of Frugal Dimensions

Source: Survey Data, 2019

The frugal concept is built upon some dimensions, and some of them has been tested on SMEs respondents in the Kumasi metropolis and the results demonstrated on table 4.5. Over 70\% of Small and Medium Enterprises respondents at Kumasi metropolis supports the idea that frugal products should be affordable since the Bottom of Pyramid (BoP) consumers are not rich but deserve their share of national wealth. It represented by 2.3 mean value and showed that any firm practising frugal concept should be able to offer affordable goods and services to consumers without compromising the quality. It implies that SMEs can achieve frugal with the simplification of enterprises processes and thereby eliminating unnecessary waste in the operational process.

Furthermore, they should stick to a planned budget and prioritizing their business activities and others to be able to achieve their expected frugal objective

Also, the majority of SMEs respondents agree that the performance level of frugal products has to fit optimally to the intended purpose and the specific requirements. Therefore, 1.9 mean value of respondents indicates that consumers of frugal products should accept what the firms have to offer them. It implies that frugal firms should collaborate with their consumers for the two parties to reach a collective agreement in terms of the demand and supply of products. By collaborating with others will aid in achieving quality with less by hiring the services of others to do what the firm cannot offer. While hiring others, the remaining jobs can be handled by internal staff to meet deadline supplies on time.

Furthermore, a vast majority of $91 \%$ of SMEs respondents affirmed the assertion that frugal innovation firms should be able to offer a solution according to the consumer's request. It was represented by 1.8 mean value-seeking innovative ways of altering traditional value Creation and maximizing product value through simplification from frugal innovation firms. By offering a solution for consumers problems, frugal firms but practice the bottom to a top approach where firms should start their production process by acknowledging consumers concerns right from the beginning till goods and services are delivered to them successfully.

Finally, 85\% of SMEs within the Kumasi metropolis expects frugal products and services through simplicity and sustainable. In this case, the 1.9 mean value of the respondents expect frugal firms to be societally responsibly by observing all the environmental rules to protect the health of the stakeholders of the firms. It implies that frugal firms should adopt practices that will keep them in business to offer frugal goods to underserved consumers. By meeting frugal consumers request, they will see the firm to be a partner and become loyal to the firms. Societal concerns should also be considered when producing frugal products because some societies patronize products that are societal friendly.

- $\quad$ Objective 3: Effects of Frugal Innovative Capabilities on SMEs

Mean responses were also gathered to assess the impacts of frugal innovative capabilities on SMEs and presented the results in Table 7

\begin{tabular}{|c|c|c|c|c|}
\hline & $\mathbf{N}$ & Minimum & Maximum & Mean \\
\hline Effects & Statistic & Statistic & Statistic & Statistic \\
\hline Ability to reframe adversity for organizational survival & 248 & 3 & 5 & 4.31 \\
\hline Using scares resources for quality offerings & 248 & 3 & 5 & 1.98 \\
\hline Flexibility and quick thinking & 248 & 2 & 5 & 3.27 \\
\hline Develop good enough solutions to job done & 248 & 1 & 5 & 3.48 \\
\hline Conjuring radically affordable solutions & 248 & 1 & 5 & 2.14 \\
\hline Using customer knowledge to meet demand & 248 & 3 & 5 & 2.35 \\
\hline $\begin{array}{c}\text { Valid N (listwise) } \\
\text { AVERAGE }\end{array}$ & 248 & & & 2.92 \\
\hline
\end{tabular}

Table 7: Descriptive Statistics on the Effects of Frugal Innovative Capabilities Source: Survey Data, 2019

An assessment of the effects of frugal innovative capabilities on SMEs has shown that adversity, as a source of innovation is vital for organisational survival and growth recorded a mean value of 4.31 as shown in Table 4.6. Impliedly, these SMEs can thrive in challenging and unpleasant business situations by the adoption of frugal innovation. Also, it is 
evident here, an observation that most of the SMEs in the study area prove to be flexible and quick thinkers to respond to unexpected changes in their business environment (3.27). SMEs are expected to develop a 'good enough' solution to get things done, and the SMEs have adequately adopted this under study. It is supported with a minimum mean value of 3.48, perhaps suggesting that SME innovators do not seek sophistication by over-engineering business offering. It is, therefore, innovative practice in the real sense of frugal innovativeness.

On the reverse side, however, the mean value of 1.98 on a 5-point Likert scale questionnaire indicates that SMEs adopt frugal innovativeness do not have adequate capabilities to use scarce resources to produce quality offerings to satisfy customers. SMEs are therefore expected to be creative and innovative to harness limited resources and still serving customer interest, and thus suggest massive support for frugal innovativeness.

Also showing some level of incapability is SMEs ability to conjuring radically affordable solutions, confirmed with a minimum mean value of 2.14. It is again suggested in Table 4.4 that SME innovators do not use customer knowledge to meet demand.A minimal mean value of 2.35 confirms it.

It is also evident in Table 4, given a minimum mean value of 2.14, suggesting that SME innovators lack the innovative capabilities to conjure radically affordable solutions to meet the needs of underserved markets.

On average, however, SMEs in the current study prove to be in support of frugal innovative practices as data in Table 4.3 gives an average mean value of approximately 2.92. It depicts SMEs agreement of frugal innovative capabilities as they regard the six principles of frugal innovativeness in contemporary enterprises research for enhanced business performance.

For further scientific analysis, the following regression model is used to complete the effects of frugal innovative practices/capacities in Small and Medium Enterprises (SMEs) performance:

$\mathrm{Y}=\mathrm{SMEs}$ performance;

$\mathrm{Y}=\mathrm{B}_{0}+\mathrm{B}_{1} \mathrm{X}_{1}+\mathrm{B}_{2} \mathrm{X}_{2}+\mathrm{B}_{3} \mathrm{X}_{3}+\mathrm{B}_{4} \mathrm{X}_{4}+\mathrm{B}_{5} \mathrm{X}_{5}+\mathrm{B}_{6} \mathrm{X}_{6}+\mathrm{E}$ where:

$\mathrm{X}_{1}=\mathrm{A}$ unit change in performance as a result of a unit increase in the ability to reframe adversity for organizational survival;

$\mathrm{X}_{2}=\mathrm{A}$ unit change in performance as a result of a unit decrease in the use of scarce resources for the quality offering;

$\mathrm{X}_{3}=\mathrm{A}$ unit change in performance as a result of a unit increase in flexibility and quick-thinking capabilities;

$\mathrm{X}_{4}=\mathrm{A}$ unit change in performance as a result of a unit increase in developing good enough solutions to the job done;

$\mathrm{X}_{5}=\mathrm{A}$ unit change in performance as a result of a unit decrease in conjuring radically affordable solutions;

$\mathrm{X}_{6}=\mathrm{A}$ unit change in performance as a result of a unit decrease in the use of customer knowledge to meet demand;

$\mathrm{E}=$ Error terms (the difference between the calculated dependents variable and the actual value);

$\mathrm{B}_{0}=$ Constant, $\mathrm{B}_{1}, \mathrm{~B}_{2}, \mathrm{~B}_{3}, \mathrm{~B}_{4}, \mathrm{~B}_{5}$, and $\mathrm{B}_{6}$ are regression co-efficient. Statistics on the regression analysis run are presented in Table 4.7, 4.8 and 4.9 .

- $\quad$ Objective 4: Benefits of Practicing Frugal Innovations

As part of the research objectives, the study sought to investigate how SMEs benefit from practising frugal innovations. This variable was investigated by meeting customer needs better, enhancing sales performance, attracting and maintaining customer loyalty and building a competitive edge as well as improving quality and satisfaction for consumers. Data gathered in these respects have been presented in Table 4.7 for frank discussions and analysis.

\begin{tabular}{|c|c|c|c|c|}
\hline & $\mathbf{N}$ & Minimum & Maximum & Mean \\
\hline Benefits & Statistic & Statistic & Statistic & Statistic \\
\hline Meeting customer needs better & 248 & 1 & 5 & 1.43 \\
\hline Enhances sales performance & 248 & 1 & 5 & 1.35 \\
\hline Attracting and maintaining a loyal customer & 248 & 3 & 5 & 4.08 \\
\hline Brings a competitive edge & 248 & 3 & 5 & 4.51 \\
\hline Brings quality and satisfaction & 248 & 3 & 5 & 4.22 \\
\hline Valid N (listwise) & 248 & & & \\
\hline
\end{tabular}

Table 8: Benefits of Frugal Innovativeness

Source: Survey Data, 2019

Observed from the data in Table 8, the most significant benefits SMEs get from frugal innovations is a competitive edge. The mean value of 4.51 suggests a good yield from SMEs motivation for promoting business growth through innovation and creativity, established earlier in this analysis. Again, it confirms that frugal innovation is vital for organisational survival.

Other benefits confirmed by most respondents are the enhanced quality of offerings with a mean value of 4.22 and maintenance of customer loyalty also with a mean value of 4.08. The results here might be as a result of SMEs' ability to use scarce resources to their advantage. Earlier in this analysis, SMEs have been noted as adopting innovation and creativity with the motive of enhancing quality and productivity. Therefore, confirmed benefits as regards quality of offering from frugal innovative practices are an achievement of a set motivation.

However, most SMEs fail to benefit significantly from meeting customer needs better than before the adoption of frugal innovation. The mean value 1.43 is minimal on a 5-point Likert scale and seems to confirm SMEs inability to have 'good enough' solutions to the job done as established earlier in this analysis. Nonetheless, advocates of frugal innovative practices suggest the use of customer to aid SMEs to meet customer demands.

Also, not adequately supported by most respondents is the benefit of enhanced sales performance. It is also clear from Table 8 that a few of the SMEs benefit improved sales performance from their frugal innovative practices, given mean 
value of 1.35. It might be the right reflection because a few of these SMEs adopt innovation and creativity with the motive of aiding marketing and sale of goods and services, as established earlier in this analysis. The result here is somewhat contradictory to respondents' position that innovation and creativity play a significant role in increasing market share with high sales volume.

- $\quad$ Objective 5: Some challenges Mitigating the adoption of Frugal Innovation

Respondents opinion were gathered to asses some factors perceived to be mitigating against the smooth passage of frugal innovation, for which data gathered was presented in Table 5.8.

\begin{tabular}{|c|c|c|c|c|}
\hline & $\mathbf{N}$ & Minimum & Maximum & Mean \\
\hline Some Mitigating Factors & Statistic & Statistic & Statistic & Statistic \\
\hline Lack of talents and skilled labour & 248 & 3 & 5 & 4.47 \\
\hline $\begin{array}{c}\text { Low cost with quality in price-sensitive } \\
\text { Environment }\end{array}$ & 248 & 1 & 5 & 1.23 \\
\hline Difficulty collaborating with external partners & 248 & 1 & 5 & 4.07 \\
\hline Outmoded tech and low capacity weaken Capability & 248 & 1 & 5 & 2.32 \\
\hline Cannot do more with fewer resources & 248 & 1 & 5 & 4.12 \\
\hline $\begin{array}{l}\text { Rely on the customer to determine business } \\
\text { operations are difficult }\end{array}$ & 248 & 2 & 5 & 1.92 \\
\hline Valid N (listwise) & 248 & & & \\
\hline
\end{tabular}

Table 9: Some Mitigating Factors against Frugal Innovation

Source: Survey Data, 2019

A lack of talented and skilful labour has been recorded as the severe factor that hinders the smooth adoption of frugal innovation. It was affirmed with a high mean value of 4.47, suggesting that majority of the respondents regard it as a challenge. The findings in research have shown that many SMEs lack talented employees to initiate and implement frugal innovative practices.

Also seen as a challenge, the SMEs under the study have the difficulty collaborating with other external partners. It was established given a high affirmative response reflecting a mean value of 4.07, indicating a majority of respondents agreeing to the existence of the challenge. The cause might perhaps be that the talented personnel are not readily available in the business environment or SMEs themselves do not have the will to partnering with external staff. Data on Table 4.8 has confirmed SMEs challenge to do more with less as expected with the practices of frugal innovations. The high mean value of 4.12 suggests that most SMEs respondents agree with such a challenge. However, serving quality offerings at a low cost of production was not seen as a severe challenge for SMEs. To buttress this, only a few respondents agree to this factor as a challenge, reflecting in a low mean response of 1.23. A lot of SMEs complain of high operational cost to adopt innovations and creativity.

Also, not supported by many respondents was reliance on customers to determine business operations. A few of the SMEs respondents, reflecting a minimum mean value of 1.92 instead hold the opinion that relying on customers to assess business operations is a challenge for frugal innovativeness and thus affects organisational performance.

In brief, SMEs inability to do more with fewer resources, lack of external collaborations and lack of expertise are key factors militating against the practices of frugal innovations. As a confirmation, most respondents reported on the use of sophisticated types of equipment and technologies in their operations. That notwithstanding, respondents confirmed the benefits of creativity and innovations capable of increasing productivity, improving the quality of offerings but increasing the cost of production.

\begin{tabular}{|c|c|c|c|c|}
\hline Model & R & R Square & Adjusted R Square & Std. Error of the Estimate \\
\hline 1 & $.937 \mathrm{a}$ & .878 & .875 & .167 \\
\hline
\end{tabular}

Table 10: Model Summary of Regress
a. Predictors: (Constant)
Source: Survey Data, 2019

Using customer knowledge to meet demand, develop good enough solutions to the job done, using scares resources for quality offering, flexibility and quick thinking, conjuring radically affordable solutions, ability to reframe adversity for organizational survival.

Evident from Table 10, the R-value suggests how the observed and predicted values of dependent variable (SMEs performance) are influenced or affected by the independent variables (frugal innovative practices-use of customer knowledge, developing right enough solutions to job done, using scarce resources for quality offerings, flexibility and quick thinking, conjuring radically affordable solutions, and reframing adversity for organisational growth).

In Table 10, the R-value of 0.93 implies a 93.7\% relationship between dependent and independent variables and explains that frugal innovative capabilities affect $93.7 \%$ of SMEs performance. However, it does not reflect the extent to which any particular variable correlates with or influences SMEs performance. Assessing the significance of the established relationship ANOVA statistics were run, as shown in Table 11. 


\begin{tabular}{|c|c|c|c|c|c|c|}
\hline \multicolumn{2}{|c|}{ Model } & Sum of Squares & Df & Mean Square & F & Sig. \\
\hline \multirow{3}{*}{1} & Regression & 48.508 & 6 & 8.085 & 290.192 & $.000^{\mathrm{a}}$ \\
\cline { 2 - 7 } & Residual & 6.714 & 241 & .028 & & \\
\cline { 2 - 7 } & Total & 55.222 & 247 & & & \\
\hline
\end{tabular}

Table 11: Analysis of Regression (ANOVA ${ }^{\text {b) }}$

Dependent Variable: SME Performance

Source: Survey Data, 2019

The ANOVA statistics of Table 11 was then used to present the significance of the regression analysis. An Fsignificant value of $\mathrm{p}=0.000$ has been established to show that there is a probability of $0.0 \%$ of the regression model presenting false information. Thus, the model is very significant. The statistics on the regression Table 12 also shows the individual regression co-efficients of the independent variable (Frugal Innovative Capabilities) to determine which of them has more effect on SMEs performance.

\begin{tabular}{|c|c|c|c|c|c|c|}
\hline \multirow{2}{*}{\multicolumn{2}{|c|}{ Model }} & \multicolumn{2}{|c|}{$\begin{array}{l}\text { Unstandardized } \\
\text { Coefficients }\end{array}$} & \multirow{2}{*}{$\begin{array}{c}\begin{array}{c}\text { Standardized } \\
\text { Coefficients }\end{array} \\
\text { Beta } \\
\end{array}$} & \multirow[t]{2}{*}{$\mathbf{T}$} & \multirow[t]{2}{*}{ Sig. } \\
\hline & & B & Std. Error & & & \\
\hline \multirow[t]{7}{*}{1} & (Constant) & 3.612 & .092 & & 39.119 & .000 \\
\hline & $\begin{array}{l}\text { Ability to reframe adversity for } \\
\text { organizational survival }\end{array}$ & -.110 & .064 & -.155 & -1.701 & .090 \\
\hline & $\begin{array}{c}\text { Using scares resources for quality } \\
\text { offering }\end{array}$ & -.515 & .027 & -.906 & -18.834 & .000 \\
\hline & Flexibility and quick thinking & .176 & .049 & .270 & 3.566 & .000 \\
\hline & $\begin{array}{l}\text { Develop good enough solutions to } \\
\text { job done }\end{array}$ & .370 & .032 & .526 & 11.542 & .000 \\
\hline & $\begin{array}{c}\text { Conjuring radically affordable } \\
\text { solutions }\end{array}$ & -.244 & .050 & -.349 & -4.874 & .000 \\
\hline & $\begin{array}{l}\text { Using customer knowledge to meet } \\
\text { demand }\end{array}$ & -.184 & .047 & -.227 & -3.877 & .000 \\
\hline
\end{tabular}

Table 12: Regression Co-efficients ${ }^{a}$

Source : Survey Data, 2019

It can then be obtained from Table 10 the regression model: $\mathrm{Y}=3.612-0.110 \mathrm{X} 1-0.515 \mathrm{X} 2+0.176 \mathrm{X} 3+0.370 \mathrm{X} 4-$ $0.244 X 5-0.184 X 6$; with $\mathrm{P}=0.000$ and $\mathrm{B}_{1}=-0.110, \mathrm{~B}_{2}=-0.515, \mathrm{~B}_{3}=0.176, \mathrm{~B}_{4}=0.370, \mathrm{~B}_{5}=-0.244$, and $\mathrm{B} 6=-0.184$. The constant $B$ value of 3.612 suggests that if the independent variables remain constant at zero, SMEs performance would be minimal at approximately $4 \%$.

It has established that SMEs performance would rise by $17.6 \%$ with a unit increase in SMEs frugal innovative capability of flexible and quick thinking and 37.0\% unit increase in developing good enough solutions to the job done, all at 95\% confident level $(\mathrm{P}=0.00)$. However, SMEs ability to reframe adversity for organisational growth leads to a decrease in SMEs performance by a margin of $11 \%$. Using scarce resources for quality offering also decrease SMEs performance by $51.5 \%$.

Conjuring radically affordable solutions decrease the performance of SMEs by $24.4 \%$ and using customer knowledge also decrease SMEs performance by 18.4\%, given all other independent variables constant at $95 \%$ confident interval significant at $\mathrm{P}=0.00$. The indication here is that SMEs practice of developing good enough solutions to the job done is a significant factor that positively influences organisational performance $(0.370)$ followed by flexibility and quick thinking as a frugal innovative capability with 0.176 , holding other factors constant.

\subsection{Conclusions from Questionnaires Analysis}

The following conclusions were drawn from the questionnaire administration and analysis of the Small and Medium Enterprises respondents at the Kumasi metropolis in the Ashanti Region of Ghana regarding the role of creativity and innovation with frugal innovative capabilities of Small and Medium Enterprises (SMEs) in Ghana.

On the part of the role of Creativity and Innovation towards the performance of SMEs, it is concluded that all the study items which includes high levels of productivity, higher profitability, competitive edge, credible customer perceptions, customer satisfaction and loyalty as well as increase market share though SMEs declined the assertion that creativity and innovation bring higher profits neither does it build credible perceptions about the organizations.

Also, this study concluded that firms improve innovativeness and creativity to meet customer demands and improves the quality of SMEs offering's and increase revenue through customer patronage resulting in high sales levels. SME businesses in the Kumasi metropolis are in support of Frugal Innovative practices and agreement of frugal innovative capabilities as regards the six principles of frugal innovativeness advocated in contemporary enterprises research for enhanced business performance.

Another conclusion is that frugal concepts realization depends mostly on the capabilities of the firms. These capabilities include financial capabilities, process or operational capabilities, employee's capabilities and many others. The 
proper integration of all the businesses capabilities by the SME Operators and management helps them to achieve their fundamental objective of producing frugal products to compete effective and efficient against high-tech businesses.

Also, any frugal firms should focus on some frugal dimensions, and the majority of them are affordability, acceptability, core functionality and sustainability by the consumers. The various aspects serve as a bond or the link between the frugal firms and the BoP consumers.

\subsection{Analysis of Interview}

It was common knowledge that among respondents describing creativity and innovations as procedures and processes of improving productivity and service delivery. Most respondents were quoted as stating that:

'Creativity and innovations improve efficiency and customer satisfaction. Creativity and innovation also border on new ways of solving an existing problem in organizations by way of enhancing the quality of offerings, value creation, improving sales and distribution and as well creating the uniqueness of firm's offerings'.

SMEs that affirmed the relevance of creativity and innovations and actual adoption of their organizational operations admitted the positive impact they have gained. Some respondents were quoted as stating that:

'Creativity and innovation save time, reduces the cost of operations, and customer satisfaction and pride. Again, creativity allows for change of operations to reflect changes in the business environment'.

Commenting on the cost-effectiveness of innovations adopted among the firms, management of most of the SMEs cited a reduction in operational cost leading to the low cost of offerings. It was further disclosed that creativity and innovative policies are often applied to the production, marketing/sales and information technology sections of the SMEs. However, respondents reported that:

'Innovative gadgets are expensive. It is therefore suggested that firms make efficient use of resources to minimise waste, using simple tools and equipment's and sourcing relevant expertise'.

It then reflects respondents support for frugal innovations and creative principles of developing 'good enough' solutions to problems and using scarce resources for quality offerings.

Not much was obtained from the management of SMEs regarding creativity and innovations in times of adversity. Some of the SMEs adopted cost reduction strategies that made use of locally available materials instead of being mechanistic. In a shoe manufacturing enterprise, management respondent stated:

'We used to take our shoes to a machine for grinding the soles, but during the periods of the energy crisis we then resorted to the use of sandpaper until now to serve the same purpose at a cheaper cost than before'.

Once again, this strategy being discussed is synonymous with frugal innovative capabilities to reframe adversity for organizational survival and growth. In consonance with the frugal innovative principle of developing 'good enough' solutions to get the job done, some respondents explained that:

'Our company resorted to the use of solar energy to augment the operational difficulties during the adversity of general hydroelectrical power crisis. This innovative strategy has since been very cost-effective to secure the competitive advantage of low pricing amid quality offerings'.

In general, SMEs that have adopted some form of creativity and innovative policies in their business operations attested to some level of positive impact in work efficiency, in the area of cost-effectiveness, customer satisfaction and improvement in revenue generation.

Many responses were gathered concerning how SME Operators and management understanding of frugal. The most occurring definition among the lot was that

'Frugal Innovation is the ability of firms to produce goods and services at an affordable rate and still receive the expected profits from their business operations.'

When SME Operators were asked whether there is a difference between frugal and standard innovation, respondents revealed a divergent view, and the higher proportion indicated that there is a difference between the two. According to the interviewees

'Standard innovation is the process of translating an idea or invention into a good or service that creates value or for which customers will pay although Frugal innovation or frugal is the process of reducing the complexity and cost of a goods and its production'.

As to whether the SMEs in the Kumasi metropolis practices frugal, the majority of the interviewees were quoted as saying

'they do practice Frugal Innovations when the opportunity presents itself for simplification and cost-cutting. The SMEs in the Kumasi metropolis does not have a formal policy of Frugal Innovations but utilizes the left-over market by Multinational Companies and uses their scarce resources to produce to supplement the goods and services of the Multinational or large firms. They believed to practice frugal because they do not possess any complex technology as well as having any R\&D to support their enterprises'.

The interviewees of SMEs in the Kumasi metropolis revealed that

'frugal innovation practices yield them their profit and survival. Meaning, out of their FI practices is their profit-making and business growth. They hinted that they often have the challenge with their business processes and sometimes result in hiring facilities from others for a short period at a fee. Again, they said they face a challenge with recruiting and maintaining competent staff because of their low salary scale. They summed it all that they face many challenges in their day to day operations since their objective is to cut down the cost to compete with foreign with higher quality'.

They further advise that, 
'government should build entrepreneurial infrastructures to support small and medium enterprises to enable them to have the needed facilities such as the internet to support their businesses. Again, they said SMEs need collaborators to do business with when their expertise falls short in terms of technical knowledge and human resource capacity building'.

Moreover, finally, financial assistance from financial institutions to support their frugal innovative ideas. All the above capabilities are the needed requirements to assist SMEs to achieve their objective of producing frugal goods and services to serve the underserved customer by multinational or larger firms in Ghana.

\subsection{Conclusions from Interview Analysis}

The following conclusions were drawn from the interview administration;

- The SMEs indicated that creativity and innovation save time, reduces the cost of operations, and customer satisfaction.

- The study further revealed that high innovative gadgets are expensive and therefore suggested that firms should make efficient use of resources to minimise waste using simple tools and equipment's and source or leverage relevant expertise.

- $\quad$ Also, SME businesses in the Kumasi metropolis resorted to the use of solar energy to augment the operational difficulties during the adversity of general hydro-electrical power crisis. This innovative strategy has since been very cost-effective to secure the competitive advantage of low pricing in the midst of quality offerings.

- It is again concluded that frugal differs from innovation and the significant difference between the two is that frugal innovation focuses on how best to serve the underserved market by utilizing the scarce or constrained factors of production to offer goods and services at an affordable rate without compromising the quality of products to meet the BoP consumers. On the other hand, innovation is the process of translating an idea or invention into a good or service that creates value or for which customers will pay.

- $\quad$ Small and Medium Enterprises in the Kumasi metropolis practice frugal unconsciously. Therefore, they practice frugal as and when the need arises to compete with the MNCs by using their scarce resources at their disposal. They lack the high-tech gadgets and a resourced R\&D though they compete with large companies that possess all the high technologies at their disposal.

- $\quad$ Frugal practices result in business profit and growth through some challenges are associated with frugal practices. Some of the challenges are recruiting and maintaining competent staff because of their low salary scale, acquiring financial support to embark on frugal projects and lack of entrepreneurial infrastructures. These infrastructures aid enterprises to develop their capabilities to meet the challenges frugal firms encounter in their quest to compete with larger firms who have the most significant muscles to compete with domestic firms with low technology.

- $\quad$ Entrepreneurial capabilities play a vital role in determining the success of every frugal firm and require proper integration of all the capabilities of the firm, which include finance, operations and employee's management and external collaborations.

\section{Findings and Discoveries}

Based on the analysis made on questionnaire and interviews administration through a sequential manner, the following findings and discoveries made were;

- It was realized that frugal is different from standard innovation. It came out that 'standard innovation is the process of translating an idea or invention into a good or service that creates value or for which customers will pay whereas frugal innovation or frugal is the process of reducing the complexity and cost of goods and its production'.

- The SMEs in the Kumasi Metropolis admitted that almost all the measuring items have a positive impact on or enhance by creativity and innovation, which invariably improve the performance of Small and Medium Enterprises (SMEs). The SMEs believed that effective, innovative strategies are capable of enhancing organisational competitiveness and business growth.

- The SMEs supported the assertion that their motivation for practising creativity and innovation geared towards meeting customer demands, promoting growth, reducing operational cost and enhancing quality and productivity.

- Frugal concepts realization depends mostly on the capabilities of the firms. These capabilities include financial capabilities, process or operational capabilities, employee's capabilities and many others.

- The most significant benefits SMEs expected from frugal innovations is a competitive edge, although most SMEs fail to benefit significantly from meeting customer needs better than before the adoption of frugal innovation.

- Some of the challenges impeding frugal innovation practices at the Kumasi metropolis are lack of talents and skilled labour, the difficulty of SMEs in collaborating with other external partners, inability to do more with less and non-reliance on customers to determine business operations.

- Frugal practising firms should focus on some frugal dimensions, and the majority of them are affordability, acceptability, core functionality and sustainability by the consumers. The various dimensions serve as a bond or the link between the frugal firms and the BoP consumers. All the frugal concepts aid in firm's simplicity, prioritizing activities, planned budgetary and effective communication to achieve all the elements of frugal dimensions.FI is often disruptive because it takes a complicated and expensive product and creates an affordable version

- It was discovered that SMEs in the Kumasi metropolis practices frugal unconsciously. The SMEs in the Kumasi 
metropolis does not have a formal policy of frugal innovations but utilizes the left-over market by Multinational Companies and uses their scarce resources to produce to supplement the goods and services of the Multinational or large firms.

- It was again realized that SMEs do not have the needed funding to acquire the high-tech and the establishment of a renowned Research and Development department to manage the frugal concept

- It was indicated that the government should build entrepreneurial infrastructures to support small and medium enterprises to enable them to have the needed facilities such as the internet to support their businesses.

\section{Recommendations}

The following under listed recommendations are offered to assist policymakers in promoting creativity and innovation with frugal innovative capabilities on Small and Medium Enterprises (SMEs) in Ghana.

- $\quad$ SMEs should acknowledge high revenue generation as a motivating from creativity and innovation factor for their firm's growth. Investment returns depend on revenue and must be seen as a motivating factor by SMEs in the Kumasi Metropolis. Failure to generate high revenue creativity and innovation is a recipe for firms' inability to survive and improve due to other factors such as meeting customer demands, promoting growth, reducing operational cost and enhancing quality and productivity.

- Frugal innovation refers to 'low-cost, good-enough' products and services that are often initially designed and developed for emerging market customers. Frugal innovations are affordable, high value, and developed under resource scarcity with minimal amounts of raw materials to meet the needs of customers with low purchasing power. Achieving the objectives as indicated is highly dependent on firms' capabilities. Frugal innovation is the ability to redefine the meaning of 'value-for-money' by minimizing the use of resources such as capital, time, employees and processes. Therefore, frugal firms should manage all their capabilities in an optimized way to achieve their frugalist objectives. Frugal innovation turns limitations in resources, whether financial, material or institutional into an advantage by using them in new ways. It can be achieved by reducing the complexity of a product or its production process, or by removing non-essential features. Firms processes can be improved by creating and implementing new concepts such as frugal and methods in the production of goods and services.

- There is a need to become frugal because of resource-constrains facing developing countries. As a consequence, frugality could mean not just reducing the cost of the product, but also in how it is designed to operate in the resource-constrained context in which it functions, in order to use fewer resources and to counter complex or lacklustre institutions. Frugal innovation also presents an opportunity in developed economies for many reasons. Firms adopt FI in order to sell products and services at a low price. Consequently, people living in poverty can become consumers.

- Moreover, in the recessionary context of low growth, firms develop frugality in order to cut their R\&D expenditure and manufacturing costs. The insight of frugal indicates that firms from developed countries can learn about innovation from less developed economies. MNCs can also learn from new technologies (very often frugal), which meet poor consumers' needs and which are developed in emerging countries, in order to transfer ideas and knowledge to their technology centre in developed countries. Frugal firms contribute to designing improved products intended for the markets of developed countries.

- No firm operates in isolation and calls for collective ecosystem collaborations where partners offer some benefits required by each other. An ecosystem encompasses, for example, extended web of suppliers providing technology and complementary products, competitor companies, and customers. An ecosystem also includes actors such as financial institutions, social and technology institutions, and regulatory agencies that enforce and regulate the functioning of the ecosystem. Unlike in developed markets, firms in emerging economies do not have access to skilled capital through vibrant labour markets, risk capital through well-functioning capital markets, or knowledge resources through existing information markets. These challenges require collaborative agreement between frugal firms and the external partners to offer what frugal firms lack at an affordable rate.

- Frugal innovation can be realized by developing an incentive to rethink the company's innovation and growth strategy. For firms to stay focus on frugal concept, they need to have a conscious plan or policy to guide the operations of the business. Among some of the principles to follow are;

- The entrepreneurial structures needed for SMEs to become viable is a shared concern to both entrepreneurs and the government. The government expect growth of the economy through taxation, employment and value creation from the entrepreneurs. In returns, the government should also build and develop the entrepreneurial structures to support entrepreneurs to become resourceful enough to run their business at a success.

\section{References}

i. Aboulnasr, K., Narasimhan, O., Blair, E., \&Chandy, R., (2008). Competitive response to radical innovation. Journal of Marketing, 72: 94-110.

ii. Acolatse, S., (2012). 'Challenges and opportunities for SME development in Ghana'. Business Sense.

iii. Afuah A. (2002). Innovation Management: Strategies, Implementation, and Profits // New York: Oxford University Press, 2nd edition.

iv. Agarwal, N., \&Brem, A., (2012). Frugal and reverse innovation-literature overview and case study insights from a German MNC in India and China. Proceedings of the 18th International Conference on Engineering, Technology and Innovation. ISBN 978-1-4673-2273-7.

v. Ahmed, S. A., (2006). The roles of SMEs in developing economy. Abuja. Omotayo and Co. Ltd. 
vi. Akova, B., Ulusoy, G., Payzin, E., \& Kaylan, A.R., (1998). New product development capabilities of the Turkish electronics industry. Fifth International Product Development Management Conference, 863- 876, Como, Italy.

vii. Alter, N., (2002). Innovation: un processes collective ambigu. Les logiques de innovation. Paris: La Découverte Recherche's, 13-40.

viii. Aldrich, H. E., \& Amy K., (1999). 'The Accidental Entrepreneur: Campbellian Antinomies and Organizational Founding's.' Pp.19-33 in Joel A. C. Baum and Bill McKelvey (eds.), Variations in Organization Science: In Honor of Donald T. Campbell. Newbury Park, CA: Sage.

ix. Anderson, J.; Markides, C., (2007). 'Strategic Innovation at the Base of the Economic Pyramid'. Management Review, 49 (1): 83-93.

X. Andel, T. (2013). Frugal price: virtue or vice? Material Handling \& Logistics, 68(11), 4.

xi. Angot, J., \&Plé, L., (2015). Serving poor people in rich countries: the bottom-of-the-pyramid business model solution. Journal of Business Strategy, 36, 3-15.

xii. Andriopoulos, C., (2001). 'Determinants of organizational creativity: a literature review', Management Decision, Vol. 39, No. 10, pp. 834- 840.

xiii. Andriopoulos, C., \& Dawson, P., (2010). Managing Change and Innovation. London: SAGE Publications Ltd.

xiv. Amabile, T., Hadley, C., \& Kramer, S., (2002). Creativity under the gun. Harvard Business Review.

xv. Aryeetey, E. \& Boateng, W., (2007). Growth, Investment and Employment in Ghana. Working Paper No. 8. Policy Integration Department. ILO. Geneva.

xvi. Badie, K., (2002). Creative Idea Generation VIA Interpretative Approach to Analogical Reasoning Kyebernetes, 31(9), Emerald Pub. Company, UK

xvii. Baregheh, A., Rowley, J., \& Sambrook, S., (2009). Towards a multidisciplinary definition of innovation. Management Decision, 47(8), 1323-1339.

xviii. Barclay, C., (2014). Using frugal innovations to support cybercrime legislations in small developing states: introducing the cyber-legislation development and implementation process model (Cyber Leg-DPM). Information Technology for Development, 20(2), 165-195.

xix. Bessant, J., Lamming, R., Noke, H., \& Phillips, W., (2005). Managing innovation beyond the steady state. Technovation, 25(12), 1366-1376.

xx. Benner, M. J., \&Tushman, M., (2002). Process management and technological innovation: A longitudinal study of the photography and paint industries, Administrative Science Quarterly, Vol. 47, No. 4, pp. 676-706

xxi. Berman, S. L., Down, J., \& Hill, C., (2002). Tacit knowledge as a source of competitive advantage in the National Basketball Association. Academy of Management Journal. 45: 13-31.

xxii. Bhattacharya, M., \& Bloch, H., (2004). Determinants of innovation, Small Business Economics, Vol. 22, No. 2, pp. 155-162.

xxiii. Bhatti, Y. A, (2012). What is Frugal, what is Innovation? Towards a Theory of Frugal Innovation. Working Paper. Academy of Management, Boston, 3-7 Aug 2012.

xxiv. Birtchnell, T., (2011). Jugaad as systemic risk and disruptive innovation in India. Contemporary South Asia, 19 (4), pp.357-372.

xxv. Bound, K., \& Thornton, I., (2012). Our Frugal Future: Lessons from India's Innovation System. London: NESTA.

xxvi. Bower, J. L., \& Christensen, C. M., (1995). Disruptive Technologies: Catching the Wave. Harvard Business Review, January-February, pp. 43-53.

xxvii. Branzei, O., \&Vertinsky, I., (2006). Strategic pathways to product innovation capabilities in SMEs. Journal of Business Venturing, 21(1), 75-105.

xxviii. Brem, A., \& Wolfram, P., (2014). Research and Development from the bottom up - Introduction of Terminologies for New Product Development in Emerging Markets. Journal of Innovation and Entrepreneurship, 3, 1-22

xxix. Bridge, S., O'Neill, K., \&Cromie S., (2003). Understanding enterprise, entrepreneurship and small business. London: Palgrave Macmillan

xxx. Brown, T., (2008). Design Thinking. Harvard Business Review, (June), 84-92.

xxxi. Bullinger, A., (2008). Innovation and Ontologies: Structuring the Early Stages of Innovation Management, Wiesbaden, Germany: Gabler.

xxxii. Burley, R., (2012). Skills Every Entrepreneur Needs. Retrieved from http://www.inc.com/ron-burley/3-skillsevery-entrepreneur-needs.html

xxxiii. Buchanan, S., \& Gibb, F., (1998). The information audit: An integrated strategic approach. International journal of information management, 18(1), 29-47.

xxxiv. Carr, D. K., \& Johansson, H. J. (1995). Best Practices in Reengineering: What Works and What Doesn't in the Reengineering Process (p. 235). New York: McGraw-Hill.

xxxv. Carson, D.J., Gilmore, A., Perry, C., \&Gronhaug, K., (2001). Qualitative Marketing Research, Sage, London

xxxvi. Carrier C., (1999). Teaching creativity, innovation and entrepreneurship: On the necessity for new pedagogical paradigms. 44th ICSB World Conference Proceedings.

xxxvii. Chandra, M., \&Neelankavil, J. P., (2008). Product development and innovation for developing countries: Potential and challenges. Journal of Management Development, 27(10), pp.1017-1025.

xxxviii. Chawla, S. K., Hazeldine, MF. Jackson, R. E., \& Lawrence, R. J., (2007).' Small business critical success factors and the legal form of the firm, 'Journal of Business and Entrepreneurship, Vol. 19(2), pp.1

xxxix. Chen J., \& Chen Y. F., (2006). Total innovation management under open environment, Science Research Management, Vol.27, Issue 3, pp. 1-8 
xl. Chen, S., Wang, Y., \& Tseng, M., (2009). Mass Customization as a Collaborative Engineering Effort', International Journal of Collaborative Engineering, Vol. 1, 2, 152-167.

xli. Churchill, N. C., Lewis V. L., (1983). The five stages of small business growth. Harvard Business Review 1983, 61(3):30-50.

xlii. Christensen, J. F., Olesen, M. H., \&Kjaer, J. S., (2005). The industrial dynamics of open innovation-evidence from the transformation of consumer electronics. Research Policy 34, 1533-1549.

xliii. Christensen, C. M., Baumann H., Ruggles R., \&Sadtler T.M. (2006). 'Disruptive innovation for social change', Harvard Business Review, December, pp. 94-101.

xliv. Cornwall, J., (2013). Entrepreneurial Career Requires Perseverance and Patience.

xlv. Couger, J. D., (1995). Creative Problem Solving and Opportunity Finding, Danvers: Boyd and Fraser.

xlvi. Covin, J. G., Slevin, D. P., \& Schultz, R. L., (1994). Implementing strategic missions: Effective strategic, structural and tactical choices. Journal of Management Studies, 31(4), 481-505.

xlvii. $\quad$ Cunha, M.P.E., Rego, A., Oliveira, P., Rosado, P., Habib, N., (2014). Product innovation in resource-poor environments: three research streams. J. Product. Innov. Manag. 31 (2), 202-210.

xlviii. Cumming, B. S., (1998). 'Innovation overview and future challenges', European Journal of Innovation Management, vol. 1, no. 1, pp.21 - 29.

xlix. Damanpour, F., \&Wischnevsky, J. D., (2006). Research on innovation in organizations: Distinguishing innovationgenerating from innovation-adopting organizations. Journal of Engineering and Technology Management, 23, 269-291.

l. Damanpour, F., (1995). Is your creative organization innovative? Creative action in organizations: Ivory tower visions and real-world voices, Eds. C.M. Ford \& D.A. Gioia, Sage Publications, London.

li. Danneels, E., (2004). Disruptive technology reconsidered: A critique and research agenda. The Journal of Product Innovation Management, 21, pp. 246-258.

lii. De Bono, E. (2010). Lateral thinking. New York, NY: Harper Collins Publishers.

liii. DeSarbo, W.S., Di Benedetto, C.A., Song, M., \& Sinha, I., (2005). Revisiting the Miles and Snow strategic framework: Uncovering interrelationships between strategic types, capabilities, environmental uncertainty, and firm performance, Strategic Management Journal, Vol. 26, pp. 47-74.

liv. Di Stefano, G., Peteraf, M. A., \& Verona, G., (2009). 'Dynamic Capabilities Deconstructed', Industrial and Corporate Change

lv. Di Minin, A., \& Bianchi. M., (2011). Safe Nests in Global Nets: 'Internalization and Appropriability of R\&D in Wireless Telecom'. Journal of International Business Studies, 42(7): 910-34.

lvi. Dierickx, I., \& Cool, K., (1989). Asset stock accumulation and sustainability of competitive advantage. Management Science, 35: 1504-1511.

lvii. Douglas, T. S., (2013). 'Contextual innovation and social engagement: From impact factor to impact', South African Journal of Science, Vol. 10. Nos. 3/4, pp. 1-20.

lviii. Drucker, P., (1998). The Discipline of Innovation. Harvard Business Review. 98604,3 November.

lix. Drucker, P. F., (1995). Innovation and Entrepreneurship: Practice and Principles, Heinemann, London.

lx. Dyer, J. H., Gregersen, H. B., \& Christensen, C., (2008). Entrepreneur behaviors, opportunity recognition, and the origins of innovative ventures. Strategic Entrepreneurship Journal, 2, 317-338.

lxi. $\quad$ Eggers, J., \& Leahy, K., (1995). Entrepreneurial Leadership. Business quarterly 59 (summer): pp. 71 -6.

lxii. Eisenhardt, K. M., \& Martin, J. A., (2000). Dynamic capabilities: What are they? Strategic Management Journal, 21(10-11), 1105-1121.

lxiii. Economist, (2011). Special Report on Innovation in Emerging Markets. The Economist, 84(6), p.16.

lxiv. ESCWA, (2005). Regional profile of the information society in Western Asia. Economic and Social Commission for Western Asia (ESCWA), United Nations, New York.

lxv. Eyring, M. J., Johnson, M. W., \& Nair, H., (2011). New Business Models in Emerging Markets. Harvard Business Review, 89(1/2), pp.88-95.

lxvi. Falkowski, G., Pedigo, P., Smith, B., \& Swanson, D., (1998). A recipe for ERP success. Beyond Computing, 6(3), 44-45.

lxvii. Frishammar, J., Lichtenthaler, U. \&Richtnér, A., (2013). Managing process development: key issues and dimensions in the front end. R \& D Management, 43(3), pp. 213-226.

lxviii. Ghana Investment Promotion Centre, (2010). Fourth Quarter Investment Report (1st October to 31st December 2010), 6(4) (2010), 6.

lxix. George, G., McGahan, A. M. \& Prabhu, J., (2012). 'Innovation for inclusive growth: Towards a theoretical framework and a research agenda', Journal of Management Studies, Vol. 49, No. 4, pp. 661-683.

lxx. Giesen, E., Riddleberger, E., Christner, R., \& Bell, R., (2010). When and how to innovate your business model. Strategy \& Leadership,38(4), 17-26.

lxxi. Godin B., (2008). Innovation: The History of a Category; Working Paper No. 1, Project on the Intellectual History of Innovation, Montreal: INRS. 62 p.

lxxii. Gilmartin, M.J., (1999). Creativity: The fuel of Innovations, Nous Admin Quarterly (23)2.

lxxiii. Guilford, J. P., (2005). Creativity. American Psychologist, 5, 444-454.

lxxiv. Gilmartin, M.J., (1999). Creativity: The fuel of Innovation, Nurs Admin Quarterly, 23(2)

lxxv. Govindarajan, V., Trimble, C., \&Nooyi, I. K., (2012). Reverse Innovation: Create Far from Home, Win Everywhere, Harvard Business Press. 
lxxvi. Govindarajan, V., \&Ramamurti, R., (2011). Reverse innovation, Emerging markets, and Global strategy. Global Strategy Journal, 1(3-4), pp.191-205.

lxxvii. Grant, R. B., (1996). A resource-based theory of competitive advantage: Implications for strategy formulation. California Management Review 33 (3), 114-135.

lxxviii. Hang, C-C., Chen, J. \& Subramanian, A. M., (2010). Developing disruptive products for emerging economies: Lessons from Asian cases. Research-Technology Management, July August, pp.21-26.

lxxix. Hart, S., \& Christensen, C., (2002). The great leap: Driving innovation from the base of the pyramid. MIT Sloan Management Review, 44, $51-56$.

lxxx. Harrington, L., \& Reed, G., (2000). Electronic commerce (finally) comes of age. Marketing in India: Cases and Readings, 60.

lxxxi. Håkansson, H., \&Johanson, J., (1992). A model of industrial networks. In: Axelson, B., Easton, G. (Eds.), Industrial Networks-A New View of Reality, Routledge, London.

lxxxii. Hastings, G., \&Saren, M., (2003). The critical contribution of social marketing theory and application. Marketing theory, 3(3), 305-322.

lxxxiii. Helfat, C., Finkelstein, S., Mitchell, W., Peteraf, M., Singh, H., Teece, D. \& Winter, S., (2007). Dynamic Capabilities: Understanding Strategic Change in Organizations. Malden, MA: Blackwell.

lxxxiv. Hess, A., \& Rothaermel, F., (2011). When are assets complementary? Star scientists, strategic alliances, and innovation in the pharmaceutical industry. Strategic Management Journal, 32: 895-909.

lxxxv. Hentschke, G. C., \& Caldwell, B. J., (2005). Entrepreneurial leadership. The essentials of school leadership, 145-159. lxxxvi. Hisrich, R. D., Michael, P. P., \& A. Shepherd (2005). 'Entrepreneurship' Sixth edition, New York: McGraw-Hill Irwin.

lxxxvii. Holland, CP., Light, B., \& Gibson, N., (1999). A Critical Success Factors Model for Enterprise Resource Planning Implementation. In ECIS (pp. 273-287).

lxxxviii. Holcomb, T. R., Ireland, R. D., Holmes Jr, R. M., \&Hitt, M. A., (2009). Architecture of entrepreneurial learning: Exploring the link among heuristics, knowledge, and action. Entrepreneurship Theory and Practice,33 (1), 167192.

lxxxix. Holger, E., Kahle, H. N., Dubiel, A., Prabhu, J., \& Subramaniam, M., (2015). 'The antecedents and consequences of affordable value innovations for emerging markets', Journal of Product Innovation Management, Vol. 32, No. 1, pp. 65-79.

xc. Hyvärinen, L., (1993). Innovativeness and its indicators in small and medium-sized industrial enterprises. Proceedings of the IntEnt93 Conference Vienna, July.

xci. Iyer, G. R., La Placa, P. J., \& Sharma, A., (2006). Innovation and new product introductions in emerging markets: strategic recommendations for the Indian market. Ind. Mark. Manag. 35 (3), 373-382.

xcii. Jassawalla, A. R., \&Sashittal, H.C., (2002). 'Cultures that's support product-innovation processes', The Academy of Management Executive, Vol. 16. No. 3, pp. 42-54.

xciii. Jain, S., (2012). 'Pragmatic agency in technology standard setting: The case of Ethernet', Research Policy, Vol. 41, No. 9, pp. 1643-1654.

xciv. Johnson, S. C., (2008). Helps Create Stronger Communities at Base of Pyramid. SC Johnson Public Report. (2008).

xcv. Kazanjian, R. K., Drazin, R. \& Glynn, M., (2008). Creativity and sense making among Professionals. New York: Handbook of Organizational Creativity.

xcvi. Kahle, H., Dubiel, A., Ernst, H., \& Prabhu, J., (2013). The democratizing effects of frugal innovation: Implications for inclusive growth and state-building. Journal of Indian Business Research, 5, 220-234.

xcvii. Kaplan, A. M., \&Haenlein, M., (2006). Toward a parsimonious definition of traditional and electronic mass customization, Journal of Product Innovation Management, Vol. 23, 2.

xcviii. Kotler, P., (2000). Marketing Management: Millennium Edition (10th Edition), Upper Saddle River, NJ: Prentice Hall.

xcix. $\quad$ Kotler, P., \& Keller. K. L., (2006). Marketing management, 12, 181-183.

c. Krishnan, R.T., (2010). From Jugaad to Systematic Innovation: The Challenge for India, Utpreraka Foundation.

ci. Kreiser, P. M., Marino, L. D., Dickson, P., \& Weaver M. K., (2010). Cultural influences on entrepreneurial orientation: The impact of national culture risk taking and reactiveness in SMEs. Entrepreneurship: Theory \& Practice, 34(5), 959-983.

cii. $\quad$ Kumar, N., \& Puranam P., (2012). India Inside: The Emerging Innovation Challenge to the West. Harvard Business Press Books, Boston.

ciii. Knight, F., (1971). Risk, Uncertainty, and Profit. Chicago: University of Chicago Press.

civ. Knorringa, P., Pesa, I., Leliveld, A., \& Van Beers, C., (2016). 'Frugal innovation and development: Aides or adversaries?' The European Journal of Development Research, Vol. 28, No. 2, pp.143-153.

cv. Lall, S., (1992). Technological capabilities and industrialization. World Development, 20(2), 165-186.

cvi. Laurens, P., Le Bas, C., (2016). L'innovation inverse: clarification conceptuelle et essaid'évaluation quantitative, Mondesendéveloppement, 173, 47-62

cvii. Lawson, B., \&Samson, D., (2001). Developing innovation capability in organizations: A dynamic capabilities approach. International Journal of Innovation Management,5(3), 377-400.

cviii. Leitch, C., Hill, F., Neergaard H., (2010). Entrepreneurial and business growth and the quest for a 'comprehensive theory': tilting at windmills? Entrepreneurship Theory and Practice 2010,34(2):249-260. 
cix. Lesáková, L., (2009a). Determinants of Innovation Activities in Small and Medium Enterprises in Slovakia, in: Innovation - Factor Determining Competitiveness of Small and Medium Enterprises in the Global Business Environment, Faculty of Economics, Matej Bel University, BanskaBystrica

cx. $\quad$ Lesáková L. et al., (2009b). Innovative Management in the Knowledge- based Economy, BanskaBystrica, Faculty of Economics, Matej Bel University; BanskaBystrica

cxi. Lubart, T.I., (2000). Models of the creativeprocess: Past, present and future. Creativity Research Journal, 13, 295303.

cxii. Lee, S., Park, G., Yoon, B., \& Park, J., (2010). 'Open Innovation in SMEs-An Intermediated Network Model,' Research Policy 39(2), 290- 300.

cxiii. LeBrasseur, R., Zanibbi, L., \& Zinger, T. J., (2003). Growth momentum in the early stages of small business start-ups. International Small Business Journal, 21(3), 315-330.

cxiv. Lesger, C., (1997). The 'Visible Hand': Views on Entrepreneurs and Entrepreneurship in Holland, 1580-1850 in Small Business Entrepreneurs in Asia and Europe, Mario Rutten and Carol Upadhya (Eds.), New Delhi/Thousand Oaks/London, Sage Publications.

cxv. Liao, S. H., Wu, C. C., Hu, D. C., \&Tsui, K. A., (2010). 'Relationships between knowledge acquisition, absorptive capacity and innovation capability: an empirical study on Taiwan's financial and manufacturing industries,' Journal of Information Science, (36:1), pp. 19-35.

cxvi. Lichtenthaler, U., (2011). 'Open Innovation: Past Research, Current Debates, and Future Directions,' Academy of Management Perspectives 25(1), 75-93.

cxvii. Levitt, B., \& March, J., (1988). Organizational learning. Annual Review of Sociology. 14: 319-340.

cxviii. March, J., (1991). Exploration and exploitation in organizational learning. Organization Science. 2: 71-87.

cxix. Majumdar, S., (2007). Growth Strategy in Small Manufacturing Organizations: A Study in Madhya Pradesh and Maharashtra, in ShivganeshBharagava (Ed.), Development Aspects of Entrepreneurship, Response Books.

cxx. Martin, M. J. C., (1994). Managing Innovation and Entrepreneurship in Technology-based Firms. John Wiley \& Sons, Inc: New York

cxxi. Marnix, A., (2006). Inhibitors of disruptive innovation capability: a conceptual model. European Journal of Innovation Management, 9(2), 215-233.

cxxii. McGrath, R. G., 1999. 'Falling forward, real options reasoning and entrepreneurial failure', Academy of Management Review, Vol. 24, No. 2, pp. 13-30.

cxxiii. McManus, J. T., Li, M., \&Moitra, D., (2007). China and India: Opportunities and threats for the global software industry. Elsevier.

cxxiv. Mensah, S., (2004). 'A Review of SME Financing Schemes in Ghana', A Presentation at the UNIDO Regional Workshop of Financing SMEs, Accra, Ghana, March 15-16.

cxxv. Miller, D., \& Friesen, P. H., (1983). Strategy-Making and Environment: The Third Link. Strategic Management Journal, 4,221-235.

cxxvi. Monch, A., (2006). Change Management, Carl Hanser Verlag, Munchen

cxxvii. Morris, M. W., \& Leung, L., (2010). Creativity East and West: Perspectives and parallels. Management and Organization Review, 6:313-327.

cxxviii. Moreno, A.M., \& Casillas, J.C., (2008). Entrepreneurial Orientation and Growth of SMEs: A Casual Model. Entrepreneurship Theory and Practice, 32(3), pp.507-28.

cxxix. Morden, T., (2012). Principles of strategic management. Ashgate Publishing, Ltd.

cxxx. Neely, A., Mills, J., Platts, K., Richards, H., Gregory, M., Bourne, M., \&Kennerley, M., (2001). Performance measurement system design: developing and testing a process-based approach. Int J Oper Prod Manag. 2000; 20(10):1119-1145.

cxxxi. Nelson, R., \& Winter, S., (1982). An evolutionary theory of economic change, The Belknap Press of Harvard University Press, Boston

cxxxii. Ngo, L. V., \&O'Cass, A., (2012). In search of innovation and customer-related performance superiority: the role of market orientation, marketing capability, and innovation capability interactions. Journal of Product Innovation Management, 29(5): 861-877.

cxxxiii. Nummela, N., Puumalainen, K., \&Saarenketo, S., (2005). International growth orientation of knowledge-intensive SMEs, Journal of International Entrepreneurship, Vol. 3, pp. 5-18.

cxxxiv. Nwokah, N. G., (2008). Strategic market orientation and business performance: The study of food and beverages organizations in Nigeria. European Journal of Marketing, 3/4, 279-286.

cxxxv. OECD., (2005). The Measurement of Scientific and Technical Activities: Proposed Guidelines for Collecting and Interpreting Technological Innovation Data (Oslo Manual). Paris, France.

cxxxvi. O'Reilly, C., \&Tushman, M., (2007). 'Ambidexterity as a Dynamic Capability: Resolving the Innovator's Dilemma', in B. Staw and A. Brief (eds) Research in Organizational Behavior, Vol. 29. Greenwich, CT: JAI Press

cxxxvii. Özsomer, A., Calantone, R. J., \& Di Benedetto, A., (1997). What makes firms more innovative? A look at organizational and environmental factors, Journal of Business \& Industrial Marketing, Vol. 12, No. 6, pp. 400-416.

cxxxviii. Parthasarathy, B., \& Yuko, A., (2006). 'From software services to R\&D services: local entrepreneurship in the software industry in Bangalore, India' Environment and Planning, Volume 38, pp 1269-1285.

cxxxix. Parida, V., Patel, P. C., Frishammar, J. \&Wincent, J., (2016). Managing the front-end phase of process innovation under conditions of high uncertainty. Quality \& Quantity, 51(219), pp. 1-18. 
cxl. Pearson, A.W., (1993). Innovation, uncertainty and the Entrepreneur. Proceedings of the IntEnt93 Conference Vienna, July.

cxli. $\quad$ PEST ANALYSIS, (2012). Infrastructure developments in Taiwan -2012. Economics Week, 683.

cxlii. Peteraf, M., \& Barney, J., (2003) 'Unraveling the Resource-Based Tangle', Managerial and Decision Economics, 2003, Vol. 24, 309-323.

cxliii. Peng, G. C., \& Nunes, M. B., (2007). Using PEST analysis as a tool for refining and focusing contexts for information systems research. In Proceedings of the 6th European Conference on Research Methodology for Business and Management Studies (pp. 229-237). Academic Conferences Limited.

cxliv. Pitt, M., \& Clarke, K, (1999). 'Competing on competence: A knowledge perspective on the management of strategic innovation', Technology Analysis and Strategic Management, vol.2, no.3, pp.301-316.

cxlv. Pinchot, G., \& Pinchot, E., (1996). Five Drivers of Innovation. Executive Excellence, January.

cxlvi. Plaschka, G. R., \&Welsch, H. P., (1990). Emerging structures in Entrepreneurship education: Curricular designs and strategies. Entrepreneurship: Theory and Practice, Spring 1990.

cxlvii. Porter, ME., (2001). Strategy and the internet. Harvard Business Review, 63-78.

cxlviii. Poskiene A. (2006). 'Organizational Culture and Innovations', Engineering Economics, vol 46, no 1, pp.45-50

cxlix. Prahalad, C. K., (2010). The Fortune at the Bottom of the Pyramid: Eradicating Poverty through Profits. Pennsylvania: Wharton School Publishing, Upper Saddle River.

cl. Prabhu, G. N., \& Gupta, S., (2014). 'Heuristics of frugal service innovations', in proceedings of the 2014 Portland International Conference on Management of Engineering and Technology (PICMET) - IEEE, 2014, pp. 3309-3312.

cli. Prahalad, C., \&Mashelkar, R., (2010). Innovation's holy grail. Harvard Business Review 88(7-8).

clii. Provance, M., Donnelly, R. G., \&Carayannis, E. G., (2011). Institutional influences on business model choice by new ventures in the micro generated energy industry. Energy Policy, 39(9), 5630-5637.

cliii. Radjou, N., Prabhu, J., (2015). Frugal Innovation: How to Do More with Less. The Economist, February 2015. ISBN 9781610395052.

cliv. Radjou, N., Prabhu, J., \& Ahuja, S., (2012). Jugaad innovation: Think frugal, be flexible, generate breakthrough growth. San Francisco, CA: Jossey Bass.

clv. Rao, B.C., (2013). How Disruptive is Frugal? Technology in Society 35(1): 65-73.

clvi. Ramamurti, R., (2012). Competing with emerging markets multinationals. Business Horizons, 55, pp.241-249.

clvii. Reichstein, T., \& Salter, A., (2006). Investigating the sources of process innovation among UK manufacturing firms. Industrial and Corporate Change, 15(4), pp. 653-682.

clviii. Reid, B., Williamson, P., \& Bound, K., (2015). Harnessing China's Commercialization Engine. Nesta.

clix. Ressi, A., (2014). What Makes a Successful Entrepreneur? Genetics, Circumstance, and Perseverance.

clx. Roland Berger Strategy Consultants, (2015). Frugal products. Think Act, June.

clxi. Romijn, H., \&Albaladejo, M., (2002). Determinants of innovation capability in small electronics and software firms in southeast England. Research Policy 31: 1053-67

clxii. Ruan, Y., Hang, C. C.\& Subramanian, A. M., (2012). Disruptive Innovation in Emerging Markets: Strategies Used in India and China. Working Paper n. 01/2012, National University of Singapore, Singapore.

clxiii. Salavou, H., Baltas, G., \&Lioukas, S., (2004). 'Organizational innovation in SMEs: the importance of strategic orientation and competitive structure', European Journal of Marketing, Vol. 38 No.9, pp.1091-112.

clxiv. Saraf, D., (2009). India's Indigenous Genius: Jugaad. [online] Available at: [Accessed 25 April 2013 ].

clxv. Schein, E., (1992). Organizational culture and leadership (2nd ed.). San Francisco: Jossey Bass.

clxvi. Schumpeter, J. A., (1934). The theory of economic development: An inquiry into profits, capital, credit, interest, and the business cycle (Vol. 55). Piscataway, USA: Transaction Publishers.

clxvii. Sehgal, V., Dehoff, K. \&Panneer, G., (2010). The Importance of Frugal Engineering. Strategy + Business, Summer (59), pp.1-5.

clxviii. Sethi, J., (2004). 'Entrepreneur and Entrepreneurship.

clxix. Sharma, A., \&Iyer, G., (2012). Resource-constrained product development: Implications for green marketing and green supply chains. Industrial Marketing Management, 41, 599-608.

clxx. Simmonds, K., (1986). Marketing as innovation; the eight paradigm, Journal of Management Studies, Vol.5/ No.23

clxxi. Sin, L.Y.M., Tse, A. C. B., Yau, O. H. M., Chow, R., \& Lee, J. S. Y., (2003). Market orientation and business performance: A comparative study of firms in Mainland China and Hong Kong. European Journal of Marketing, 37(5), 910-936.

clxxii. Singh, R., Gupta, V., \& Mondal, A., (2012). Jugaad - From 'Making Do' and 'Quick Fix' to an Innovative, Sustainable and Low-Cost Survival Strategy at the Bottom of the Pyramid. International Journal of Rural Management, 8 (1\&2), pp.87-105.

clxxiii. Simula, H., Hossain, M. \&Halme, M., (2015). 'Frugal and reverse innovations - quo vadis?' Current Science, Vol. 109, No. 5, pp. 1-6.

clxxiv. Sloman, J., \& Sutcliffe, M.,2001). Economics for Business, 2ndEdition Smith, K., (2006). The Oxford Handbook of Innovation. In J. Fagerberg, D. C. Mowery, \& R. R. Nelson (Eds.), The Oxford Handbook of Innovation (Vol. 1, pp. 148-177). Oxford, England: Oxford University Press.

clxxv. Solomon, G., \& Fernald, L., (1991). Trends in small business management and Entrepreneurship education in the United States. Entrepreneurship: Theory and Practice, Spring 1991.

clxxvi. Steinberg, R.J., Grigorenko, E.L., \& Singer, J.L., (2004). Creativity: From Potential to Realization, Washinton, DC America Psychological Association 
clxxvii. Sumner, M., (1999). Critical success factors in enterprise wide information management systems projects. In Proceedings of the 1999 ACM SIGCPR conference on Computer personnel research (pp. 297-303). ACM

clxxviii. Teece, D., Pisano, G., \&Shuen, A., (1997). Dynamic capabilities and strategic managerial. Strategic Managerial Journal, 18(7), 509-533.

clxxix. Teece, D. J., (2010). Technological innovation and the theory of the firm: The role of enterprise-level knowledge, complementarities, and (dynamic) capabilities. Handbook of the Economics of Innovation, 1, 679-730

clxxx. Tellis G. J., (2006). 'Disruptive Technology or Visionary Leadership?'JPIM 23 (1), 34-38.

clxxxi. Tidd, J., (2001). Innovation management in context: environment, organization and performance, International Journal of Management Reviews, Vol. 3, No. 3, pp. 169-183.

clxxxii. Tseng, M., \& Jiao, J., (2001). Mass Customization, in: Handbook of Industrial Engineering, Technology and Operation Management (3rd ed.). New York, NY: Wiley. ISBN 0-471-33057-4.

clxxxiii. Tiwari, R., \&Herstatt, C, (2012). Frugal Innovation for the 'Unserved' Customer: An Assessment of India's Attractiveness as a Lead Market for Cost-effective products. Journal of Indian Business Research, 4 (2), pp. 97-115.

clxxxiv. Tiwari, R., Kalogerakis, K. \&Herstatt, C., (2016). 'Frugal innovations in the mirror of scholarly discourse: Tracing theoretical basis and antecedents', in proceedings of the 2016 R \& D Management Conference, Cambridge, UK.

clxxxv. Trott, P., (2008). Innovation management and new product development. Harlow, UK: Prentice-Hall.

clxxxvi. Vahter, P., Love, J. H., \& Roper, S., (2014). Openness and innovation performance: are small firms different? Industry and Innovation, 21(7-8), 553-573.

clxxxvii. Van de Ven, A. H., Polley, D. E., Garud, R., \& Venkataraman, S., (1999). Mapping the Innovation Journey. The Innovation Journey (pp. 21-25). New York: Oxford University Press.

clxxxviii. Van de Vrande, V., De Jong, J. P., Vanhaverbeke, W., \& De Rochemont, M., (2009). Open innovation in SMEs: Trends, motives and management challenges. Technovation,29(6), 423-437

clxxxix. Verhees, F. H. M., \& Meulenberg, M. T. G, (2004). 'Market Orientation, Innovativeness, Product Innovation, and Performance in Small Finns,'journal of Small Business Management 42(2), 86-91.

cxc. Vij, S., \&Bedi, H. S., (2012). Relationship between entrepreneurial orientation and business performance: A review of literature. The IUP Journal of Business Strategy, IX (3), 17-31.

cxci. Viswanathan, M., Sridharan, S., \& Ritchie, R., (2010). Understanding consumption and entrepreneurship in subsistence marketplaces. Journal of Business Research, 63(6): 570-581.

cxcii. Vrontis, D., \&Vignali, C., (2001). Dairy Milk in France-A marketing investigation of the situational environment. British Food Journal, 103 (4), 291-296.

cxciii. Wee, S., (2000). Juggling toward ERP success: keep key success factors high. ERP news, 1-5.

cxciv. Winter, S. G. (2000). 'The satisficing principle in capability learning.' Strategic Management Journal 21 (Oct-Nov (special issue): 981-996.

cxcv. Wade, M., \&Hulland, J., (2004). The resource-based view and information systems research: Review, extension, and suggestions for future research. Management Information Systems Quarterly, 28(1), 107-142.

cxcvi. $\quad$ Winter, S., \&Szulanski, G., (2001). Replication as strategy. Organizational Science. 12: 730-743.

cxcvii. Winter, S., (2003): 'One can define dynamic capabilities as those that operate to extend, modify or createordinary capabilities.'

cxcviii. Wiklund,J.,\&Shepherd, D., (2003).'Aspiringfor,andAchievingGrowth:TheModeratingRoleofResources and Opportunities', Journal of Management Studies 40 (8), 1919-1941.

cxcix. Wolff, J. A., \&Pett, T. L., (2006). Small-firm performance: Modeling the role of the product and process improvements. Journal of Small Business Management 44(2), 268 - 284.

cc. Woolridge, A. (2010). The World Turned Upside Down. A Special Report on Innovation in Emerging Markets. The Economist.

cci. Wang, C. L., \& Ahmed, P. K., (2004). 'The Development and Validation of the Organizational Innovativeness Construct Using Confirmatory Factor Analysis,' European Journal of Innovation Management, 7 (4), 303-13.

ccii. Wolff, J. A., \&Pett, T. L, (2006). Small-firm performance: Modeling the role of the product and process improvements. Journal of Small Business Management 44(2), 268 - 284.

cciii. Yang, T., Lim, Jamus J., \& Kanamori, T., (2008). Strategies for the People's Republic of China's Small and Medium Enterprise Development within the National Innovation System, ADBI Research Paper Series, No. 73, Asian Development Bank Institute (ADBI), Tokyo,

cciv. Ye, G., Wan, Q., \& Chen, J., (2011). Political resources, business model and headquarters location of private enterprises. Nankai Business Review International, 2(2), 172-194.

ccv. Zander, U., \&Kogut, B., (1995). Knowledge and the speed of the transfer and imitation of organizational capabilities: an empirical test. Management Science, 6: 76-92.

ccvi. Zhao, Hongxin, Xuesong Tong, Poh K., Wong, \&Jishan Z., (2005). Types of technology sourcing and innovative capability: An exploratory study of Singapore manufacturing firms. Journal of High Technology Management Research 16: 209-24.

ccvii. Zhilong, T., Yongqiang, G., \& Wu, W., (2003). A study of political tactics and behavior of China's enterprises. Management World, 12, 009.

ccviii. Zakon, R. H., (2011). Hobbes' Internet Timeline 10.2. [online] Available at: [Accessed 11 March 2013].

ccix. Zollo, M., \& Winter, S. G., (2002). 'Deliberate Learning and the Evolution of Dynamic Capabilities', Organization Science 13(3): 339-51. 
ccx. Zeschky, M., Widenmayer, B., \& Gassmann, O., (2011). Frugal Innovation in Emerging Markets. ResearchTechnology Management, 54, 38-45.

ccxi. Zeschky, M., Widenmayer, B., \& Gassmann, 0., (2014). Organising for reverse innovation in Western MNCs: The role of frugal product innovation capabilities. International Journal of Technology Management 64(2/3/4): 255-275.

ccxii. Zimmerer T. W., \& Scarborough N. M., (1998). Essentials of Entrepreneurship and Small Business Management. Prentice Hall: USA.

ccxiii. https://www.core.ac.uk/download/pdf/82388490.pdf

ccxiv. http://www.ijbarr.com/downloads/3105201412.pdf

ccxv. https://www.memoireonline.com/11/11/4963/The-role-of-SMEs-in-rwanda-from-1995-to-2010.html

ccxvi. https://www.pdfs.semanticscholar.org/5251/ad1cf94020c28fd024ce645d88c771e91fe7.pdf

ccxvii. https://www.scholarsarchive.byu.edu/cgi/viewcontent.cgi?article=3864\&context=etd

ccxviii. https://www.scielo.conicyt.cl/scielo.php?script=sci_arttext\&pid=S0718-27242011000300002

ccxix. https://www.ukessays.com/essays/commerce/small-and-medium-scale-enterprises-in-ghana-commerceessay.php

\section{Appendix}

Analysis of Creativity and Innovation with Frugal Innovative Capabilities on Small And Medium Enterprises (SMEs) in Ghana

\section{Review Questionnaire for Small and Medium Enterprises (SMEs) in Ghana}

Frugal innovation is more than a strategy. It denotes a new frame of mind: one that sees resource constraints not as a liability but as an opportunity and one that favors agility over efficiency. Frugal organizations do not seek to delight customers with technically sophisticated products, but instead strive to create good-quality solutions that deliver the greatest value to customers at the lowest cost.

- Question 1: To find out the role of Creativity and Innovation towards the performance of Small and Medium Enterprises in Ghana

(On a scale of 4 to 1, where (4= Highly Positive, 3= Positive, 2=Highly Negative and 1= Negative)

\begin{tabular}{|c|c|c|c|c|}
\hline Role of Creativity and Innovations on SMEs in Ghana & $\begin{array}{c}\text { Highly } \\
\text { Positive }\end{array}$ & Positive & $\begin{array}{l}\text { Highly } \\
\text { Negative }\end{array}$ & Negative \\
\hline \multicolumn{5}{|l|}{$\begin{array}{l}\text { Firms with a high level of innovation have higher levels of } \\
\text { productivity }\end{array}$} \\
\hline \multicolumn{5}{|l|}{$\begin{array}{l}\text { Adoption of a large number of technical and administrative } \\
\text { innovations leads to greater profitability }\end{array}$} \\
\hline \multicolumn{5}{|l|}{$\begin{array}{l}\text { Innovation capability will gain competitiveness against } \\
\text { competitors }\end{array}$} \\
\hline \multicolumn{5}{|l|}{ Creativity and Innovation contributes to the growth of SMEs } \\
\hline \multicolumn{5}{|l|}{$\begin{array}{c}\text { Creativity and Innovation enables SMEs to build credible } \\
\text { perception from consumers }\end{array}$} \\
\hline \multicolumn{5}{|l|}{ Creativity and Innovation breads customer satisfaction loyalty } \\
\hline $\begin{array}{l}\text { Creativity and innovation help SMEs to increase their market } \\
\text { share sales }\end{array}$ & & & & \\
\hline
\end{tabular}

Table 13

- Objective 2: To find out the motivations for innovation and creativity by Small and Medium Enterprises

(On a scale of 5 to 1, where (5=Strongly Agree, 4=Agree, 3=Neutral 2= Strongly Disagree and 1=Disagree)

\begin{tabular}{|c|c|c|c|c|c|}
\hline $\begin{array}{c}\text { Motivations for creativity and innovative } \\
\text { Practices by SMEs }\end{array}$ & $\begin{array}{l}\text { Strongly } \\
\text { Agree }\end{array}$ & Agree & Neutral & $\begin{array}{l}\text { Strongly } \\
\text { Disagree }\end{array}$ & Disagree \\
\hline $\begin{array}{l}\text { Implementation of creativity and innovation } \\
\text { helps to meet customers demand on time }\end{array}$ & & & & & \\
\hline $\begin{array}{c}\text { Creativity and Innovation practices increase } \\
\text { revenue }\end{array}$ & & & & & \\
\hline $\begin{array}{c}\text { Creativity and Innovation practices promote } \\
\text { business growth }\end{array}$ & & & & & \\
\hline $\begin{array}{l}\text { Creativity and Innovations are adopted to reduce } \\
\text { cost of operations }\end{array}$ & & & & & \\
\hline $\begin{array}{c}\text { Creativity and innovations enhance quality and } \\
\text { productivity }\end{array}$ & & & & & \\
\hline $\begin{array}{l}\text { Creativity and Innovations aid marketing and } \\
\text { selling of goods and services }\end{array}$ & & & & & \\
\hline
\end{tabular}

Table 14 
- Objective 3: To find out the effects of frugal innovation capacities on Small and Medium Enterprises

Overview of Frugal Innovative and Capability Concept

(On a scale of 5 to 1, where (4=Strongly Agree, 3=Agree, 2=Strongly Disagree and 1=Disagree)

\begin{tabular}{|l|l|l|l|l|}
\hline Overview of Frugal & $\begin{array}{l}\text { Strongly } \\
\text { Agree }\end{array}$ & Agree & $\begin{array}{l}\text { Strongly } \\
\text { Disagree }\end{array}$ & Disagree \\
\hline Frugal is the same as innovations & & & & \\
\hline $\begin{array}{l}\text { Frugal implies the careful and cautious use of } \\
\text { organizational resources to minimize waste and to } \\
\text { ensure optimum utilization of scarce resources }\end{array}$ & & & & \\
\hline $\begin{array}{l}\text { Frugal innovation is a constraint-based response to } \\
\text { the unmet needs of Bottom of Pyramid consumers }\end{array}$ & & & & \\
\hline $\begin{array}{l}\text { Frugal is about cheap goods and services } \\
\text { Frugal innovative capabilities lead to firm's ability } \\
\text { to perform and compete well }\end{array}$ & & & & \\
\hline $\begin{array}{l}\text { Firms without frugal innovative capabilities risk an } \\
\text { opportunity to adopt frugalism concept }\end{array}$ & & & & \\
\hline $\begin{array}{l}\text { Frugal innovative capabilities involve finance, } \\
\text { factory operations and employee management }\end{array}$ & & & & \\
\hline
\end{tabular}

Table 15

Dimensions of Frugal Innovative Concept

(On a scale of 5 to 1, where (4=Strongly Agree, 3=Agree, 2=Strongly Disagree and 1=Disagree)

\begin{tabular}{|c|c|c|c|c|}
\hline Frugal Dimensions & $\begin{array}{c}\text { Strongly } \\
\text { Agree }\end{array}$ & Agree & $\begin{array}{c}\text { Strongly } \\
\text { Disagree }\end{array}$ & Disagree \\
\hline Affordability & & & & \\
\hline Acceptability & & & & \\
\hline Core Functionality & & & & \\
\hline Sustainability & & & & \\
\hline
\end{tabular}

Table 16

Effects of Frugal Innovation Capacities on Small and Medium Enterprises

(On a scale of 5 to 1, where (5=Highly Agree, 4=Agree, 3=Neutral 2=Highly Disagree and 1= Disagree)

\section{Six principles of Frugal Innovations}

The ability to reframe adversity as a source of innovation and growth is vital for any organization to survive and thrive

It is possible to use scarce resources to produce quality products and services to satisfy consumers

Innovators flexibility and quick thinking help them to respond quickly to unexpected changes in their environment

Innovation is not about seeking sophistication or perfection by over engineering products, but rather about developing a 'good enough' solution that gets the job done Innovator firms conjure up radically affordable solutions to meet the needs of these underserved markets

Knowledge of customers aids companies to meet their demands

\begin{tabular}{|l|l|l|l|l|}
\hline $\begin{array}{c}\text { Highly } \\
\text { Agree }\end{array}$ & Agree & Neutral & $\begin{array}{c}\text { Highly } \\
\text { Disagree }\end{array}$ & Disagree \\
\hline & & & & \\
\hline & & & & \\
\hline & & & & \\
\hline & & & & \\
\hline & & & & \\
\hline & & & & \\
\hline
\end{tabular}

Table 17 
Objectives 4: To investigate the benefits of practicing Frugal Innovations by SMEs

(On a scale of 5 to 1, where (5=Strongly Agree, 2=Agree, 3=Neutral 4=N Strongly Disagree and 5=Disagree)

\begin{tabular}{|l|l|l|l|l|l|}
\hline Benefits of practicing Frugal Innovative & Strongly Agree & Agree & Neutral & $\begin{array}{l}\text { Strongly } \\
\text { Disagree }\end{array}$ & Disagree \\
\hline $\begin{array}{l}\text { Innovation allows organizations to better meet } \\
\text { consumer needs }\end{array}$ & & & & & \\
\hline $\begin{array}{l}\text { Innovation enhance sales performance in the } \\
\text { market }\end{array}$ & & & & & \\
\hline $\begin{array}{l}\text { Innovation attract new and maintain loyal } \\
\text { customers }\end{array}$ & & & & & \\
\hline Innovations bring about competitive advantage & & & & & \\
\hline Innovations bring about quality and satisfaction & & & & & \\
\hline
\end{tabular}

Table 18

Objective 5: To identify some challenges mitigating adaptation of Frugal Innovation by SMEs

(On a scale of 5 to 1, where (5=Strongly Agree, 4=Agree, 3=Neutral 2=N Strongly Disagree and 1=Disagree)

\begin{tabular}{|l|l|l|l|l|l|}
\hline $\begin{array}{l}\text { Some challenges that mitigate the adoption } \\
\text { of Frugal Innovation practices by the SMEs }\end{array}$ & $\begin{array}{l}\text { Strongly } \\
\text { Agree }\end{array}$ & Agree & Neutral & $\begin{array}{l}\text { Strongly } \\
\text { Disagree }\end{array}$ & Disagree \\
\hline $\begin{array}{l}\text { Lack of skilled talent and the lack of quality } \\
\text { among the labor pool impedes Frugal Innovation }\end{array}$ & & & & & \\
\hline $\begin{array}{l}\text { low-cost combined with quality is a challenge in } \\
\text { this very price-sensitive environment }\end{array}$ & & & & & \\
\hline $\begin{array}{l}\text { It is difficult to collaborate with external partner } \\
\text { to achieve frugal innovation objectives }\end{array}$ & & & & & \\
\hline $\begin{array}{l}\text { Outdated technologies and low capital lead to } \\
\text { the weakness in innovation capabilities }\end{array}$ & & & & & \\
\hline Doing more with less is impossible & & & & & \\
\hline $\begin{array}{l}\text { It is difficult to rely on customers to determine } \\
\text { business operations }\end{array}$ & & & & & \\
\hline
\end{tabular}

Table 19

Do you use sophisticated equipment and technologies for your operations? Yes [] or No []

Explain your answer.

How can creativity and innovations bring down cost of productivity?.

Analysis of Creativity and Innovation with Frugal Innovative Capabilities on Small and Medium Enterprises (SMEs) in Ghana

Interview Guide for Small and Medium Enterprises (SMEs) In Ghana

Frugal innovation is more than a strategy. It denotes a new frame of mind: one that sees resource constraints not as a liability but as an opportunity and one that favors agility over efficiency. Frugal organizations do not seek to delight customers with technically sophisticated products, but instead strive to create good-quality solutions that deliver the greatest value to customers at the lowest cost.

(Together these six principles of Frugal Innovation help drive resilience, frugality, adaptability, simplicity, inclusivity, empathy and passion)

1. Indicate your industry of business?

2. Please how do you understand Innovation?

3. Is it necessary to develop creativity and innovation at work operations?

4. Has your company indulged in any innovative policy over the past three years?

5. What was the impact of the innovation adopted if any by your company?

6. How do you see the cost effectiveness of on your company's innovation? Cost reduction in production leading to low pricing [ ] Increment in cost of production leading to higher pricing of the product [] All of the above [] None of them [ ]

7. Which section of your company do innovative policies affect most? Production [ ] Information technology [ ] Marketing/Sales [] Profitability [] others.....

8. Is the cost of your innovative gadgets expensive? Yes [] or []

9. What could be done to further reduce cost of production with scarce resources

10.

1. How do you understand frugal innovation? 
11. Is innovation different from standard innovation? Yes [ ] No [] Don't know []

12. If yes, explain the difference between innovation and frugal innovation

13. Does your enterprise practice frugal innovations? Yes [ ] No [ ] Don't know []

14. If yes, how does frugal impacts on your enterprise

15. Which of your enterprise capabilities help you to produce frugal products if any? 16. Does your enterprise find it difficult to adopt frugal concept? Yes [] No [] Don't know []

17. If yes, explain some of the challenges your enterprise encounter

18. 9. Kindly advise SMEs how they can embrace frugal innovative concepts to compete against MNCs who are able to afford the higher technological cost

19. The ability to reframe adversity as a source of innovation and growth is vital for any organization to survive and thrive. Does your company have the capacity to innovate in times of challenges? Yes [] or No []

20. If yes, kindly share with us how your organizational created something innovated out of adversity.

21. Do you agree that your organization can use scarce resources to produce quality products and services to satisfy consumers? Yes [] or []

22. If yes, give example(s) of how your company was able to use scarce resources to your customers' demands.

How would your company respond to the unexpected

changes in your business environment?

23. Does your innovative policy support less sophisticated technology? Yes [] or No []

24. If no, can your company's innovative policy support less sophisticated gadgets or technology? Explain how it could be done...

25. How do you relate to your customers? How often do you discuss issues concerning your product and services with

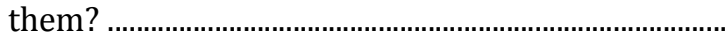

26. What effect does your innovative policy have on your company?

Positive [ ] or Negative []

27. Explain or list those areas of your business operations that are affected, whether positive or negative 